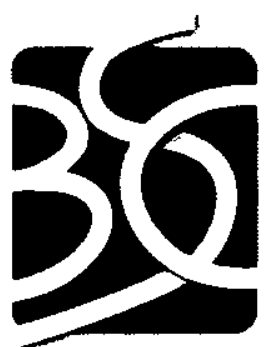

BECHTEL

\title{
Calibrated Properties Model
}

MDL-NBS-HS-000003 REV 02

October 2004

QA: QA

Prepared for:

U.S. Department of Energy

Office of Civilian Radioactive Waste Management

Office of Repository Development

1551 Hillshire Drive

Las Vegas, Nevada 89134-6321

Prepared by:

Bechtel SAIC Company, LLC

1180 Town Center Drive

Las Vegas, Nevada 89144

Under Contract Number

DE-AC28-01RW12101 


\section{DISCLAIMER}

This report was prepared as an account of work sponsored by an agency of the United States Government. Neither the United States Government nor any agency thereof, nor any of their employees, nor any of their contractors, subcontractors or their employees, makes any warranty, express or implied, or assumes any legal liability or responsibility for the accuracy, completeness, or any third party's use or the results of such use of any information, apparatus, product, or process disclosed, or represents that its use would not infringe privately owned rights. Reference herein to any specific commercial product, process, or service by trade name, trademark, manufacturer, or otherwise, does not necessarily constitute or imply its endorsement, recommendation, or favoring by the United States Government or any agency thereof or its contractors or subcontractors. The views and opinions of authors expressed herein do not necessarily state or reflect those of the United States Government or any agency thereof. 


\begin{tabular}{|l|l|l|}
\hline OCRWM & Model Signature Page/Change History & Page iil \\
\cline { 3 - 3 } & & 1. Tolal Pageg: 1i4 \\
\hline
\end{tabular}

2. Type of Mathematical Madel

X Process Model

Deserba Intonded Use of Model

To provide callorated propertios for the Utosacwated Zone and Sespage Models

3. THis:

Cabbrasod Propterties Modol

4. DI (inatuoung Rev. No, If applleable):

MDLANBSHS-000003 REV 02

\begin{tabular}{|l|l|}
\hline $\begin{array}{l}\text { E. Toral Appandjeas } \\
\text { Two }\end{array}$ & $\begin{array}{l}\text { 6. No. W Pages in Each Appondix } \\
\text { A-8, B-8 }\end{array}$ \\
\hline
\end{tabular}

\begin{tabular}{|c|c|c|c|}
\hline & Printed Narno & Finguru & Dato \\
\hline 7. Originator & T. A. Oherezabei & & 10. \\
\hline $\begin{array}{l}\text { 8. Independent Tochnical } \\
\text { Revieurar }\end{array}$ & T. Hadga & & \\
\hline 9. Checker & Q. Zuang & & \\
\hline 10. QER , & P. Buervigige & & \\
\hline 11. Responsblble Managerfloed & HAf. Ing/Y-S, Wu & & \\
\hline 12. Responsiblo Manager & M. Znan & & \\
\hline
\end{tabular}

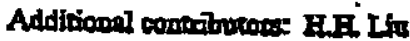

\begin{tabular}{|c|c|}
\hline & Crange History \\
\hline 14. Revialon No. & 15. Description of Change \\
\hline REV OO & Initinl Lam \\
\hline REV 00 ION 01 & 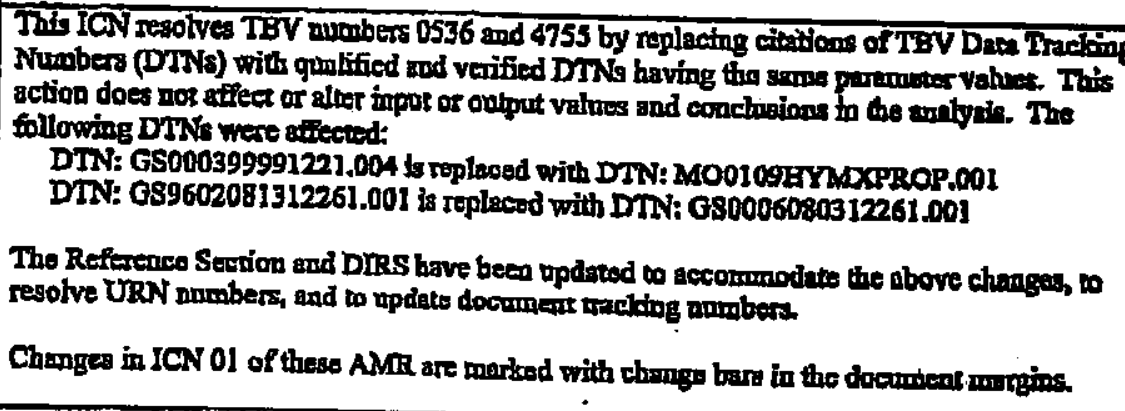 \\
\hline
\end{tabular}




\begin{tabular}{|c|c|}
\hline & $\begin{array}{l}\text { Attachment IV of this technical product contains documentation of single use software routines } \\
\text { of macros that were qualified under procedure AP-SI.1Q, Software Management, prior to the } \\
\text { release of Rev. 03 of said procedure. As the scope of this ICN did not involve a change to the } \\
\text { routine codes, and they have not been used to develop additional quality affecting information } \\
\text { in this technical product, these single use software routines or macros will remain documented } \\
\text { herein, in accordance with AP-SI.1Q prior to the release of Rev. } 03 \text {. } \\
\text { The following Sections (pages) are affected by this ICN: Section } 1 \text { (p.11), } 2 \text { (p.13), } 3 \text { (p. 15), } 4 \\
\text { (p. 19), } 6 \text { (p.39), } 7 \text { (pp. 27, 29-30, 33, 35, 67, 69-70), 8 (pp. 71-75), and Attachment I. } \\
\text { Document Input Reference Sheet has been removed from Attachment I. }\end{array}$ \\
\hline REV 01 & $\begin{array}{l}\text { Entire model documentation was revised to update the model and calibrated property sets that } \\
\text { are compatible with the revised grid and hydrologic property data. Side bars are not used } \\
\text { because the changes were too extensive to use Step 5.9d)1) per AP-SIII.10Q/Rev.0/ICN 2. }\end{array}$ \\
\hline REV 01 Errata 001 & Errata to correct typographical errors in the text. \\
\hline REV 02 & $\begin{array}{l}\text { Increased transparency in response to the regulatory-focused evaluation performed by the } \\
\text { Regulatory Integration Team. Entire model documentation was revised. Side bars are not used } \\
\text { because the changes were too extensive to use per AP-SIII.10Q/Rev. 2/ICN 7, Section } 5.8 \mathrm{f}) \\
\text { 1). }\end{array}$ \\
\hline
\end{tabular}




\section{CONTENTS}

Page

ACRONYMS AND ABBREVIATIONS .................................................................... xi

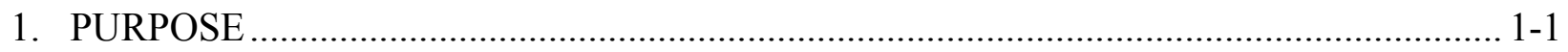

2. QUALITY ASSURANCE .................................................................................. 2-1

3. USE OF SOFTWARE ...................................................................................... $3-1$

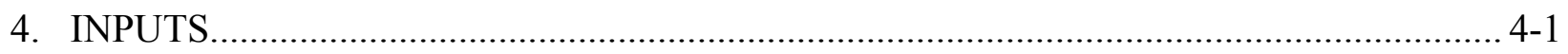

4.1 DIRECT INPUTS ................................................................................ $4-1$

4.1.1 Output from Other Models and Analyses .............................................. 4-1

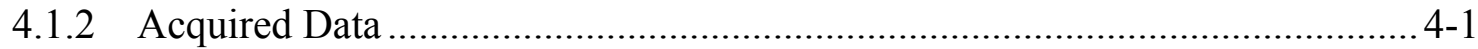

4.1.2.1 Saturation Data ...................................................................... 4-1

4.1.2.2 Water-Potential Data .......................................................... 4-8

4.1.2.3 Pneumatic Pressure Data ................................................................ 4-8

4.1.2.4 Use of Established Fact Data........................................................ 4-8

4.1.3 Use of Historical Technical Product Outputs (TPOs) ................................... 4-9

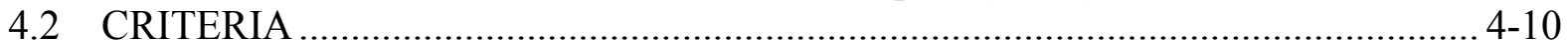

4.3 CODES, STANDARDS, AND REGULATIONS .............................................. 4-12

5. ASSUMPTIONS ............................................................................................. 5

6. MODEL DISCUSSION ....................................................................................... 6 -

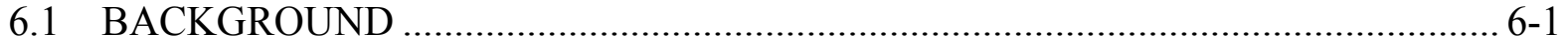

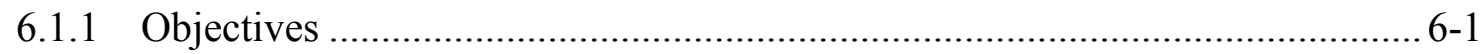

6.1.2 Scientific Notebooks ................................................................................... 6-1

6.1.3 Features, Events, and Processes................................................................ 6-1

6.1.4 Conceptual Model and Alternative Models ................................................ 6-2

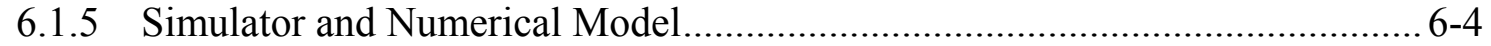

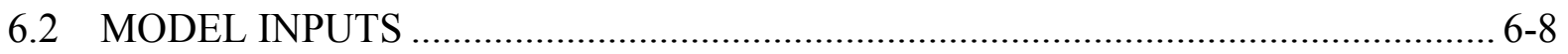

6.2.1 Numerical Grids................................................................................ $6-8$

6.2.2 Matrix-Saturation and Water-Potential Data ................................................. 6-9

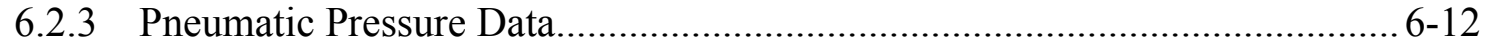

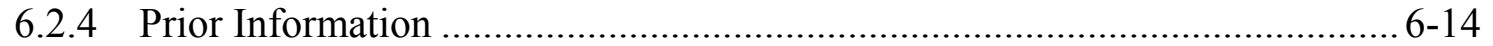

6.2.5 Boundary and Initial Conditions .......................................................... 6-14

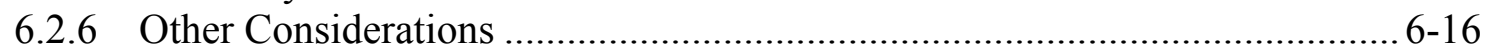

6.3 UZ FLOW MODEL PARAMETER CALIBRATION ...................................... 6-16

6.3.1 General Calibration Approach ............................................................ 6-16

6.3.2 Calibration of Drift-Scale Parameters......................................................... 6-17

6.3.3 Calibration of Mountain-Scale Parameters ................................................. 6-27

6.3.4 Calibration of Fault Parameters ............................................................. 6-30

6.4 DISCUSSION OF PARAMETER UNCERTAINTY ....................................... 6-35

6.4.1 Sources of Parameter Uncertainty ............................................................ 6-35 


\section{CONTENTS (Continued)}

Page

6.4.2 Quantification of Parameter Uncertainty ………........................................... 6-37

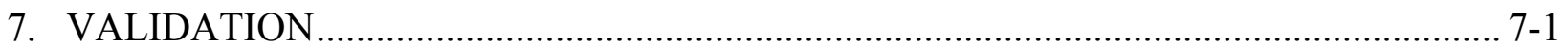

7.1 CONFIDENCE BUILDING DURING MODEL DEVELOPMENT TO ESTABLISH SCIENTIFIC BASIS AND ACCURACY FOR INTENDED USE....... 7-1

7.2 MODEL VALIDATION AFTER MODEL DEVELOPMENT TO SUPPORT THE SCIENTIFIC BASIS OF THE MODEL.......................................................... 7-2

7.2.1 Validation with Observed Saturation Data ………............................................ 7-4

7.2.2 Validation with Observed In Situ Water Potential Data.................................. 7-5

7.2.3 Validation with the Dynamic Pneumatic Pressure Data .................................... 7-5

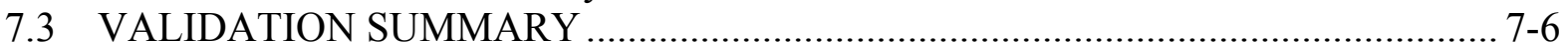

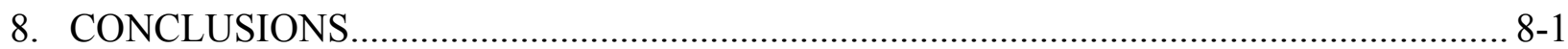

8.1 PARAMETER CALIBRATIONS AND UNCERTAINTIES ..................................... 8-1

8.2 ADDITIONAL THREE-DIMENSIONAL CALIBRATIONS .................................. 8-1

8.3 HOW THE ACCEPTANCE CRITERIA ARE ADDRESSED …….......................... 8-3

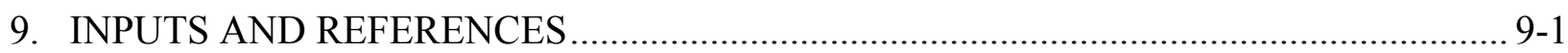

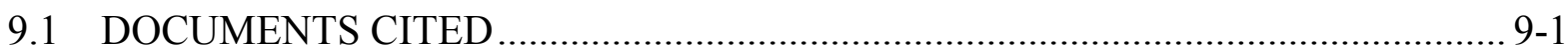

9.2 CODES, STANDARDS, REGULATIONS, AND PROCEDURES ........................... 9-5

9.3 SOURCE DATA, LISTED BY DATA TRACKING NUMBER …………............... 9-5

9.4 OUTPUT DATA, LISTED BY DATA TRACKING NUMBER ………………........ 9-8

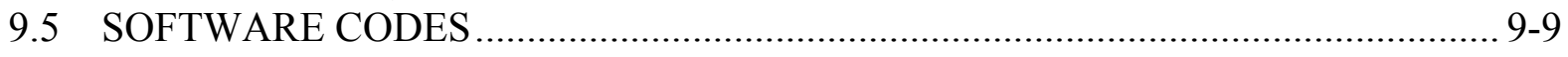

APPENDIX A - DESCRIPTION OF EXCEL FILES ……………………………............ A-1 APPENDIX B - RECENT WATER-POTENTIAL DATA …………………………….......... 


\section{FIGURES}

4-1. Locations of Boreholes

6-1. Saturation Matches at USW SD-9 for One-Dimensional, Drift-Scale, Calibrated Parameter Set for the Base-Case Infiltration Scenario

6-2. Water-Potential Matches at USW SD-12 for One-Dimensional, Drift-Scale, Calibrated Parameter Set for the Base-Case Infiltration Scenario

6-3. Saturation Matches at USW SD-9 for One-Dimensional, Drift-Scale, Calibrated Parameter Set for the Upper-Bound Infiltration Scenario

6-4. Water-Potential Matches at USW SD-12 for a One-Dimensional, Drift-Scale, Calibrated Parameter Set for the Upper-Bound Infiltration Scenario

6-5. Saturation Matches at USW SD-9 for a One-Dimensional, Drift-Scale, Calibrated Parameter Set for the Lower-Bound Infiltration Scenario

6-6. Water-Potential Matches at USW SD-12 for a One-Dimensional, Drift-Scale, Calibrated Parameter Set for the Lower-Bound Infiltration Scenario $6-26$

6-7. Pneumatic Pressure Matches at USW SD-12 for the One-Dimensional, Mountain-Scale, Calibrated Parameter Set for the Base-Case Infiltration Scenario.

6-8. Saturation Matches at USW UZ-7a Used in the Two-Dimensional Calibrated Fault Parameter Set for the Base-Case Infiltration Scenario

6-9. Water-Potential Matches at USW UZ-7a Used in the Two-Dimensional Calibrated Fault Parameter Set for the Base-Case Infiltration Scenario

6-10. Pneumatic Pressure Matches at USW UZ-7a Used in the Two-Dimensional Calibrated Fault Parameter Set for the Base-Case Infiltration Scenario.

B-1. $\quad$ Measured Water Potential (from Available Instrument Stations of Borehole USW NRG-7a) Breakthrough (Starting from October 1994, as Month 1) and the Determined Steady-State Value Used in the Inverse Model for Hydraulic Property Calibration (DIRS 170678)

B-2. Measured Water Potential (from Available Instrument Stations of Borehole USW NRG-6) Breakthrough (Starting from October 1994, as Month 1) and the Determined Steady-State Value Used in the Inverse Model for Hydraulic Property Calibration (DIRS 170678)

B-3. Measured Water Potential (from Available Instrument Stations of Borehole UE25 UZ\#4) Breakthrough (Starting from October 1994, as Month 1) and the Determined Steady-State Value Used in the Inverse Model for Hydraulic Property Calibration (DIRS 170678)

B-4. Measured Water Potential (from Available Instrument Stations of Borehole UE25 SD-12) Breakthrough (Starting from October 1994, as Month 1) and the Determined Steady-State Value Used in the Inverse Model for Hydraulic Property Calibration (DIRS 170678). 


\section{INTENTIONALLY LEFT BLANK}




\section{TABLES}

Page

3-1. Qualified Software Used in This Report...................................................................... 3-1

4-1. Input Data Sources and Data Tracking Numbers ...................................................... 4-2

4-2. Uncalibrated Matrix Properties and Uncertainty Data (the Relation Between

HGUs and UZ Model Layers Is Given in Table 6-3) ................................................ 4-4

4-3. Uncalibrated Fracture Property Data ………......................................................... 4-5

4-4. Input Data from Superceded Model Report............................................................ 4-9

4-5. Project Requirements and Yucca Mountain Review Plan Acceptance Criteria

Applicable to This Model Report …………………….......................................... 4-10

6-1. Scientific Notebooks .............................................................................................. 6-1

6-2. $\quad$ FEPs Addressed in This Model Report................................................................. 6-2

6-3. GFM2000 Lithostratigraphy, UZ Model Layer, and Hydrogeologic Unit

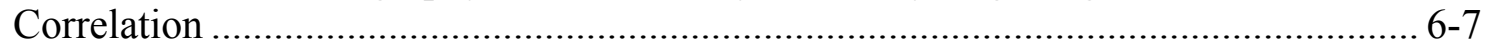

6-4. $\quad$ Pneumatic Pressure Data Used for Inversion............................................................ 6-13

6-5. Area-Averaged Infiltration Rates ( $\mathrm{mm} /$ year) Used in the One-Dimensional Inversions .......................................................................................................... 6-15

6-6. Data Used for One-Dimensional Calibration of Drift-Scale Properties from Each

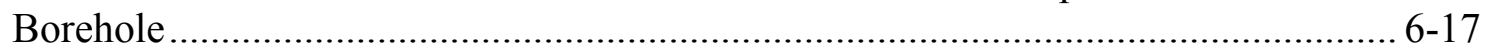

6-7. Initial Estimates of the Active Fracture Parameter, $\gamma$, for Saturation and WaterPotential Data Inversion....................................................................................... 6-20

6-8. Calibrated Parameters from One-Dimensional Inversion of Saturation, and

Water-Potential Data for the Base-Case Infiltration Scenario

6-9. Calibrated Parameters from One-Dimensional Inversion of Saturation, and Water-Potential Data for the Upper-Bound Infiltration Scenario

6-10. Calibrated Parameters from One-Dimensional Inversion of Saturation and Water-Potential Data for the Lower-Bound Infiltration Scenario ............................... 6-25

6-11. The Calculated $\log (\mathrm{d})$ Factors for the Three Infiltration Maps................................... 6-29

6-12. Calibrated Mountain-Scale Fracture Permeabilities $\left(\mathrm{m}^{2}\right)$......................................... 6-29

6-13. Pneumatic Pressure Data Used for Inversion.......................................................... 6-32

6-14. Calibrated Fault Parameters from Two-Dimensional Inversions of Saturation, Water Potential, and Pneumatic Data ......................................................................... 6-33

6-15. Average Residual for Calibrated Matrix Properties for Three Infiltration

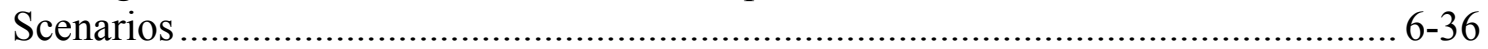

6-16. Average Absolute Residual for Calibrated Matrix Properties for Three Infiltration Scenarios............................................................................................ 6-37

6-17. Uncertainties of Calibrated Parameters …………................................................... 6-39

7-1. Validation in Terms of Saturation for Three Infiltration Scenarios............................... 7-5

7-2. Validation in Terms of Water Potential for Three Infiltration Scenarios ...................... 7-5

7-3. Usage of the Observed Dynamic Pneumatic Pressure Data .......................................... 7-6

7-4. Validation in Terms of Pneumatic Data for Three Infiltration Scenarios...................... 7-6 


\section{TABLES (Continued)}

Page

A1-1. Excel Cell Addresses of Borehole Data.................................................................... A-4

A1-2. Excel Formulae and Cell Addresses ........................................................................ A-5 


\section{ACRONYMS AND ABBREVIATIONS}

$\mathrm{CFu} \quad$ Crater Flat undifferentiated hydrogeologic unit

CHn Calico Hills nonwelded hydrogeologic unit

DTN data tracking number

ESF Exploratory Studies Facility

FEP feature, event, and process

HGU hydrogeologic unit

LA license application

PTn Paintbrush nonwelded hydrogeologic unit

RMSE root-mean-square error

TCw Tiva Canyon welded hydrogeologic unit

TDMS Technical Data Management System

TPO technical product output

TSPA Total System Performance Assessment

TSw Topopah Spring welded hydrogeologic unit

TWP technical work plan

UZ unsaturated zone

UZ models unsaturated zone flow and transport models 


\section{INTENTIONALLY LEFT BLANK}




\section{PURPOSE}

The purpose of this model report is to document the calibrated properties model that provides calibrated property sets for unsaturated zone (UZ) flow and transport process models (UZ models). The calibration of the property sets is performed through inverse modeling. This work followed, and was planned in, Technical Work Plan (TWP) for: Unsaturated Zone Flow Analysis and Model Report Integration (BSC 2004 [DIRS 169654], Sections 1.2.6 and 2.1.1.6). Direct inputs to this model report were derived from the following upstream analysis and model reports:

- Analysis of Hydrologic Properties Data (BSC 2004 [DIRS 170038])

- Development of Numerical Grids for UZ Flow and Transport Modeling (BSC 2004 [DIRS 169855])

- Simulation of Net Infiltration for Present-Day and Potential Future Climates (BSC 2004 [DIRS 170007])

- Geologic Framework Model (GFM2000) (BSC 2004 [DIRS 170029]).

Additionally, this model report incorporates errata of the previous version and closure of the Key Technical Issue agreement TSPAI 3.26 (Section 6.2.2 and Appendix B), and it is revised for improved transparency.

The calibrated property sets correspond to the maps of the best estimate of present-day net infiltration, as well as maps representing the expected upper and lower bounds of net infiltration. The calibrated property sets submitted to the Technical Data Management System are:

- Drift-scale calibrated parameter sets based on one-dimensional inversions (Output-DTNs: LB0208UZDSCPMI.002 for base-case infiltration, LB0208UZDSCPUI.002 for upper-bound infiltration, and LB0208UZDSCPLI.002 for lower-bound infiltration)

- Mountain-scale calibrated parameter sets based on one-dimensional inversions (Output-DTN: LB02091DSSCP3I.002)

- Calibrated fault parameters (one set for all three infiltration scenarios) based on two-dimensional inversions (Output-DTN: LB02092DSSCFPR.002).

These calibrated property sets are used by the following downstream model reports:

- Drift-Scale Coupled Processes (DST and TH Seepage) Models

(DTN: LB0208UZDSCPMI.002)

- Drift Scale THM Model (DTN: LB0208UZDSCPMI.002)

- In-Drift Natural Convection and Condensation (DTN: LB0208UZDSCPMI.002)

- Mountain-Scale Coupled Processes (TH/THC/THM) (DTN: LB0208UZDSCPMI.002) 
- Multiscale Thermohydrologic Model (DTN: LB0208UZDSCPMI.002, LB0208UZDSCPLI.002)

- Particle Tracking Model and Abstraction of Transport Process

(DTNS: LB0208UZDSCPMI.002, LB0208UZDSCPLI.002, LB0208UZDSCPUI.002)

- Seepage Model for PA Including Drift Collapse (DTN: LB0208UZDSCPMI.002)

- UZ Flow Models and Submodels (DTNS: LB0208UZDSCPMI.002, LB02091DSSCP3I.002, LB02092DSSCFPR.002).

The caveats and limitations for use of each of these property sets are documented in Section 6.0. The limitations of the calibrated properties model are also discussed in Section 6.0. Because this model report is the basis for the above listed documents, the features, events, and processes (FEPs) addressed herein are also traceable through those documents and are, thereby, implicitly included in the TSPA for license application (LA). 


\section{QUALITY ASSURANCE}

Development of this model report and the supporting modeling activities have been determined to be subject to the Yucca Mountain Project's quality assurance program as indicated in Technical Work Plan for: Unsaturated Zone Flow Analysis and Model Report Integration (BSC 2004 [DIRS 169654], Section 8.1). Approved quality assurance procedures identified in the TWP (BSC 2004 [DIRS 169654], Section 4) have been used to conduct and document the activities described in this model report. The TWP also identifies the methods used to control the electronic management of data (BSC 2004 [DIRS 169654], Section 8.4) during the modeling and documentation activities.

This model report provides calibrated values for hydrologic properties of the UZ rocks above and below the repository. The UZ rocks above and below the repository are natural barriers that are classified in the Q-List (BSC 2004 [DIRS 168361]) as "Safety Category" because they are important to waste isolation, as defined in AP-2.22Q, Classification Analyses and Maintenance of the Q-List. The report contributes to the analysis data used to support the Total System Performance Assessment (TSPA); the conclusions do not directly impact engineered features important to preclosure safety, as defined in AP-2.22Q. 


\section{INTENTIONALLY LEFT BLANK}




\section{USE OF SOFTWARE}

The software programs used in this study are listed in Table 3-1. These are appropriate for the intended application and are used only within the range of validation. They were obtained from Software Configuration Management, and qualified under LP-SI.11Q-BSC, Software Management.

Table 3-1. Qualified Software Used in This Report

\begin{tabular}{|l|l|l|l|}
\hline Software Name & \multicolumn{1}{|c|}{ Version } & \multicolumn{1}{|c|}{$\begin{array}{c}\text { Software Tracking Number } \\
\text { (STN) }\end{array}$} & \multicolumn{1}{|c|}{$\begin{array}{c}\text { Document Input } \\
\text { Reference System } \\
\text { (DIRS) ID }\end{array}$} \\
\hline iTOUGH2 & 5.0 & $10003-5.0-00$ & $\begin{array}{l}\text { LBNL 2002 } \\
\text { (DIRS 160106) }\end{array}$ \\
\hline infil2grid & 1.6 & $10077-1.6-00$ & $\begin{array}{l}\text { LBNL 1999 } \\
\text { (DIRS 134754) }\end{array}$ \\
\hline infil2grid & 1.7 & $10077-1.7-00$ & $\begin{array}{l}\text { LBNL 2002 } \\
\text { (DIRS 154793) }\end{array}$ \\
\hline aversp_1 & 1.0 & $10878-1.0-00$ & $\begin{array}{l}\text { LBNL 2002 } \\
\text { (DIRS 146533) }\end{array}$ \\
\hline TBgas3D & 2.0 & $10882-2.0-00$ & $\begin{array}{l}\text { LBNL 2002 } \\
\text { (DIRS 160107) }\end{array}$ \\
\hline e9-3in & 1.0 & $10126-1.0-00$ & $\begin{array}{l}\text { LBNL 1999 } \\
\text { (DIRS 146536) }\end{array}$ \\
\hline
\end{tabular}

Standard Excel spreadsheets and visual display graphics programs (Excel 97 SR-1 and Tecplot V7.0) were also used but are not subject to software quality assurance requirements. All information needed to reproduce the work using these standard software programs, including the input, computation, and output is included in this report (Appendix A). All computations are described by the title in Sections 6 and 7, with reference to Appendix A. 


\section{INTENTIONALLY LEFT BLANK}




\section{INPUTS}

This section discusses input data and parameters in this model report. This model report contains six (6) additional input DTNs that were not listed in the previous revision of the report (BSC 2003 [DIRS 166509], Section 9.3). Five of these DTNs are recent water potential data, which are not used in inversions, and the sixth DTN consists compiled charts of these recent data as described in Appendix B.

\subsection{DIRECT INPUTS}

Source information on the direct inputs is summarized in Table 4-1 and is further documented below. The appropriateness of the inputs is also described.

\subsubsection{Output from Other Models and Analyses}

Developed data include the spatially varying infiltration maps from the infiltration model and several numerical grids, which are documented in separate reports (BSC 2004 [DIRS 170007]; BSC 2004 [DIRS 169855]). These data sets are too large to reproduce here, but are listed by data tracking number (DTN) in Table 4-1. Uncalibrated properties and property-estimate uncertainties of the matrix and fractures, which are used as inputs to the calibration, are listed in Table 4-2 and Table 4-3, respectively. Porosity, residual saturation, satiated saturation, and van Genuchten parameter $m$ are not calibrated. All other properties and uncertainty data are used to constrain the calibration. The infiltration maps are the best estimates of infiltration rate distributions for UZ currently available. The appropriateness of the numerical grids for modeling flow and transport in UZ is presented in a scientific analysis report (BSC 2004 [DIRS 169855]).

\subsubsection{Acquired Data}

Acquired data include saturation; water potential; pneumatic pressure; fracture, matrix, and fault properties; infiltration maps; numerical grids. In all cases, the data sets are too large to reproduce here, but are listed by DTN in Table 4-1. These data are developed prior to use in the inversions as documented in Sections 6.2 and 6.3.4. Data that are not used are also discussed.

\subsubsection{Saturation Data}

Saturation data measured on core from Boreholes USW SD-6, USW SD-7, USW SD-9, USW SD-12, USW UZ-14, UE-25 UZ\#16, USW WT-24, USW UZ-N11, USW UZ-N31, USW UZ-N 32, USW UZ-N33, USW UZ-N37, USW UZ-N38, USW UZ-N53, USW UZ-N54, USW UZN55, USW UZ-N57, USW UZ-N58, USW UZ-N59, and USW UZ-N61 are used for the onedimensional inversions or model validation. The locations of these boreholes are shown in Figure 4-1. These boreholes do not intersect mapped faults, and thus the saturation data from these boreholes are representative of the rock mass of Yucca Mountain. Saturation data measured on core from Borehole USW UZ-7a (location shown in Figure 4-1) are used for the two-dimensional inversions. This borehole intersects the Ghost Dance fault, and saturation data from this borehole are judged to be representative of the faulted rock at Yucca Mountain. 
Saturation data measured on core from several boreholes and tunnels at Yucca Mountain are not included in any of the inversions. Saturation data measured on core from Boreholes USW NRG-6 and USW NRG-7a are not used because handling of the core caused excessive drying (Rousseau et al. 1999 [DIRS 102097], p. 125). Saturation data measured on core from the Exploratory Studies Facility (ESF), Enhanced Characterization of Repository Block Cross-Drift, alcoves, and niches are not used, because they represent only a single layer in the stratigraphic column. Geophysical measurements of saturation are not used because of larger uncertainties associated with these data, compared with direct measurements of saturation by oven drying. A detailed discussion of the relevant geophysical measurements was presented by BSC (2004 [DIRS 169854], Appendix B) as compared with the corresponding core-measurements. The geophysical data may be useful for future model calibration activities as corroborative data.

Table 4-1. Input Data Sources and Data Tracking Numbers

\begin{tabular}{|c|c|c|}
\hline DTN & Data Description & $\begin{array}{l}\text { Section } \\
\text { Describing Data } \\
\text { Use }\end{array}$ \\
\hline $\begin{array}{l}\text { MO0109HYMXPROP.001 } \\
\text { (DIRS 155989) }\end{array}$ & $\begin{array}{l}\text { Saturation data from cores for Boreholes USW SD-7, } \\
\text { USW SD-9, USW SD-12, USW UZ-14, UE-25 UZ\#16, } \\
\text { USW UZ-7a, USW WT-24, USW UZ-N11, USW UZ-N31, } \\
\text { USW UZ-N32, USW UZ-N33, USW UZ-N37, USW UZ- } \\
\text { N38, USW UZ-N53, USW UZ-N54, USW UZ-N55, USW } \\
\text { UZ-N57, USW UZ-N58, USW UZ-N59, and USW UZ- } \\
\text { N61. }\end{array}$ & $\begin{array}{l}6.2 .2 \\
6.3 .2\end{array}$ \\
\hline $\begin{array}{l}\text { GS980808312242.014 } \\
\text { (DIRS 106748) }\end{array}$ & Saturation Data from Cores for Borehole USW SD-6. & $\begin{array}{l}6.2 .2 \\
6.3 .2 \\
\end{array}$ \\
\hline $\begin{array}{l}\text { GS980708312242.010 } \\
\text { (DIRS 106752) }\end{array}$ & Saturation Data from Cores for Borehole USW WT-24. & $\begin{array}{l}6.2 .2 \\
6.3 .2 \\
\end{array}$ \\
\hline $\begin{array}{l}\text { GS950208312232.003 } \\
\text { (DIRS 105572) } \\
\text { GS951108312232.008 } \\
\text { (DIRS 106756) } \\
\text { GS960308312232.001 } \\
\text { (DIRS 105573) } \\
\text { GS960808312232.004 } \\
\text { (DIRS 105974) } \\
\text { GS970108312232.002 } \\
\text { (DIRS 105975) } \\
\text { GS970808312232.005 } \\
\text { (DIRS 105978) } \\
\text { GS971108312232.007 } \\
\text { (DIRS 105980) } \\
\text { GS031208312232.003 } \\
\text { (DIRS 171287) }\end{array}$ & $\begin{array}{l}\text { In situ Water-Potential Data for Boreholes USW NRG-6, } \\
\text { USW NRG-7a, USW SD-12, UE-25 UZ\#4, \& USW UZ- } \\
\text { 7a. }\end{array}$ & 6.2 .2 \\
\hline $\begin{array}{l}\text { GS000608312261.001 } \\
\text { (DIRS 155891) }\end{array}$ & $\begin{array}{l}\text { In situ Pneumatic Pressure Data for Borehole UE-25 } \\
\text { NRG\#5. }\end{array}$ & 6.2 .3 \\
\hline
\end{tabular}


Table 4-1. Input Data Sources and Data Tracking Numbers (Continued)

\begin{tabular}{|c|c|c|}
\hline DTN & Data Description & $\begin{array}{c}\text { Section } \\
\text { Describing Data } \\
\text { Use }\end{array}$ \\
\hline $\begin{array}{l}\text { GS950208312232.003 } \\
\text { (DIRS 105572) }\end{array}$ & \multirow[t]{4}{*}{$\begin{array}{l}\text { In situ Pneumatic Pressure Data for Borehole } \\
\text { USW NRG-6 \& USW NRG-7a. }\end{array}$} & \multirow[t]{4}{*}{6.2 .3} \\
\hline $\begin{array}{l}\text { GS951108312232.008 } \\
\text { (DIRS 106756) }\end{array}$ & & \\
\hline $\begin{array}{l}\text { GS960308312232.001 } \\
\text { (DIRS 105573) }\end{array}$ & & \\
\hline $\begin{array}{l}\text { GS960808312232.004 } \\
\text { (DIRS 105974) }\end{array}$ & & \\
\hline $\begin{array}{l}\text { GS960908312261.004 } \\
\text { (DIRS 106784) }\end{array}$ & In situ Pneumatic Pressure Data for Borehole USW SD-7. & 6.2 .3 \\
\hline $\begin{array}{l}\text { GS960308312232.001 } \\
\text { (DIRS 105573) }\end{array}$ & $\begin{array}{l}\text { In situ Pneumatic Pressure Data for Borehole } \\
\text { USW SD-12 \& USW UZ-7a. }\end{array}$ & \begin{tabular}{|l|}
6.2 .3 \\
6.3 .4
\end{tabular} \\
\hline $\begin{array}{l}\text { GS000308311221.005 } \\
\text { (DIRS 147613) }\end{array}$ & $\begin{array}{l}\text { Infiltration Map (modern climate—mean, lower and } \\
\text { upper). }\end{array}$ & 6.2 .5 \\
\hline $\begin{array}{l}\text { LB02081DKMGRID.001 } \\
\text { (DIRS 160108) }\end{array}$ & One-dimensional and two-dimensional grids. & 6.2 .1 \\
\hline $\begin{array}{l}\text { LB0205REVUZPRP.001 } \\
\text { (DIRS 159525) }\end{array}$ & Uncalibrated Fracture Property Data. & 6.2 .4 \\
\hline $\begin{array}{l}\text { LB0207REVUZPRP.002 } \\
\text { (DIRS 159672) }\end{array}$ & Uncalibrated Matrix Property Data. & $\begin{array}{l}6.2 .4 \\
6.4 .1\end{array}$ \\
\hline $\begin{array}{l}\text { LB0207REVUZPRP.001 } \\
\text { (DIRS 159526) }\end{array}$ & Uncalibrated Fault Property Data. & 6.2 .4 \\
\hline 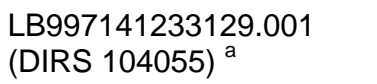 & \multirow[t]{3}{*}{$\begin{array}{l}\text { Calibrated Base-Case Infiltration One-Dimensional } \\
\text { Parameter Set for the UZ flow and transport model. }\end{array}$} & \multirow[t]{3}{*}{6.3 .3} \\
\hline 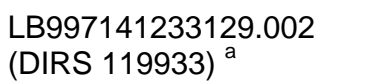 & & \\
\hline $\begin{array}{l}\text { LB997141233129.003 } \\
\text { (DIRS 119940) }^{\mathrm{a}}\end{array}$ & & \\
\hline $\begin{array}{l}\text { LB991091233129.001 } \\
{\text { (DIRS } 125868)^{a}}^{a}\end{array}$ & $\begin{array}{l}\text { One-Dimensional, Mountain-Scale Calibration for } \\
\text { calibrated properties model. }\end{array}$ & $\begin{array}{l}6.2 .2 \\
6.2 .5 \\
6.3 .2 \\
\end{array}$ \\
\hline $\begin{array}{l}\text { LB991091233129.003 } \\
\text { (DIRS 119902) }^{a}\end{array}$ & $\begin{array}{l}\text { Two-dimensional, Fault Calibration for calibrated } \\
\text { properties model. }\end{array}$ & 6.3 .4 \\
\hline $\begin{array}{l}\text { MO0012MWDGFM02.002 } \\
\text { (DIRS 153777) }\end{array}$ & Geologic Framework Model (GFM2000). & $\begin{array}{l}6.2 .2 \\
6.2 .3 \\
\end{array}$ \\
\hline $\begin{array}{l}\text { GS940208314211.008 } \\
\text { (DIRS 145581) }\end{array}$ & $\begin{array}{l}\text { Table of Contacts in Boreholes USW UZ-N57, N59 and } \\
\text { N61. }\end{array}$ & 6.2 .2 \\
\hline
\end{tabular}

${ }^{a}$ Historical TPOs (see Section 4.1.3 for justifications for use of historical TPOs). 
Table 4-2. Uncalibrated Matrix Properties and Uncertainty Data (the Relation Between HGUs and UZ Model Layers Is Given in Table 6-3)

\begin{tabular}{|c|c|c|c|c|c|c|c|c|c|c|c|c|c|}
\hline HGU & $\phi$ & $\begin{array}{c}\mathbf{k} \\
{\left[\mathrm{m}^{2}\right]}\end{array}$ & $\begin{array}{c}\log (k) \\
{\left[\log \left(m^{2}\right)\right]}\end{array}$ & $\sigma_{\log (\mathrm{k})}$ & $N$ & \begin{tabular}{|c|}
$\mathbf{N}$ \\
non- \\
detect
\end{tabular} & $S E_{\log (k)}$ & $\begin{array}{c}1 / \alpha \\
{[\mathrm{Pa}]}\end{array}$ & $\begin{array}{c}\log (1 / \alpha) \\
{[\log (\mathrm{Pa})]}\end{array}$ & $\mathrm{SE}_{\log (1 / \alpha)}$ & $\mathrm{m}$ & $\mathrm{SE}_{\mathrm{m}}$ & $S_{r}$ \\
\hline $\begin{array}{l}\text { CCR \& } \\
\text { CUC }\end{array}$ & 0.241 & 4.7E-15 & -14.33 & 0.47 & 3 & 0 & 0.27 & $8.27 \mathrm{E}+4$ & 4.918 & 0.279 & 0.388 & 0.085 & 0.02 \\
\hline CUL \& CW & 0.088 & $6.4 \mathrm{E}-20$ & -19.20 & 2.74 & 15 & 25 & 0.43 & $5.46 \mathrm{E}+5$ & 5.737 & 0.178 & 0.280 & 0.045 & 0.20 \\
\hline CMW & 0.200 & $1.8 \mathrm{E}-16$ & -15.74 & 2.38 & 5 & 1 & 0.97 & $2.50 \mathrm{E}+5$ & 5.398 & 0.188 & 0.259 & 0.042 & 0.31 \\
\hline CNW & 0.387 & 4.0E-14 & -13.40 & 2.05 & 10 & 0 & 0.65 & $2.03 \mathrm{E}+4$ & 4.308 & 0.199 & 0.245 & 0.032 & 0.24 \\
\hline BT4 & 0.428 & $4.1 \mathrm{E}-13$ & -12.39 & 1.41 & 11 & 0 & 0.43 & $4.55 \mathrm{E}+3$ & 3.658 & 0.174 & 0.219 & 0.019 & 0.13 \\
\hline TPY & 0.233 & 1.3E-15 & -14.90 & 0.64 & 2 & 0 & 0.46 & $7.63 \mathrm{E}+4$ & 4.883 & 0.379 & 0.247 & 0.064 & 0.07 \\
\hline BT3 & 0.413 & 1.3E-13 & -12.87 & 1.09 & 11 & 1 & 0.31 & $8.90 \mathrm{E}+3$ & 3.950 & 0.088 & 0.182 & 0.008 & 0.14 \\
\hline TPP & 0.498 & 1.1E-13 & -12.96 & 0.39 & 11 & 0 & 0.12 & $2.12 \mathrm{E}+4$ & 4.325 & 0.104 & 0.300 & 0.023 & 0.06 \\
\hline BT2 & 0.490 & $6.7 \mathrm{E}-13$ & -12.17 & 1.12 & 21 & 0 & 0.24 & $1.74 \mathrm{E}+4$ & 4.239 & 0.170 & 0.126 & 0.013 & 0.05 \\
\hline $\mathrm{TC}$ & 0.054 & $4.4 \mathrm{E}-17$ & -16.36 & 3.02 & 6 & 5 & 0.91 & $2.71 \mathrm{E}+5$ & 5.432 & 0.310 & 0.218 & 0.054 & 0.21 \\
\hline TR & 0.157 & 3.2E-16 & -15.50 & 0.94 & 46 & 1 & 0.14 & $9.43 \mathrm{E}+4$ & 4.974 & 0.116 & 0.290 & 0.025 & 0.07 \\
\hline TUL & 0.155 & $2.8 \mathrm{E}-17$ & -16.56 & 1.61 & 37 & 12 & 0.23 & $1.75 E+5$ & 5.244 & 0.111 & 0.283 & 0.024 & 0.12 \\
\hline TMN & 0.111 & $4.5 \mathrm{E}-19$ & -18.34 & 0.97 & 74 & 35 & 0.09 & $1.40 \mathrm{E}+6$ & 6.147 & 0.108 & 0.317 & 0.042 & 0.19 \\
\hline TLL & 0.131 & 3.7E-17 & -16.44 & 1.65 & 51 & 24 & 0.19 & $6.01 \mathrm{E}+4$ & 4.779 & 0.521 & 0.216 & 0.061 & 0.12 \\
\hline TM2 \& TM1 & 0.103 & 2.3E-20 & -19.63 & 3.67 & 21 & 42 & 0.46 & $3.40 \mathrm{E}+6$ & 6.532 & 0.097 & 0.442 & 0.073 & 0.20 \\
\hline PV3 & 0.043 & 2.9E-18 & -17.54 & 1.57 & 16 & 2 & 0.37 & $1.00 \mathrm{E}+6$ & 6.000 & 0.278 & 0.286 & 0.065 & 0.42 \\
\hline PV2a & 0.275 & $a$ & $a$ & $a$ & $a$ & $a$ & $a$ & $2.17 E+5$ & 5.336 & 0.156 & 0.059 & 0.007 & 0.36 \\
\hline PV2V & 0.229 & 4.3E-13 & -12.37 & 1.38 & 16 & 0 & 0.34 & $1.94 \mathrm{E}+4$ & 4.287 & 0.042 & 0.293 & 0.011 & 0.13 \\
\hline BT1a & 0.285 & 3.5E-17 & -16.45 & 2.74 & 9 & 1 & 0.87 & $4.72 \mathrm{E}+6$ & 6.674 & 0.183 & 0.349 & 0.073 & 0.38 \\
\hline BT1v & 0.331 & 2.1E-13 & -12.67 & 1.11 & 35 & 0 & 0.19 & $1.35 \mathrm{E}+4$ & 4.131 & 0.049 & 0.240 & 0.008 & 0.06 \\
\hline $\mathrm{CHV}$ & 0.346 & 1.6E-12 & -11.81 & 1.62 & 46 & 0 & 0.24 & $3.39 E+3$ & 3.530 & 0.094 & 0.158 & 0.008 & 0.06 \\
\hline $\mathrm{CHZ}$ & 0.322 & $5.2 \mathrm{E}-18$ & -17.28 & 0.91 & 99 & 17 & 0.08 & $4.45 \mathrm{E}+5$ & 5.649 & 0.094 & 0.257 & 0.022 & 0.26 \\
\hline BTa & 0.271 & 8.2E-19 & -18.08 & 2.05 & 9 & 8 & 0.50 & $6.42 \mathrm{E}+6$ & 6.808 & 0.043 & 0.499 & 0.036 & 0.36 \\
\hline BTV & $b$ & b & $\mathrm{b}$ & $\mathrm{b}$ & $\mathrm{b}$ & $\mathrm{b}$ & b & $5.04 \mathrm{E}+4$ & 4.703 & 0.207 & 0.147 & 0.020 & $b$ \\
\hline PP4 & 0.321 & $1.5 \mathrm{E}-16$ & -15.81 & 2.74 & 6 & 2 & 0.97 & $5.00 \mathrm{E}+5$ & 5.699 & 0.401 & 0.474 & 0.224 & 0.29 \\
\hline PP3 & 0.318 & 6.4E-15 & -14.20 & 0.75 & 51 & 0 & 0.11 & $1.32 \mathrm{E}+5$ & 5.120 & 0.084 & 0.407 & 0.031 & 0.08 \\
\hline
\end{tabular}


Table 4-2. Uncalibrated Matrix Properties and Uncertainty Data (the Relation Between HGUs and UZ Model Layers Is Given in Table 6-3) (Continued)

\begin{tabular}{|c|c|c|c|c|c|c|c|c|c|c|c|c|c|}
\hline HGU & $\phi$ & $\begin{array}{c}\mathbf{k} \\
{\left[\mathrm{m}^{2}\right]}\end{array}$ & $\mid \begin{array}{c}\log (\mathbf{k}) \\
{\left[\log \left(m^{2}\right)\right]}\end{array}$ & $\sigma_{\log (k)}$ & $\mathbf{N}$ & $\begin{array}{c}\mathbf{N} \\
\text { non- } \\
\text { detect }\end{array}$ & $\mathrm{SE}_{\log (k)}$ & $\begin{array}{c}1 / \alpha \\
{[\mathrm{Pa}]}\end{array}$ & $\left|\begin{array}{c}\log (1 / \alpha) \\
{[\log (P a)]}\end{array}\right|$ & $S E_{\log (1 / \alpha)}$ & m & $\mathrm{SE}_{\mathrm{m}}$ & $S_{r}$ \\
\hline P2 & 0.221 & $5.4 \mathrm{E}-17$ & -16.27 & 1.18 & 34 & 3 & 0.19 & $6.22 \mathrm{E}+5$ & 5.794 & 0.147 & 0.309 & 0.041 & 0.10 \\
\hline PP1 & 0.297 & $8.1 \mathrm{E}-17$ & -16.09 & 1.52 & 27 & 1 & 0.29 & $1.13 \mathrm{E}+5$ & 5.052 & 0.234 & 0.272 & 0.036 & 0.30 \\
\hline BF3/TF & 0.175 & $1.1 \mathrm{E}-15$ & -14.95 & 1.64 & 7 & 1 & 0.58 & $8.94 E+4$ & 4.951 & 0.931 & 0.193 & 0.117 & 0.11 \\
\hline $\mathrm{BF} 2$ & 0.234 & c & c & c & c & c & c & $8.46 \mathrm{E}+6$ & 6.927 & 0.032 & 0.617 & 0.070 & 0.21 \\
\hline
\end{tabular}

DTN: $\quad$ LB0207REVUZPRP.002 (DIRS 159672).

NOTES: $\quad k$ is permeability; $\sigma$ is standard deviation; $N$ is number of samples; $\phi$ is porosity.

$\alpha$ and $m$ are fitting parameters for the van Genuchten water potential relationship.

SE is standard error.

$\mathrm{S}_{\mathrm{r}}$ is residual liquid saturation.

Nondetect means permeability too low to measure.

BTa and BTv correspond to zeolitic and vitric BT, respectively, in Table 6-3.

${ }^{a}$ BT1a was used as an analogue for permeability because only one permeability data point is available for PV2a.

${ }^{\mathrm{b}}$ BT1v was used as an analogue for porosity, residual saturation, and permeability because only one sample is available for BTV.

${ }^{c}$ PP1 was used as an analogue for permeability because only one measurable permeability data point is available for BF2.

Table 4-3. Uncalibrated Fracture Property Data

\begin{tabular}{|c|c|c|c|c|c|c|c|c|c|c|c|c|}
\hline \multirow[b]{2}{*}{ UZ Model Layer } & \multicolumn{4}{|c|}{ permeability $\left(\mathrm{m}^{2}\right)$} & \multicolumn{3}{|c|}{ frequency $\left(m^{-1}\right)$} & \multicolumn{3}{|c|}{ van Genuchten } & \multirow[b]{2}{*}{ porosity (-) } & \multirow[b]{2}{*}{ Std (-) } \\
\hline & $\mathbf{k}_{\mathbf{G}}$ & $\log \left(k_{G}\right)$ & $\sigma_{\log (\mathrm{kG})}$ & $\mathbf{N}$ & $f$ & $\sigma_{f}$ & $\mathbf{N}$ & $\alpha\left(\mathrm{Pa}^{-1}\right)$ & $\log (\alpha)$ & m (-) & & \\
\hline tcw11 & 3.0E-11 & -10.52 & - & 2 & 0.92 & 0.94 & 76 & $5.0 \mathrm{E}-3$ & -2.30 & 0.633 & 2.4E-2 & - \\
\hline tcw12 & 5.3E-12 & -11.28 & 0.78 & 80 & 1.91 & 2.09 & 1241 & 2.2E-3 & -2.66 & 0.633 & 1.7E-2 & - \\
\hline tcw13 & $4.5 \mathrm{E}-12$ & -11.35 & 1.15 & 3 & 2.79 & 1.43 & 60 & $1.9 \mathrm{E}-3$ & -2.73 & 0.633 & 1.3E-2 & - \\
\hline ptn21 & 3.2E-12 & -11.49 & 0.88 & 12 & 0.67 & 0.92 & 76 & $2.7 \mathrm{E}-3$ & -2.57 & 0.633 & $9.2 \mathrm{E}-3$ & - \\
\hline ptn22 & $3.0 \mathrm{E}-13$ & -12.52 & 0.20 & 4 & 0.46 & - & - & $1.4 \mathrm{E}-3$ & -2.86 & 0.633 & 1.0E-2 & - \\
\hline ptn23 & 3.0E-13 & -12.52 & 0.20 & 4 & 0.57 & - & 63 & 1.2E-3 & -2.91 & 0.633 & 2.1E-3 & - \\
\hline ptn24 & 3.0E-12 & -11.52 & - & 1 & 0.46 & 0.45 & 18 & 3.0E-3 & -2.53 & 0.633 & 1.0E-2 & - \\
\hline ptn25 & 1.7E-13 & -12.78 & 0.10 & 7 & 0.52 & 0.6 & 72 & 1.1E-3 & -2.96 & 0.633 & $5.5 \mathrm{E}-3$ & - \\
\hline ptn26 & 2.2E-13 & -12.66 & - & 1 & 0.97 & 0.84 & 114 & $9.6 \mathrm{E}-4$ & -3.02 & 0.633 & 3.1E-3 & - \\
\hline tsw31 & 8.1E-13 & -12.09 & - & - & 2.17 & 2.37 & 140 & 1.1E-3 & -2.96 & 0.633 & 5.0E-3 & - \\
\hline tsw32 & 7.1E-13 & -12.15 & 0.66 & 31 & 1.12 & 1.09 & 842 & $1.4 \mathrm{E}-3$ & -2.86 & 0.633 & 8.3E-3 & - \\
\hline tsw33 & $7.8 \mathrm{E}-13$ & -12.11 & 0.61 & 27 & 0.81 & 1.03 & 1329 & $1.6 \mathrm{E}-3$ & -2.80 & 0.633 & $5.8 \mathrm{E}-3$ & - \\
\hline tsw34 & 3.3E-13 & -12.48 & 0.47 & 180 & 4.32 & 3.42 & 10646 & 6.7E-4 & -3.18 & 0.633 & 8.5E-3 & 2.50E-03 \\
\hline alternate tsw34 & $1.5 \mathrm{E}-13$ & -12.81 & 0.75 & 180 & & & & & & & & \\
\hline tsw35 & $9.1 \mathrm{E}-13$ & -12.04 & 0.54 & 31 & 3.16 & - & 595 & 1.0E-3 & -2.99 & 0.633 & 9.6E-3 & - \\
\hline tsw3[67] & 1.3E-12 & -11.87 & 0.28 & 19 & 4.02 & - & 526 & 1.1E-3 & -2.96 & 0.633 & 1.3E-2 & - \\
\hline tsw38 & 8.1E-13 & -12.09 & - & - & 4.36 & - & 37 & $8.9 \mathrm{E}-4$ & -3.05 & 0.633 & 1.1E-2 & - \\
\hline tsw39 & 8.1E-13 & -12.09 & - & - & 0.96 & - & 46 & $1.5 \mathrm{E}-3$ & -2.82 & 0.633 & 4.3E-3 & - \\
\hline $\operatorname{ch} 1 Z e$ & 2.5E-14 & -13.60 & - & - & 0.04 & - & 3 & 1.4E-3 & -2.86 & 0.633 & 1.6E-4 & - \\
\hline $\operatorname{ch} 1 \mathrm{VI}$ & 2.2E-13 & -12.66 & - & - & 0.10 & - & 11 & 2.1E-3 & -2.69 & 0.633 & 6.1E-4 & - \\
\hline
\end{tabular}


Table 4-3.Uncalibrated Fracture Property Data (Continued)

\begin{tabular}{|c|c|c|c|c|c|c|c|c|c|c|c|c|}
\hline \multirow[b]{2}{*}{ UZ Model Layer } & \multicolumn{4}{|c|}{ permeability $\left(\mathrm{m}^{2}\right)$} & \multicolumn{3}{|c|}{ frequency $\left(\mathrm{m}^{-1}\right)$} & \multicolumn{3}{|c|}{ van Genuchten } & \multirow[b]{2}{*}{ porosity (-) } & \multirow[b]{2}{*}{ Std (-) } \\
\hline & $\mathbf{k}_{\mathbf{G}}$ & $\log \left(k_{G}\right)$ & $\sigma_{\log (\mathrm{kG})}$ & $\mathbf{N}$ & $f$ & $\sigma_{f}$ & $\mathbf{N}$ & $\alpha\left(\mathrm{Pa}^{-1}\right)$ & $\log (\alpha)$ & $m(-)$ & & \\
\hline $\operatorname{ch}[23456] \mathrm{VI}$ & 2.2E-13 & -12.66 & - & - & 0.14 & - & 25 & 1.9E-3 & -2.73 & 0.633 & 7.7E-4 & - \\
\hline $\operatorname{ch}[2345] \mathrm{Ze}$ & $2.5 \mathrm{E}-14$ & -13.60 & - & 1 & 0.14 & - & 25 & $8.9 \mathrm{E}-4$ & -3.05 & 0.633 & 3.7E-4 & - \\
\hline $\operatorname{ch} 6$ & $2.5 \mathrm{E}-14$ & -13.60 & - & - & 0.04 & - & - & $1.4 \mathrm{E}-3$ & -2.86 & 0.633 & 1.6E-4 & - \\
\hline pp4 & 2.5E-14 & -13.60 & - & - & 0.14 & - & - & $8.9 \mathrm{E}-4$ & -3.05 & 0.633 & 3.7E-4 & - \\
\hline pp3 & 2.2E-13 & -12.66 & - & - & 0.20 & - & - & $1.6 \mathrm{E}-3$ & -2.78 & 0.633 & 9.7E-4 & - \\
\hline pp2 & 2.2E-13 & -12.66 & - & - & 0.20 & - & - & 1.6E-3 & -2.78 & 0.633 & 9.7E-4 & - \\
\hline pp1 & $2.5 \mathrm{E}-14$ & -13.60 & - & - & 0.14 & - & - & 8.9E-4 & -3.05 & 0.633 & 3.7E-4 & - \\
\hline bf3 & 2.2E-13 & -12.66 & - & - & 0.20 & - & - & 1.6E-3 & -2.78 & 0.633 & 9.7E-4 & - \\
\hline bf2 & $2.5 \mathrm{E}-14$ & -13.60 & - & - & 0.14 & - & - & $8.9 \mathrm{E}-4$ & -3.05 & 0.633 & 3.7E-4 & - \\
\hline tr3 & 2.2E-13 & -12.66 & - & - & 0.20 & - & - & $1.6 \mathrm{E}-3$ & -2.78 & 0.633 & 9.7E-4 & - \\
\hline $\operatorname{tr} 2$ & 2.5E-14 & -13.60 & - & - & 0.14 & - & - & $8.9 \mathrm{E}-4$ & -3.05 & 0.633 & 3.7E-4 & - \\
\hline tcwf & 2.7E-11 & -10.57 & - & - & 1.90 & - & - & 3.8E-3 & -2.42 & 0.633 & 2.9E-2 & - \\
\hline ptnf & 3.1E-12 & -11.51 & - & - & 0.54 & - & - & $2.8 \mathrm{E}-3$ & -2.55 & 0.633 & 1.1E-2 & - \\
\hline tswf & 1.5E-11 & -10.82 & - & - & 1.70 & - & - & 3.2E-3 & -2.49 & 0.633 & $2.5 \mathrm{E}-2$ & - \\
\hline chnf & 3.7E-13 & -12.43 & - & - & 0.13 & - & - & $2.3 \mathrm{E}-3$ & -2.64 & 0.633 & 1.0E-3 & - \\
\hline
\end{tabular}

DTNS: LB0205REVUZPRP.001 (DIRS 159525); LB0207REVUZPRP.001 (DIRS 159526).

NOTES: $k$ is permeability.

G refers to geometric mean.

$\sigma$ is standard deviation.

$\mathrm{N}$ is number of samples.

$\mathrm{f}$ is fracture frequency.

$\alpha$ and $m$ are fitting parameters for the van Genuchten water potential relationship.

Std refers to standard deviation for fracture porosity. 


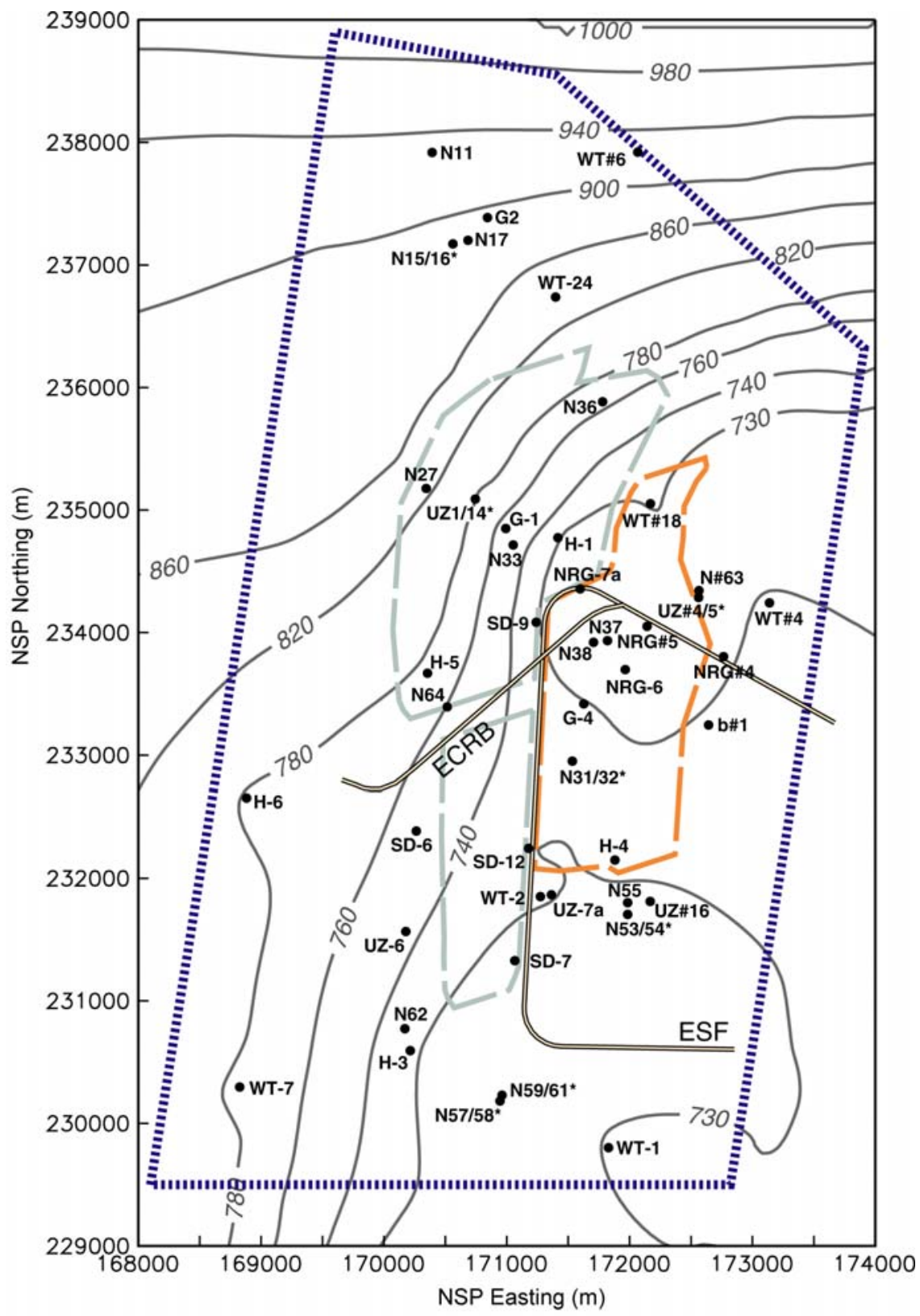

\begin{tabular}{|c|c|c|}
\hline \multicolumn{3}{|l|}{ LEGEND } \\
\hline 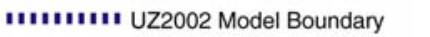 & $-900-$ & Water Table Elevation Contours \\
\hline$=2002$ Repository Boundary & UZ\#16 & Boreholes \\
\hline$=$ ESF and ECRB & $\begin{array}{l}\text { Note: }{ }^{*} \text { Der } \\
\text { adj }\end{array}$ & $\begin{array}{l}\text { notes single location used for } \\
\text { acent boreholes. }\end{array}$ \\
\hline
\end{tabular}

Source: $\quad$ BSC (2004 [DIRS 169855], Figure 6-2).

NOTE: NSP refers to Nevada State Plane.

Figure 4-1. Locations of Boreholes 


\subsubsection{Water-Potential Data}

Water-potential data measured in situ in Boreholes USW NRG-6, USW NRG-7a, UE-25 UZ\#4, and USW SD-12 are used in the one-dimensional inversions and model validations. These boreholes do not intersect mapped faults, and thus the water-potential data are representative of the rock mass of Yucca Mountain. Water-potential data measured in situ in Borehole USW UZ-7a are used for the two-dimensional inversions. This borehole intersects the Ghost Dance fault, and thus the water-potential data are judged to be representative of the faulted rock of Yucca Mountain. Water potential data measured in situ in Borehole UE-25 UZ\#5 are not used because this borehole is very close to Borehole UE-25 UZ\#4; the inversion results could be biased if both datasets (representing a smaller fraction of the whole region) were included. Compilation of the above water potential data is obtained from DTN: LB991091233129.001 (DIRS 125868) (see Sections 4.1.3 and 6.2.2).

Water-potential data measured on cores are not used because drying during drilling and/or handling may have substantially changed the water potential. In contrast with saturation data, for which the amount of change may be estimated (see Section 6.2.2), there is no way to reliably estimate the change in water potential. Such an estimate would depend on both the amount of saturation change and the relationship between saturation and water potential, and the uncertainty would be too great to contribute meaningful information to the parameter estimation procedure.

\subsubsection{Pneumatic Pressure Data}

Pneumatic pressure data measured in situ in Boreholes UE-25 NRG\#5, USW NRG-6, USW NRG-7a, USW SD-7, and USW SD-12 are used in the one-dimensional inversion and/or model validation. These boreholes do not intersect mapped faults, and thus the pneumatic pressure data from these boreholes are representative of the rock mass of Yucca Mountain. Pneumatic pressure data measured in situ in Borehole USW UZ-7a are used in the twodimensional inversion. This borehole intersects the Ghost Dance fault, and thus the pneumatic pressure data from this borehole are judged to be representative of the faulted rock of Yucca Mountain.

Pneumatic pressure data from Boreholes UE-25 UZ\#4 and UE-25 UZ\#5 are not used for the onedimensional inversion because they are close to a small, unnamed fault which, while it does not affect the in situ water-potential data, could affect the pneumatic data. While data from these boreholes and from USW NRG-6 do show the influence of the ESF, which is transmitted via faults, they are not used for calibration of fault parameters because three-dimensional models would be required, and only a single parameter, Topopah Spring welded hydrogeologic unit (TSw) horizontal fracture permeability, could be calibrated.

\subsubsection{Use of Established Fact Data}

Established fact data are used in Equations 6-6 through 6-8 (Section 6.2.2). These data include physical properties of air, the molecular weight and critical temperature and critical pressure of both air and water, and mole fraction of water vapor in air. The data values and sources are specified in Section 6.2.2 of this report. 


\subsubsection{Use of Historical Technical Product Outputs (TPOs)}

Inputs taken from the superceded model report Calibrated Properties Model (BSC 2001 [DIRS 161316]) and their usage in this current model report are given in Table 4-4. These inputs are considered suitable for their intended uses in this model report for the following reasons:

1. The Calibrated Properties Model (BSC 2001 [DIRS 161316]) report and its supporting model inputs and outputs were originated by personnel from Lawrence Berkeley National Laboratory. The originating personnel and the institution have a record of quality work.

2. The inputs obtained from these historical TPOs are the best available data for their intended purposes as explained by the additional justifications in Table 4-4.

3. Results reported in this model report, which use inputs obtained from the historic TPOs, were published in peer reviewed conference proceedings (Ahlers et al. 1998 [DIRS 124842]) and journals (Ahlers et al. 1999 [DIRS 109715]).

Descriptions and specific additional justifications for using the input data files obtained from the historical TPOs are given in Table 4-4.

Table 4-4. Input Data from Superceded Model Report

\begin{tabular}{|c|c|c|c|}
\hline No & DTN & Data Description & Data Use and Additional Justifications \\
\hline 1 & $\begin{array}{l}\text { LB997141233129.001 } \\
\text { (DIRS 104055) } \\
\end{array}$ & $\begin{array}{l}\text { Calibrated 1-D parameter set for } \\
\text { base-case infiltration scenario. }\end{array}$ & $\begin{array}{l}\text { These data were used as initial guesses for inverse } \\
\text { modeling. }\end{array}$ \\
\hline 2 & $\begin{array}{l}\text { LB997141233129.002 } \\
\text { (DIRS 119933) }\end{array}$ & $\begin{array}{l}\text { Calibrated one-dimensional } \\
\text { parameter set for upper-bound } \\
\text { infiltration scenario. }\end{array}$ & \multirow{2}{*}{$\begin{array}{l}\text { Selecting an initial guess that is close to the final } \\
\text { value of the calibrated parameter improves the } \\
\text { chance of finding a good match with observed data } \\
\text { (see Section 6.2.4). These data obtained from the } \\
\text { historic TPOs are considered the best available } \\
\text { guesses because they were derived through rigorous } \\
\text { inverse modeling exercise that met all the quality } \\
\text { assurance requirements in place at the time. }\end{array}$} \\
\hline 3 & $\begin{array}{l}\text { LB997141233129.003 } \\
\text { (DIRS 119940) }\end{array}$ & $\begin{array}{l}\text { Calibrated one-dimensional } \\
\text { parameter set for lower bound } \\
\text { infiltration scenario. }\end{array}$ & \\
\hline 4 & $\begin{array}{l}\text { LB991091233129.001 } \\
\text { (DIRS 125868) }\end{array}$ & $\begin{array}{l}\text { Compiled water potential data } \\
\text { (file name: in_situ_pcap2.xIs), } \\
\text { formatted gas pressure data } \\
\text { (file name: *.txt) and formatted } \\
\text { boundary condition (file name: } \\
\text { timvsp.dat). }\end{array}$ & $\begin{array}{l}\text { These compiled and formatted input files were } \\
\text { directly used for one-dimensional, mountain-scale } \\
\text { calibration and validation (see Sections } 6.2 .2,6.2 .5 \text {, } \\
\text { and } 7.5 \text { ). } \\
\text { These input files were considered appropriate for } \\
\text { their intended use in this model report because they } \\
\text { were derived from qualified data sources. }\end{array}$ \\
\hline 5 & $\begin{array}{l}\text { LB991091233129.003 } \\
\text { (DIRS 119902) }\end{array}$ & $\begin{array}{l}\text { Compiled saturation data (file } \\
\text { name: UZ7asat.xIs), compiled } \\
\text { water potential data (file name: } \\
\text { UZ-7acap.xIs) and formatted } \\
\text { pneumatic pressure data (file } \\
\text { name: *.prn). }\end{array}$ & $\begin{array}{l}\text { These compiled and formatted input files were } \\
\text { directly used for calibration of fault parameters (see } \\
\text { Section 6.3.4). } \\
\text { These input files were considered appropriate for } \\
\text { their intended use in this model report because they } \\
\text { were derived from qualified data sources. }\end{array}$ \\
\hline
\end{tabular}

1-D=one-dimensional; TPO=technical product output 


\subsection{CRITERIA}

The licensing criteria for postclosure performance assessment are stated in 10 CFR 63 (DIRS 156605). The requirements to be satisfied by TSPA are identified in the Yucca Mountain Project Requirements Document (Canori and Leitner 2003 [DIRS 166275]). The acceptance criteria that will be used by the U.S. Nuclear Regulatory Commission to determine whether the technical requirements for this model report have been met are identified in Yucca Mountain Review Plan, Final Report (YMRP; NRC 2003 [DIRS 163274]). The pertinent requirements and criteria for this model report are summarized in Table 4-5.

Table 4-5. Project Requirements and Yucca Mountain Review Plan Acceptance Criteria Applicable to This Model Report

\begin{tabular}{|c|l|c|l|}
\hline $\begin{array}{c}\text { Requirement } \\
\text { Number }\end{array}$ & \multicolumn{1}{c|}{ Requirement Title $^{\mathbf{a}}$} & $\begin{array}{c}\text { 10 CFR 63 } \\
\text { Link }^{\mathbf{b}}\end{array}$ & \multicolumn{1}{c|}{ Applicable Criteria $^{\mathbf{c}}$} \\
\hline PRD-002/T-015 & $\begin{array}{l}\text { Requirements for } \\
\text { Performance Assessment }\end{array}$ & $\begin{array}{c}\text { 10 CFR 63.114 } \\
\text { (a)-(c) }\end{array}$ & $\begin{array}{l}\text { Criteria 2 and 3 for Flow Paths in the } \\
\text { Unsaturated Zone apply to 10 CFR 63.114 }\end{array}$ \\
\hline
\end{tabular}

\footnotetext{
${ }^{a}$ From Canori and Leitner (2003 [DIRS 166275]).

b 10 CFR 63 [DIRS 156605].

c From NRC (2003 [DIRS 163274], Section 2.2.1.3.6.3).
}

In cases where subsidiary criteria are listed in the Yucca Mountain Review Plan for a given criterion, only the subsidiary criteria addressed by this scientific analysis are listed below. Applicable acceptance criteria identified in Section 2.2.1.3.6 (Flow Paths in the Unsaturated Zone) of the Yucca Mountain Review Plan (NRC 2003 [DIRS 163274]) are listed below.

\section{Acceptance Criteria from Section 2.2.1.3.6, Flow Paths in the Unsaturated Zone}

\section{Acceptance Criterion 1, System Description and Model Integration Are Adequate.}

1. Total system performance assessment adequately incorporates, or bounds, important design features, physical phenomena, and couplings, and uses consistent and appropriate assumptions throughout the flow paths in the unsaturated zone abstraction process. Couplings include thermal-hydrologic-mechanical-chemical effects as appropriate;

2. The aspects of geology, hydrology, geochemistry, physical phenomena, and couplings that may affect flow paths in the unsaturated zone are adequately considered. Conditions and assumptions in the abstraction of flow paths in the unsaturated zone are readily identified and consistent with the body of data presented in the description;

9. Guidance in NUREG-1297 (Altman et al. 1988 [DIRS 103597]) and NUREG-1298 (Altman et al. 1988 [DIRS 103750]), or other acceptable approaches for peer review and data qualification is followed. 


\section{Acceptance Criterion 2, Data are Sufficient for Model Justification.}

1. Hydrological and thermal-hydrological-mechanical-chemical values used in the license application are adequately justified. Adequate descriptions of how the data were used, interpreted, and appropriately synthesized into the parameters are provided;

2. The data on the geology, hydrology, and geochemistry of the unsaturated zone, are collected using acceptable techniques;

3. Estimates of deep-percolation flux rates constitute an upper bound, or are based on a technically defensible unsaturated zone flow model that reasonably represents the physical system. The flow model is calibrated, using site-specific hydrologic, geologic, and geochemical data. Deep-percolation flux is estimated, using the appropriate spatial and temporal variability of model parameters, and boundary conditions that consider climateinduced change in soil depths and vegetation;

4. Appropriate thermal-hydrologic tests are designed and conducted, so that critical thermalhydrologic processes can be observed, and values for relevant parameters estimated;

5. Sensitivity or uncertainty analyses are performed to assess data sufficiency, and verify the possible need for additional data;

6. Accepted and well-documented procedures are used to construct and calibrate numerical models; and

7. Reasonably complete process-level conceptual and mathematical models are used in the analyses. In particular: (i) mathematical models are provided that are consistent with conceptual models and site characteristics; and (ii) the robustness of results from different mathematical models is compared.

\section{Acceptance Criterion 3, Data Uncertainty is Characterized and Propagated Through the Model Abstraction.}

1. Models use parameter values, assumed ranges, probability distributions, and bounding assumptions that are technically defensible, reasonably account for uncertainties and variabilities, and do not result in an under-representation of the risk estimate;

4. The initial conditions, boundary conditions, and computational domain used in sensitivity analyses and/or similar analyses are consistent with available data. Parameter values are consistent with the initial and boundary conditions and the assumptions of the conceptual models for the Yucca Mountain site;

5. Coupled processes are adequately represented; and

6. Uncertainties in the characteristics of the natural system and engineered materials are considered. 


\subsection{CODES, STANDARDS, AND REGULATIONS}

No codes, standards, or regulations, other than those identified in the Project Requirements Documents (Canori and Leitner 2003 [DIRS 166275], Table 2-3) and determined to be applicable in Table 4-5, were used in this analysis/model report. 


\section{ASSUMPTIONS}

The following assumptions are used to develop the calibrated properties model. This section presents the rationale for these assumptions and references the section of this model report in which each assumption is used. Other assumptions basic to the UZ models of Yucca Mountain are elements of the conceptual model, which are summarized at the beginning of Section 6 and are fully documented in Conceptual Model and Numerical Approaches for Unsaturated Zone Flow and Transport (BSC 2004 [DIRS 170035]).

1. It is assumed that layers bf 3 and bf 2 have the same hydraulic properties as $\operatorname{tr} 3$ and $\operatorname{tr} 2$, respectively (Section 6.3.2).

Rationale: no data except geologic contacts exist for layers tr3 or tr2 (the Tram Tuff). Because the Tram Tuff has a structure similar to the Bullfrog Tuff and the two tuffs are divided into similar model layers (BSC 2004 [DIRS 170029], Table 6-2), the hydrologic properties should also be similar. Further, model layers tr 3 and tr 2 constitute only a small portion of the UZ in the northern part of the model area and along the foot wall of the Solitario Canyon fault, so the properties are not likely to have a large impact on simulations of flow and transport.

2. It is assumed that reported saturation values greater than 1.0 are equal to 1.0 (Section 6.2.2).

Rationale: measurement error causes calculated saturation values (based on measurements of initial, saturated, and dry weight) to be greater than 1.0, but this is not physically possible. Saturation is constrained to a maximum of 1.0 .

3. When the matrix saturation data is derived from a single measurement, the respective sample standard error is assumed to be 0.05 (Section 6.2.2).

Rationale: the standard deviation $\sigma$ of a sample (hence, the standard error) is not defined for a single measurement (sample size $\mathrm{N}=1$ ). The standard error for matrix saturations derived from a single measurement is assumed to be 0.05 . This value is within the range of computed standard errors $(0.001$ to 0.268$)$ derived from multiple measurements $(\mathrm{N}$ greater than 1$)$ of saturation (DTNs: MO0109HYMXPROP.001 [DIRS 155989]; GS980808312242.014 [DIRS 106748]; GS980708312242.010 [DIRS 106752]).

4. For the purpose of inversions, the standard error of uncalibrated $\log (\alpha)$ for fractures is assumed to be 2 (Section 6.2.2).

Rationale: the uncalibrated $\log (\alpha)$ for fractures is estimated from fracture permeability and fracture density data. This method of estimation does not provide standard error of the $\log (\alpha)$. Therefore, a conservative estimate of 2 is chosen to represent the standard error of fracture $\log (\alpha)$. This value is approximately double of the largest standard error of matrix fracture $\log (\alpha)$ given in Table 4-2.

Based on the rationales stated above, these assumptions do not need to be verified. 


\section{INTENTIONALLY LEFT BLANK}




\section{MODEL DISCUSSION}

\subsection{BACKGROUND}

\subsubsection{Objectives}

The UZ models are used to represent past, present, and future thermal-hydrological and chemical conditions within the UZ of Yucca Mountain. The UZ models consist of hydrological (flow and transport) and thermal properties and a numerical grid, which together form input for the TOUGH family of simulators. This model report documents the development of some of the hydrologic properties for the UZ models. Assumptions used in this section and their bases are presented in Section 5. The intended use of the output data developed using approaches in this section is given in Section 1.

\subsubsection{Scientific Notebooks}

The key scientific notebooks (with relevant page numbers) used for the modeling activities described in this model report are listed in Table 6-1.

Table 6-1. Scientific Notebooks

\begin{tabular}{|l|l|l|l|}
\hline \multicolumn{1}{|c|}{ LBNL Scientific Notebook ID } & $\begin{array}{c}\text { Management \& Operating } \\
\text { Contractor Scientific Notebook ID }\end{array}$ & Relevant Pages & \multicolumn{1}{c|}{ Citation } \\
\hline YMP-LBNL-UZ-CFA-1 & SN-LBNL-SCI-003-V2 & $84-97$ & $\begin{array}{l}\text { Wang 2002 } \\
\text { (DIRS 160401) }\end{array}$ \\
\hline YMP-LBNL-GSB-LHH-3 & SN-LBNL-SCI-215-V1 & $65-98,100$ & $\begin{array}{l}\text { Wang 2002 } \\
\text { (DIRS 160401) }\end{array}$ \\
\hline YMP-LBNL-GSB-LP-6 & SN-LBNL-SCI-229-V1 & $9-21$ & $\begin{array}{l}\text { Wang 2002 } \\
\text { (DIRS 160401) }\end{array}$ \\
\hline YMP-LBNL-YSW-3 & SN-LBNL-SCI-199-V1 & $98-99,104$ & $\begin{array}{l}\text { Wang 2002 } \\
\text { (DIRS 160401) }\end{array}$ \\
\hline
\end{tabular}

ID=identification; LBNL=Lawrence Berkeley National Laboratory

\subsubsection{Features, Events, and Processes}

The selected FEPs for this report (Table 6-2) are those taken from the LA FEP list (DTN: MO0407SEPFEPLA.000 [DIRS 170760]) and are associated with the subject matter of this report. Consideration of the LA FEP list is in accordance with the activities represented in the TWP (BSC 2004 [DIRS 169654], Table 2.1.5-1), though the list of FEPs may differ from that in the TWP. The FEP discussion in this and other model and analysis reports form the technical basis for evaluation of the listed FEPs. The cross-reference for each FEP to the relevant section of this report is given in Table 6-2. 
Table 6-2. FEPs Addressed in This Model Report

\begin{tabular}{|l|l|l|}
\hline \multicolumn{1}{|c|}{ FEP No. } & \multicolumn{1}{|c|}{ FEP Name } & \multicolumn{1}{|c|}{$\begin{array}{c}\text { Sections Where FEP Is } \\
\text { Addressed }\end{array}$} \\
\hline 1.2.02.01.0A & Fractures & $\begin{array}{l}\text { 6.1.5, 6.2.1, 6.2.3, 6.2.4, 6.2.6, } \\
6.3 .2,6.3 .3,6.3 .4,6.4 .2 \\
\text { (Table 6-12, Table 6-17) }\end{array}$ \\
\hline 1.2.02.02.0A & Faults & $6.3 .4,6.4 .2$ (Table 6-14, Table 6-17) \\
\hline $2.2 .03 .01 .0 \mathrm{~A}$ & Stratigraphy & $\begin{array}{l}\text { 6.1.4, Table 6-3, Table 6-8, } \\
\text { Table 6-9, Table 6-10 }\end{array}$ \\
\hline $2.2 .03 .02 .0 \mathrm{~A}$ & Rock properties of host rock and other units & $6.3 .2,6.3 .3,6.4$ \\
\hline $2.2 .07 .02 .0 \mathrm{~A}$ & Unsaturated ground-water flow in the geosphere & 6.1 .4$, Table 6-15, Table 6-16 \\
\hline $2.2 .07 .04 .0 \mathrm{~A}$ & Focusing of unsaturated flow (fingers and weeps) & $6.1 .4,6.3 .2$ \\
\hline $2.2 .07 .08 .0 \mathrm{~A}$ & Fracture flow in the UZ & 6.1 .4 \\
\hline $2.2 .07 .09 .0 \mathrm{~A}$ & Matrix imbibition in the UZ & 6.1 .5 \\
\hline
\end{tabular}

FEP=feature, event, and process

\subsubsection{Conceptual Model and Alternative Models}

Property calibration of the UZ models is a key step in its development. Property calibration is necessary to refine the property estimates derived from laboratory and field data, so that they are suitable for use in the UZ models and so that the UZ models accurately depicts hydrological conditions in the mountain. The UZ models considers large-scale hydrological processes; where properties are scale-dependent, upscaling will inherently be part of the calibration process. The calibration process also reduces property-estimate uncertainty and bias. Property estimates from laboratory and field data, like any other estimates, will have uncertainty associated with them because of data limitations (e.g., sampling and measurement biases, limited number of samples). The conceptual model and numerical schemes used to develop the numerical representation of the UZ models have been documented in Conceptual Model and Numerical Approaches for Unsaturated Zone Flow and Transport (BSC 2004 [DIRS 170035]). The aspects of the conceptual model and numerical schemes that are most relevant to this study are highlighted in this section. Alternative models and numerical approaches are also discussed in this section.

A variety of numerical approaches have been proposed to deal with flow and transport processes in fractured media at field scale (BSC 2004 [DIRS 170035], Section 6.3.1). When classified according to the manner in which fracture networks are treated in the model structure, the approaches fall into three groups: (1) continuum approaches (including effective continuum, dual continuum, and multiple interacting continua), (2) discrete fracture-network approaches, and (3) other approaches (e.g., a combination of the continuum approaches and the discrete fracturenetwork approaches). Based on overall flow and transport behavior in the UZ, scale of the problem under consideration, and a compromise between modeling accuracy and computational feasibility, the dual-permeability method (a continuum approach) is considered appropriate for describing flow and transport in the UZ (BSC 2004 [DIRS 170035], Section 6.3.2). Consequently, the dual-permeability method is used for all the modeling studies documented in this report. The alternative approaches (including discrete fracture-network approaches and other approaches) generally involve computational generation of synthetic fracture networks and subsequent modeling of flow and transport in each individual fracture. While these approaches 
are useful as tools for concept evaluation, they are not practically feasible for dealing with largescale problems (BSC 2004 [DIRS 170035], Section 6.3).

Because the Paintbrush nonwelded hydrogeologic unit (PTn) greatly attenuates episodic infiltration pulses, liquid water flow below the PTn is considered to be approximately in steady state under ambient conditions (BSC 2004 [DIRS 170035], Sections 6.1.2 and 6.1.6). Steadystate liquid flow conditions are thus used in all the modeling studies documented in this report. Note that the existence of episodic flow through the PTn (possibly through faults) is indicated by the finding of potential "bomb-pulse" signature of ${ }^{36} \mathrm{Cl}$ in the UZ. However, this flow component is believed to carry only a small amount of water (BSC 2004 [DIRS 170035], Sections 6.1.6 and 6.1.7).

Heterogeneities exist at different scales within both the fracture and matrix continua in the UZ at Yucca Mountain. Treatment of subsurface heterogeneity and parameterization (use of a number of parameters to represent the heterogeneous distribution) is highly relevant to calibration of hydraulic properties. A geologic-based, deterministic approach is mainly used for characterizing subsurface heterogeneity in the UZ (BSC 2004 [DIRS 170035], Section 6.3.4). This is based on the following considerations: (1) overall behavior of large-scale flow and transport processes are mainly determined by relatively large-scale heterogeneities associated with the geologic structures of the mountain, (2) the heterogeneity model needs to be consistent with the available data, and (3) this approach is also supported by field observation (e.g., matrix-saturation distributions) (BSC 2004 [DIRS 170035], Section 6.3.5). Therefore, the heterogeneity of hydrological properties in this study is treated as a function of geologic layering, shown in Table 6-3, so that any one geologic layer has homogeneous properties (referred to as layer average properties), except where faulting or variable alteration (e.g., zeolitization) is present. In these cases, two sets of properties are used for layers with variable alteration, one for the portion of the layer that is altered beyond some threshold and one for the remaining portion. The Scientific Analysis report Development of Numerical Grids for UZ Flow and Transport Modeling (BSC 2004 [DIRS 169855], Section 6) documents this process. Heterogeneity in faults is treated as a function of major hydrogeologic units shown in Table 6-3, with the Calico Hills nonwelded hydrogeologic unit $(\mathrm{CHn})$ and $\mathrm{CFu}$ combined (i.e., only four sets of hydrological properties are used for the faults).

The van Genuchten (1980 [DIRS 100610], pp. 892 to 893) relations, originally developed for porous media, have been used as constitutive relationships for liquid flow in the UZ (BSC 2004 [DIRS 170035], Section 6.3.5). This treatment results from the use of porous-medium equivalence for describing flow in fractures. Recently, Liu and Bodvarsson (2001 [DIRS 160110]) developed a new constitutive-relationship model for unsaturated flow in fracture networks, based mainly on numerical experiments. They found that the van Genuchten model is approximately valid for low fracture saturations corresponding to ambient conditions. Therefore, the van Genuchten model is still used in this study. Note that model calibrations are performed using data collected under ambient conditions.

The base-case output data of the calibrated properties model are developed from base-case (mean), present-day infiltration maps (Section 6.2.5). However, to capture potential uncertainties introduced by the estimation of infiltration rates, alternative models based on the 
lower- and upper-bound infiltration maps are also fully developed and calibrated in this report (Section 6.2.5).

In a number of laboratory scale experiments, Glass et al. (1996 [DIRS 139237]) demonstrated that gravity-driven fingering flow is a common flow mechanism in individual fractures. Fingering flow can occur at different scales. It has been well known in the subsurface hydrology community that flow and transport processes and the related parameters are scale-dependent (e.g., Neuman 1994 [DIRS 105731]). Fingering flow at a fracture network scale, resulting from subsurface heterogeneity and nonlinearity involved in an unsaturated system, is a more important mechanism for liquid flow in the UZ than fingering flow in individual fractures. This is because the UZ flow model deals with flow and transport at large scales consisting of a great number of fractures. The active fracture model of the report by Liu et al. (1998 [DIRS 105729]) is used for considering the mechanism of fingering flow at a fracture network scale (BSC 2004 [DIRS 170035], Section 6.3.7). The active fracture concept is based on the reasoning that, as a result of fingering flow, only a portion of fractures in a connected, unsaturated fracture network contributes to liquid water flow. A detailed evaluation of the active fracture model based on both theoretical arguments and field observations is presented in BSC (2004 [DIRS 170035], Section 7).

Liquid flow occurs predominantly in the matrix in the PTn (see Table 6-3) and occurs only in the matrix in vitric portions of the $\mathrm{CHn}$. The dominant matrix flow results from relatively high matrix permeabilities and low fracture densities in these units (BSC 2004 [DIRS 170035], Section 6.1.2). In the welded units (layers), liquid flow occurs predominantly in the fractures. This conceptual model is supported by UZ flow tests conducted in nonwelded tuffs at Busted Butte and in the ESF Alcove 4. The tests at Busted Butte conducted in the upper CHn(v) show that flow took place in the matrix; fracture flow was not observed, given the limits of the observational capability (even though fractures are present) (BSC 2004 [DIRS 170004], Section 6.13). Tests in ESF Alcove 4 conducted in the PTn unit also show that flow around a large, through-going fracture is matrix-dominant (BSC 2004 [DIRS 170004], Section 6.7).

It is well known that permeability is scale-dependent (Neuman 1994 [DIRS 105731]). Calibrated properties are necessary on two scales, mountain-scale and drift-scale. Calibration of the mountain-scale properties considers pneumatic pressure data that reflect the mountain-scale process of barometric pumping. Mountain-scale properties are intended for use in models of processes at the mountain scale. Calibration of the drift-scale properties does not consider the pneumatic pressure data. Drift-scale properties are intended for use in models of processes at the drift scale.

\subsubsection{Simulator and Numerical Model}

In this study, iTOUGH2 V5.0 (LBNL 2002 [DIRS 160106]) is used for model calibration. This program uses the integral-finite-difference method for spatial discretization, and is a generalpurpose inverse and forward numerical simulator for multidimensional, coupled fluid and heat flow of multiphase, multicomponent fluid mixtures in porous and fractured media. To the best of the authors' knowledge, iTOUGH2 represents the state of the art in the area of inverse modeling of multiphase flow process in fractured media. This code has been comprehensively tested under different conditions (Finsterle 1998 [DIRS 103783]; 1999 [DIRS 104367]). The 
forward flow simulation in iTOUGH2 V5.0 (LBNL 2002 [DIRS 160106]) involves numerically solving the following governing equation (for an arbitrary flow domain $V_{n}$ with the boundary $\Gamma_{n}$ ) (Pruess 1987 [DIRS 100684], Section 3)

$$
\frac{d}{d t} \int_{V_{n}} M d V=\int_{\Gamma_{n}} F \bullet n d \Gamma+\int_{V_{n}} q d V
$$

where $t$ is time, $M$ is the accumulation (storage) term, $F$ is the mass flux, $n$ is the unit vector normal to the domain boundary, and $q$ is the source term.

The inverse modeling approach used by iTOUGH2 V5.0 (LBNL 2002 [DIRS 160106]) is based on the classical weighted least-squares method, which consists of minimizing the objective function

$$
S=\mathbf{r}^{T} \mathbf{C}_{z z}^{-1} \mathbf{r}
$$

The residual vector $\mathbf{r}$ contains the differences between the measured value, $z *$, and the corresponding model prediction, $z(\mathbf{p})$, which is a function of the unknown, $n$-dimensional parameter vector $\mathbf{p}$, i.e., $r_{i}=\left(z_{i}{ }^{*}-z(\mathbf{p})_{i}\right), i=1 \ldots m$, where $m$ is the number of calibration points. The inverse of the covariance matrix $\mathbf{C}_{z z}$, which holds the expected variances of the final residuals on its diagonal, is used as a weighting matrix. The objective function is a measure of the misfit between the model output and the measured data. The objective function is automatically minimized using the Levenberg-Marquardt algorithm implemented in iTOUGH2 V5.0 (Finsterle 1999 [DIRS 104367], Section 2.7.4).

The covariance matrix of the estimated parameters is asymptotically given by:

$$
\mathbf{C}_{p p}=s_{0}^{2}\left(\mathbf{J}^{T} \mathbf{C}_{z z}^{-1} \mathbf{J}\right)^{-1}
$$

where $\mathbf{J}$ is an $m \times n$ Jacobian matrix holding the partial derivatives of the predicted seepage with respect to the unknown parameters, $J_{i j}=\partial z_{i} / \partial p_{j}$, and $s_{0}^{2}$ is the estimated error variance, which represents the variance of the mean weighted residual; it is an aggregate measure of goodness-of-fit:

$$
s_{0}^{2}=\frac{\mathbf{r}^{T} \mathbf{C}_{z z}^{-1} \mathbf{r}}{m-n}
$$

The impact of parameter uncertainty (expressed through matrix $\mathbf{C}_{p p}$ ) on model predictions can be evaluated by means of first-order-second-moment uncertainty propagation analysis. The covariance matrix of the model prediction, $\mathbf{C}_{\hat{z} \hat{z}}$, is calculated based on a linearity and normality assumption using 


$$
\mathbf{C}_{\hat{z} \hat{z}}=\mathbf{J C}_{p p} \mathbf{J}^{T}
$$

The inverse modeling methodology and its numerical implementation are described in detail in the iTOUGH2 software documentation, specifically Finsterle (1999 [DIRS 104367], Section 2).

The upstream weighting numerical technique for the relative permeability is used for inversions. While this is considered to be an approximation for calculating flow from fractures to the matrix (matrix imbibition), it is still expected to be a reasonable scheme for this study. First, it is well known that upstream weighting is a robust approach to avoid numerical oscillations for multiphase flow in highly heterogeneous systems (Forsyth et al. 1995 [DIRS 161743]). Simulation of unsaturated flow in the UZ is numerically challenging because of a combination of heterogeneity and nonlinearity. To perform numerical simulation for such a complex system, both numerical accuracy and computational feasibility need to be considered. It is a reasonably practical choice to use this scheme to avoid the potential numerical problems. Secondly, use of the approach is not expected to result in significant errors for simulating matrix imbibition processes in the UZ. In nonwelded units, the flow mainly occurs in the matrix, and the flow component from fractures to the matrix is expected to be small. In the welded units, flow mainly occurs in fractures (because of small matrix permeability), again resulting in a relatively small flow component from fractures to the matrix. Finally, the approximation introduced by the weighting scheme is also compensated by the model calibration procedure that includes the effects of both numerical grids and numerical schemes. 
Table 6-3. GFM2000 Lithostratigraphy, UZ Model Layer, and Hydrogeologic Unit Correlation

\begin{tabular}{|c|c|c|c|}
\hline $\begin{array}{l}\text { Major Unit (Modified from } \\
\text { Montazer and Wilson } 1984 \\
\text { [DIRS 100161]) }\end{array}$ & $\begin{array}{c}\text { GFM2000 Lithostratigraphic } \\
\text { Nomenclature }\end{array}$ & UZ Model Layer & $\begin{array}{c}\text { Hydrogeologic } \\
\text { Unit (Flint 1998 } \\
\text { [DIRS 100033], } \\
\text { Table 1) } \\
\end{array}$ \\
\hline \multirow{5}{*}{$\begin{array}{l}\text { Tiva Canyon welded } \\
\text { hydrogeologic unit } \\
\text { (TCW) }\end{array}$} & Tpcr & tcw11 & CCR, CUC \\
\hline & Tpcp & \multirow[t]{2}{*}{ tcw12 } & \multirow[t]{2}{*}{ CUL, CW } \\
\hline & TpcLD & & \\
\hline & Tpcpv3 & \multirow[t]{2}{*}{ tcw13 } & \multirow[t]{2}{*}{ CMW } \\
\hline & Tpcpv2 & & \\
\hline \multirow{10}{*}{$\begin{array}{l}\text { Paintbrush nonwelded } \\
\text { hydrogeologic unit } \\
\text { (PTn) }\end{array}$} & Tpcpv1 & ptn21 & CNW \\
\hline & \begin{tabular}{|l|} 
Tpbt4 \\
\end{tabular} & \multirow[t]{2}{*}{ ptn22 } & \multirow[t]{2}{*}{ BT4 } \\
\hline & \multirow[t]{3}{*}{ Tpy (Yucca) } & & \\
\hline & & ptn23 & TPY \\
\hline & & \multirow[t]{2}{*}{ ptn24 } & \multirow[t]{2}{*}{ BT3 } \\
\hline & Tpbt3 & & \\
\hline & Tpp (Pah) & ptn25 & TPP \\
\hline & Tpbt2 & \multirow[t]{3}{*}{ ptn26 } & \multirow[t]{3}{*}{ BT2 } \\
\hline & Tptrv3 & & \\
\hline & Tptrv2 & & \\
\hline \multirow{11}{*}{$\begin{array}{l}\text { Topopah Spring welded } \\
\text { hydrogeologic unit } \\
\text { (TSw) }\end{array}$} & Tptrv1 & \multirow[t]{2}{*}{ tsw31 } & \multirow[t]{2}{*}{ TC } \\
\hline & \multirow[t]{2}{*}{ Tptrn } & & \\
\hline & & tsw32 & TR \\
\hline & \begin{tabular}{|l} 
Tptrl, Tptf \\
\end{tabular} & \multirow[t]{2}{*}{ tsw33 } & \multirow[t]{2}{*}{ TUL } \\
\hline & Tptpul, RHHtop & & \\
\hline & Tptpmn & tsw34 & TMN \\
\hline & \begin{tabular}{|l|} 
Tptpll \\
\end{tabular} & tsw35 & TLL \\
\hline & \multirow[t]{2}{*}{ Tptpln } & tsw36 & $\begin{array}{l}\text { TM2 (upper 2/3 of } \\
\text { Tptpln) }\end{array}$ \\
\hline & & tsw37 & $\begin{array}{l}\text { TM1 (lower } 1 / 3 \text { of } \\
\text { Tptpln) }\end{array}$ \\
\hline & Tptpv3 & tsw38 & PV3 \\
\hline & Tptpv2 & tsw39 (vit, zeo) & PV2 \\
\hline
\end{tabular}


Table 6-3. GFM2000 Lithostratigraphy, UZ Model Layer, and Hydrogeologic Unit Correlation (Continued)

\begin{tabular}{|c|c|c|c|}
\hline $\begin{array}{c}\text { Major Unit } \\
\text { (Modified from Montazer and } \\
\text { Wilson 1984 [DIRS 100161]) }\end{array}$ & $\begin{array}{c}\text { GFM2000 Lithostratigraphic } \\
\text { Nomenclature }\end{array}$ & UZ Model Layer & \begin{tabular}{|c|} 
Hydrogeologic Unit \\
(Flint 1998 \\
[DIRS 100033] \\
Table 1)
\end{tabular} \\
\hline \multirow{14}{*}{$\begin{array}{l}\text { Calico Hills nonwelded } \\
\text { hydrogeologic unit } \\
(\mathrm{CHn})\end{array}$} & Tptpv1 & \multirow[t]{2}{*}{ ch1 (vit, zeo) } & BT1 or \\
\hline & Tpbt1 & & BT1a (altered) \\
\hline & \multirow[t]{4}{*}{ Tac (Calico) } & $\operatorname{ch} 2$ (vit, zeo) & $\mathrm{CHV}$ (vitric) \\
\hline & & ch3 (vit, zeo) & or \\
\hline & & ch4 (vit, zeo) & \multirow[t]{2}{*}{$\mathrm{CHZ}$ (zeolitic) } \\
\hline & & ch5 (vit, zeo) & \\
\hline & Tacbt (Calicobt) & ch6 (vit, zeo) & BT \\
\hline & Tcpuv (Prowuv) & pp4 & PP4 (zeolitic) \\
\hline & Tcpuc (Prowuc) & pp3 & PP3 (devitrified) \\
\hline & Tcpmd (Prowmd) & \multirow[t]{2}{*}{ pp2 } & \multirow[t]{2}{*}{ PP2 (devitrified) } \\
\hline & Tcplc (Prowlc) & & \\
\hline & Tcplv (Prowlv) & \multirow[t]{3}{*}{ pp1 } & \multirow[t]{3}{*}{ PP1 (zeolitic) } \\
\hline & Tcpbt (Prowbt) & & \\
\hline & Tcbuv (Bullfroguv) & & \\
\hline \multirow{11}{*}{$\begin{array}{l}\text { Crater Flat undifferentiated } \\
\text { (CFu) }\end{array}$} & Tcbuc (Bullfroguc) & \multirow[t]{3}{*}{ bf3 } & \multirow[t]{3}{*}{ BF3 (welded) } \\
\hline & Tcbmd (Bullfrogmd) & & \\
\hline & Tcblc (Bullfroglc) & & \\
\hline & Tcblv (Bullfroglv) & \multirow[t]{3}{*}{ bf2 } & \multirow[t]{3}{*}{ BF2 (nonwelded) } \\
\hline & Tcbbt (Bullfrogbt) & & \\
\hline & Tctuv (Tramuv) & & \\
\hline & Tctuc (Tramuc) & \multirow[t]{3}{*}{ tr3 } & \multirow[t]{3}{*}{ Not Available } \\
\hline & Tctmd (Trammd) & & \\
\hline & Tctlc (Tramlc) & & \\
\hline & Tctlv (Tramlv) & \multirow[t]{2}{*}{ tr2 } & \multirow[t]{2}{*}{ Not Available } \\
\hline & Tctbt (Trambt)and below & & \\
\hline
\end{tabular}

Source: BSC (2004 [DIRS 169855], Table 6-5).

\subsection{MODEL INPUTS}

This section discusses model inputs for parameter calibration activities documented in this report. These inputs include numerical grids, infiltration rates, matrix-saturation and waterpotential data, pneumatic pressure data and rock-hydraulic-property data. Some model inputs for fault property calibration are documented in Section 6.3.4.

\subsubsection{Numerical Grids}

One-dimensional, vertical-column numerical grids and a two-dimensional, cross-sectional numerical grid are used for the corresponding model calibrations. Numerical grids under DTN: LB02081DKMGRID.001 (DIRS 160108) are slightly modified in this study (Wang 2002 [DIRS 160401], SN-LBNL-SCI-003-V2, pp. 85 to 86). The eight-character element-name format in this DTN is not compatible with all necessary iTOUGH2 V5.0 (LBNL 2002 [DIRS 160106]) features. In response, the element names are converted to a five-character format. In an eight-character name, the first character is either " $F$ " or " $M$ " (corresponding to 
fracture or matrix element). The second and third characters are simply zeros. The fourth and fifth characters represent grid layers and the corresponding material layers. The last three characters are the name of the corresponding column. In the corresponding five-character name, the first character is again " $F$ " or " $M$ ". The second character $(0, A, B, \ldots Z)$ represents grid layers within given material (model) layers defined in Table 6-3. The third character $(1,2, \ldots 9$, $\mathrm{A}, \mathrm{B}, \ldots \mathrm{Z})$ is an indicator of the material layer. The last two characters represent names of the corresponding columns. To be consistent with the conceptual model regarding water flow in nonwelded vitric units (Section 6.1), investigators effectively remove fractures in vitric regions by reducing (by 50 orders of magnitude) the connection areas between fracture elements in these units and the corresponding matrix elements. Connections are also added between fractures in welded layers and matrix in nonwelded layers, to facilitate flow between matrix and fractures at interfaces where the fracture frequency changes significantly.

\subsubsection{Matrix-Saturation and Water-Potential Data}

Saturation and water-potential data, which are inverted to obtain the calibrated parameter sets, are developed so that they can be compared to the numerical model predictions. The core saturation data are available on intervals as small as $0.3 \mathrm{~m}$. To compare these data to the saturation profiles predicted by the numerical model on intervals as large as several tens of meters (corresponding to model layer thickness), investigators averaged the data. The averaged data and their uncertainties are used for calibrating UZ parameters (Section 6.3). In situ waterpotential data are measured at depth intervals equal to or greater than the numerical grid spacing, so these data do not need to be averaged. The in situ water-potential data do need to be analyzed, however, as discussed below, to determine when the sensor is in equilibrium with the surrounding rock. Inversions using iTOUGH2 V5.0 (LBNL 2002 [DIRS 160106]) need both averaged (gridblock scale) matrix saturation and water-potential data and their uncertainties as inputs. The procedures to determine these data values and their uncertainties are also described below.

Saturation Data from Core (DTNs: MO0109HYMXPROP.001 [DIRS 155989]; GS980808312242.014 [DIRS 106748]; GS980708312242.010 [DIRS 106752])—The number, arithmetic mean, and standard deviation of the core measurements (see Section 4.1.2.1 for description of data) that correspond to the intervals covered by each numerical grid element are calculated using software aversp_1 V1.0 (LBNL 2002 [DIRS 146533]). The elevations of core sample locations are determined from borehole collar elevations from file contracts00md.dat in DTN: MO0012MWDGFM02.002 (DIRS 153777) and the depth of the top of the Tptrn from DTN: GS940208314211.008 (DIRS 145581) for Borehole USW UZ-N57, N59 and N61 (Wang 2002 [DIRS 160401], SN-LBL-SCI-003-V2, p. 84). Saturation values greater than 1.0 are assumed to be 1.0 (Assumption 2, in Section 5).

iTOUGH2 V5.0 (LBNL 2002 [DIRS 160106]) allows the data to be weighted. The weight of each saturation data point is estimated from the number of measurements, the standard deviation of the measurements, and estimates of handling and measurement error. The total error, TE, which is equal to the inverse of the weight, is

$$
\mathrm{TE}=\mathrm{SE}+\mathrm{ME}+\mathrm{HE}
$$

where $S E$ is the standard error, $M E$ is the measurement error, and $H E$ is the handling error. 
Standard error, $S E$, is defined here as

$$
S E=\frac{\sigma}{\sqrt{N}}
$$

where $\sigma$ is the unbiased estimate of the standard deviation and $N$ is the number of measurements. For $\mathrm{N}=1, \sigma$ and thus $S E$ are assumed to be 0.05 (Assumption 3, in Section 5). Flint (1998 [DIRS 100033], p. 17) reports that the measurement error for bulk properties is less than 0.5 percent. The measurement error for saturation is thus taken to be 0.005 .

Drying of core during handling is a potential source of error for saturation data (Flint 1998 [DIRS 100033], pp. 18 to 19; Rousseau et al. 1999 [DIRS 102097], pp. 129 to 131). The HE is estimated for the core drying effects. Saturation is not easily quantifiable because of the variable nature of the forces controlling the drying. Drying during handling at the surface is related to saturation, water potential (and variation of water potential with saturation), and temperature of the core-as well as temperature, pressure, relative humidity, and speed of the air around the core. Drying of the core during drilling is related to similar factors. Rather than correct the measured saturation data by an uncertain drying estimate, a contribution to the total uncertainty of the saturation data is made by an estimate of drying losses. This contribution is included as the handling error, $H E$, in Equation 6-6 above.

A simplified model of core drying during handling is used to estimate the rate of evaporation from the core. A fully saturated core is approximated as a spherical rock with a surface that is always completely wet and that has the same area as the core. A solution for evaporation from a spherical drop of water in an air stream is given by Bird et al. (1960 [DIRS 103524], p. 648) as

$$
W=\eta \pi \delta^{2} \frac{x_{0}-x_{\infty}}{1-x_{\infty}}
$$

where $W$ is the evaporation rate, $\eta$ is the mass-transfer coefficient of water vapor in air, $\delta$ is the diameter of a sphere with the same surface area as the core, $x_{0}$ is the water mole fraction in the air at the surface of the core, and $x_{\infty}$ is the water mole fraction in air far away from the core. The mass-transfer coefficient of water vapor in air, $\eta$, is given by Bird et al. (1960 [DIRS 103524], p. 649) as

$$
\eta=\frac{c D}{\delta}\left[2+0.6\left(\frac{v \delta \rho}{\mu}\right)^{1 / 2}\left(\frac{\mu}{D \rho}\right)^{1 / 3}\right]
$$

where $c$ is the total molar concentration of the air-water mixture, $D$ is the effective binary diffusivity of water vapor in air, $v$ is air speed, $\rho$ is density of air, and $\mu$ is viscosity of air. 
Effective binary diffusivity, $D\left[\mathrm{~cm}^{2} / \mathrm{s}\right]$, for an air and water-vapor (components $A$ and $B$ ) mixture is given by Bird et al. (1960 [DIRS 103524], p. 505) as

$$
D=\frac{3.64 \times 10^{-4}}{p}\left(\frac{T}{\sqrt{T_{c A} T_{c B}}}\right)^{2.334}\left(p_{c A} p_{c B}\right)^{1 / 3}\left(T_{c A} T_{c B}\right)^{5 / 12}\left(\frac{1}{M_{A}}+\frac{1}{M_{B}}\right)^{1 / 2}
$$

where $p$ is pressure (atm), $T$ is temperature $(\mathrm{K})$, and $p_{c}, T_{c}$, and $M$ are the critical pressure (atm), critical temperature $(\mathrm{K})$, and molecular weight (g/g-mole), respectively, of components $A$ and $B$.

The evaporation rate is estimated by setting the temperature of the core at $25^{\circ} \mathrm{C}$ and the temperature, pressure, relative humidity, and speed of the air far from the core at $30^{\circ} \mathrm{C}, 1 \mathrm{~atm}, 25$ percent, and $3 \mathrm{~km} / \mathrm{h}$, respectively. These are all reasonable values for field conditions at Yucca Mountain. Neglecting the small effect of the water vapor in the air, the physical properties of air at $27.5^{\circ} \mathrm{C}$ (the average temperature) are $c=4.05 \times 10^{-5} \mathrm{~g}-\mathrm{mole} / \mathrm{cm}^{3}, \rho=0.00118 \mathrm{~g} / \mathrm{cm}^{3}$, and $\mu=1.84 \times 10^{-4} \mathrm{~g} / \mathrm{cm} / \mathrm{s}$ (Roberson and Crowe 1990 [DIRS 124773], p. A-22). The molecular weight, critical temperature and critical pressure of air are $28.97 \mathrm{~g} / \mathrm{g}-\mathrm{mole}, 132 \mathrm{~K}$, and $36.4 \mathrm{~atm}$, respectively (Bird et al. 1960 [DIRS 103524], p. 744). The molecular weight and critical temperature and pressure of water are $18.02 \mathrm{~g} / \mathrm{g}$-mole, $647.25 \mathrm{~K}$, and $218.3 \mathrm{~atm}$, respectively (Weast 1987 [DIRS 114295], pp. B-94, F-66). The mole fraction of water vapor in air at the surface of the core, $x_{0}$, is 0.0313 (Weast 1987 [DIRS 114295], p. D-190). Given a relative humidity of 25 percent, the mole fraction of water vapor in air far from the core, $x_{\infty}$, is 0.0126 (Weast 1987 [DIRS 114295], p. D-190). The core is approximately $7 \mathrm{~cm}$ in diameter and $10 \mathrm{~cm}$ in length (Flint 1998 [DIRS 100033], p. 11). Using these values, an evaporation rate of 2.69 $\times 10^{-4} \mathrm{~g}-\mathrm{mole} / \mathrm{s}$ is calculated based on Equations 6-8 through 6-10.

At this evaporation rate, the saturation of a fully saturated core of matrix porosity 22.3 percent (a typical value for tuff matrix [Table 4-3]) will be reduced by 2.2 percent after 5 minutes, which is the handling time given by Flint (1998 [DIRS 100033], p. 11). A fully dry core will have no reduction in saturation. Using these two points, a linear dependence of saturation change on saturation yields the relation

$$
\Delta S=0.022 S
$$

where $S$ is the uncorrected saturation value and $\Delta S$ is saturation change resulting from handling, or $H E$. Although the actual relation between $\Delta \mathrm{S}$ and $\mathrm{S}$ may be much more complex than Equation 6-11, this equation is in practice adequate for estimating $H E$ here. Average porosity for the entire mountain is calculated as a layer-thickness weighted average of individual layer porosities. Calculations for handling, measurement and total errors in saturation data are performed with Excel file layavsat.xls (Appendix A). Also note that water lost to drilling air is not considered here, because an approach to accurately estimate water loss is not available. However, the estimation of HEs does not consider the effect of matrix water potential, resulting in overestimated handling errors. This may partially compensate for the effects of water lost to drilling air.

In Situ Water Potential Data-Measuring water potential in situ requires that the rock near the borehole and the granular fill of the borehole come into equilibrium with the surrounding rock. 
Prior to installation of the in situ sensors, these boreholes were open, and rock immediately around the borehole may have dried out (Rousseau et al. 1999 [DIRS 102097], pp. 143 to 151). Thus, the in situ data (see Section 4.1.2.2 for description of data) vary with time for given locations and need to be evaluated to determine the equilibrium value of the data.

Because the conceptual model used for calibration is a steady-state model, stabilized water potential values are used. Data are available from Boreholes USW NRG-6 and USW NRG-7a from 11/94 through 3/98, from Borehole UE-25 UZ\#4 from 6/95 through 3/98, and from Borehole USW SD-12 from 11/95 through 3/98 in the DTNs listed above in Section 4. Each DTN covers from three to six months of data. The arithmetic average and trend (i.e., slope) of the data points for the time period covered by each DTN for each borehole, depth, and instrument station (there are two instrument stations per depth) were calculated. Values for each instrument station were then compared between DTNs (providing an approximate time history of water potentials) to find the value that best represented the equilibrium (steady state) value. The determined stabilized in situ water potential values are available from file in_situ_pcap2.xls in DTN: LB991091233129.001 (DIRS 125868). This file is used as a direct input into the calibrated properties model (Section 6.3). This DTN was mainly developed from DTNs: GS950208312232.003 (DIRS 105572), GS951108312232.008 (DIRS 106756), GS960308312232.001 (DIRS 105573), $\quad$ GS960808312232.004 (DIRS 105974), GS970108312232.002 (DIRS 105975), GS970808312232.005 GS971108312232.007 (DIRS 105980), and GS031208312232.003 (DIRS 171287).

Rousseau et al. (1999 [DIRS 102097], p. 144) give $\pm 0.2 \mathrm{MPa}$ as the $95 \%$ confidence interval (two standard deviations) for the in situ water-potential measurements. One standard deviation, $0.1 \mathrm{MPa}$, is used as an estimate for the uncertainty. Because water potential is lognormally distributed, the standard error of $\log \left(\right.$ water potential), $S E_{\log (\Psi)}$, is estimated as

$$
S E_{\log (\Psi)}=\log (\Psi+0.1)-\log (\Psi)
$$

where $\Psi$ is the value of the water potential data point in MPa. The calculation of the standard error is performed using Excel file in_situ_pcap.xls (Appendix A).

The equilibrium (steady-state) water potential values used for calibration in this model report are consistent with more recent water potential data collected from April 1998 to December 2001 as shown in Appendix B.

\subsubsection{Pneumatic Pressure Data}

Thirty days of data from each borehole (see Section 4.1.2.3 for description of data) are used for the inversions (and/or model validations). Several criteria are used to select data for the inversions: The data must include both diurnal pressure changes and longer-period, weatherassociated pressure changes; and must have been obtained prior to any influence from construction of the ESF. Table 6-4 shows the starting and ending dates for the data that were used in the inversion. Data from the instrument station or port nearest the bottom of the Tiva Canyon welded hydrogeologic unit $(\mathrm{TCw})$ are included because they show the lack of attenuation and lag in the barometric signal through the TCw. Data from stations between the lowermost in the $\mathrm{TCW}$ and the surface are not included, because they would not add information 
to the inversion and would weight the $\mathrm{TCw}$ data more than other data. Data from all instrument stations or ports in the PTn are included because there is substantial attenuation and lag in the barometric pumping signal through the PTn. Individual layers in the PTn are expected to have widely variable permeability, so it is important to include data that show the amount of barometric-signal attenuation and lag in different layers of the PTn. Data from the uppermost and lowermost instrument stations or ports in the TSw are included, because they show the lack of significant attenuation and lag in the barometric pumping signal characteristics through the TSw. Data from the stations in between the uppermost and lowermost stations are not included, for the same reason cited above for the TCw data. Table 6-4 shows the subunit in which the sensors are placed. Data from the two lowest instrument stations in Borehole USW SD-12 are not included because these data are affected by the presence of perched water, which is not adequately reproduced in the one-dimensional simulations. Data from the third-lowest instrument station in USW SD-12 are not included because it was not properly isolated from the surface (Rousseau et al. 1997 [DIRS 100178], p. 31). Data from USW NRG-6 are used for model validation only (Section 7) and therefore not included in Table 6-4. The elevation of a location where gas pressure was monitored is determined by the ground surface elevation of the corresponding boreholes (available from Contacts00md.dat of DTN: MO0012MWDGFM02.002 [DIRS 153777]) minus depths of the measurement locations (available from DTNs in Table 6-4).

Table 6-4. Pneumatic Pressure Data Used for Inversion

\begin{tabular}{|c|c|c|c|c|}
\hline Borehole & Subunit & Dates & Elevation $^{\mathrm{a}}(\mathrm{m})$ & DTNs \\
\hline \multirow[t]{6}{*}{ UE-25 NRG\#5 } & Tрср & 7/17-8/16/95 & 1211.3 & \multirow{6}{*}{$\begin{array}{l}\text { GS000608312261.001 } \\
\text { (DIRS 155891) }\end{array}$} \\
\hline & Tpy & 7/17-8/16/95 & 1194.8 & \\
\hline & Tpp & 7/17-8/16/95 & 1177.1 & \\
\hline & Tpbt2 & 7/17-8/16/95 & 1161.0 & \\
\hline & Tptrn & 7/17-8/16/95 & 1143.9 & \\
\hline & Tptpmn & 7/17-8/16/95 & 1008.3 & \\
\hline \multirow[t]{4}{*}{ USW NRG-7a } & Tрср & $3 / 27-4 / 26 / 95$ & 1276.8 & \multirow{4}{*}{$\begin{array}{l}\text { GS950208312232.003 } \\
\text { (DIRS 105572); } \\
\text { GS951108312232.008 } \\
\text { (DIRS 106756); } \\
\text { GS960308312232.001 } \\
\text { (DIRS 105573); } \\
\text { GS960808312232.004 } \\
\text { (DIRS 105974) }\end{array}$} \\
\hline & Tpy & 3/27-4/26/95 & 1231.7 & \\
\hline & Tptrn & $3 / 27-4 / 26 / 95$ & 1164.0 & \\
\hline & Tptpul & $3 / 27-4 / 26 / 95$ & 1078.7 & \\
\hline \multirow[t]{4}{*}{ USW SD-7 } & Трср & $4 / 5-5 / 5 / 96$ & 1271.6 & \multirow{4}{*}{$\begin{array}{l}\text { GS960908312261.004 } \\
\text { (DIRS 106784) }\end{array}$} \\
\hline & Tpp & $4 / 5-5 / 5 / 96$ & 1256.4 & \\
\hline & Tptrn & $4 / 5-5 / 5 / 96$ & 1241.4 & \\
\hline & Tptpmn & $4 / 5-5 / 5 / 96$ & 1119.2 & \\
\hline \multirow[t]{4}{*}{ USW SD-12 } & Tрср & 12/1-12/31/95 & 1258.5 & \multirow{4}{*}{$\begin{array}{l}\text { GS960308312232.001 } \\
\text { (DIRS 105573) }\end{array}$} \\
\hline & Tpbt2 & 12/1-12/31/95 & 1232.0 & \\
\hline & Tptrn & 12/1-12/31/95 & 1217.1 & \\
\hline & Tptpll & $12 / 1-12 / 31 / 95$ & 1001.3 & \\
\hline
\end{tabular}




\subsubsection{Prior Information}

Uncalibrated rock-property data (Tables 4-3 and 4-4) are used as prior information. These data are just as important to the parameter calibration as data on the state of the system (e.g., saturation). The combination of the two types of information allows the calibration to match the data as close as possible, while simultaneously estimating model parameters that are reasonable according to the prior information. Standard errors of parameters for weighting the prior information are taken from Tables 4-2 and 4-3. Matrix permeability data are weighted by the inverse of the standard error (Equation 6-7), giving more weight to the more certain measurements (Finsterle 1999 [DIRS 104367], Sections 1.5 and 2.5.3). Because permeability is lognormally distributed, $\sigma$ and thus $S E$ are estimated for the log-transformed permeabilities, i.e. $\log (k)$. The number of samples used for calculation of the standard error does not include nondetect samples (i.e., $N$ in Equation 6-7 is the total number of samples minus the number of nondetect samples, as shown in Table 4-3). As discussed below, drift-scale fracture permeabilities are directly assigned from the prior information, and therefore standard error data are not needed for model calibration of drift-scale fracture permeabilities. Mountain-scale fracture permeabilities, however, are calibrated using the pneumatic data, because the pneumatic data correspond to a mountain-scale process. In inversions of pneumatic pressure data, prior information does not significantly contribute to the objective function (Section 6.3.1) because the number of data points is considerably larger than the number of calibrated fracture permeabilities. Therefore, the choice of standard error used to weigh the prior information is inconsequential to the inversion. For simplicity, a standard error of two orders of magnitude is assigned to fracture permeabilities in $\mathrm{TCW}$ and PTn for calibrating mountain-scale nonfault property sets, and a standard error of one order of magnitude for calibrating fault property sets. For layers tsw31 through tsw37, fracture permeabilities are calibrated by a technique that does not require weighting, so no standard errors are used (see Section 6.3.3). Standard error is given for $\log (\alpha)$ because $\alpha$ is lognormally distributed. For fracture properties, the uncalibrated value of $\alpha_{F}$ is estimated based on fracture permeability and fracture frequency data (BSC 2004 [DIRS 170038], Section 6). Since a directly measured $\alpha_{F}$ value is not available, a relatively large value of 2 (or two orders of magnitude, compared with values for matrix $\log (\alpha)$ ) is assigned as standard error for $\log \left(\alpha_{F}\right)$ in inversions (Assumption 4 in Section 5).

\subsubsection{Boundary and Initial Conditions}

Infiltration rates (DTN: GS000308311221.005 [DIRS 147613]) are used as top boundary conditions during model calibration activities. The base-case present-day infiltration map and the lower- and upper-bound present-day infiltration maps are used to calculate infiltration rates corresponding to the calibration boreholes. For each infiltration map (DTN: GS000308311221.005 [DIRS 147613]), the infiltration rate at each calibration borehole, shown in Table 6-5, is determined, using infil2grid V1.6 (LBNL 1999 [DIRS 134754]), as an averaged infiltration-rate value over a circular area of $200 \mathrm{~m}$ radius with the center at the borehole location (Wang 2002 [DIRS 160401], SN-LBNL-SCI-215-V1, pp. 93 to 94; SN-LBNL-SCI-003-V2, p. 87). A relatively large value of the radius (compared with the lateral gridblock sizes) is used because of capillary-dispersion considerations (lateral redistribution of moisture resulting from a capillary gradient from wet areas under high infiltration zones to dry areas under low infiltration zones) within the PTn unit. During fault-parameter calibration involving the two-dimensional numerical grid, the infiltration rates are directly calculated using 
infil2grid V1.7 (LBNL 2002 [DIRS 154793]), based on the corresponding sizes of top elements of the grid. In all the simulations in this study, bottom boundaries correspond to the water table. Note that three different infiltration boundary conditions were used here for inversions, to examine alternative models and the corresponding parameter sets. For inversions of matrix saturation and water potential data, steady-state water flow fields are simulated.

Table 6-5. Area-Averaged Infiltration Rates ( $\mathrm{mm} / \mathrm{year}$ ) Used in the One-Dimensional Inversions

\begin{tabular}{|l|l|l|l|}
\hline \multicolumn{1}{|c|}{ Borehole } & \multicolumn{1}{c|}{ Lower Bound } & \multicolumn{1}{c|}{ Base Case } & \multicolumn{1}{c|}{ Upper Bound } \\
\hline USW NRG-6 & $1.00 E-4$ & 0.53 & 2.72 \\
\hline USW SD-6 & 1.17 & 6.54 & 15.33 \\
\hline USW SD-7 & $1.11 \mathrm{E}-3$ & 1.06 & 2.59 \\
\hline USW SD-9 & 0.08 & 1.04 & 3.63 \\
\hline USW SD-12 & 0.80 & 3.37 & 7.95 \\
\hline UE-25 UZ\#4 & 0.02 & 0.41 & 3.79 \\
\hline USW UZ-14 & 0.20 & 2.28 & 8.72 \\
\hline UE-25 UZ\#16 & $1.00 E-4$ & 0.22 & 2.91 \\
\hline USW UZ-N11 & 3.64 & 10.62 & 22.67 \\
\hline USW UZ-N31 & 0.54 & 1.75 & 4.45 \\
\hline USW UZ-N33 & 0.08 & 0.53 & 4.76 \\
\hline USW UZ-N37 & $1.00 E-4$ & 0.07 & 4.40 \\
\hline USW UZ-N53 & $1.00 E-4$ & 0.16 & 1.45 \\
\hline USW UZ-N57 & 0.23 & 5.03 & 18.08 \\
\hline USW UZ-N61 & 0.15 & 4.84 & 17.58 \\
\hline USW WT-24 & 1.87 & 5.50 & 11.96 \\
\hline
\end{tabular}

Source: Wang (2002 [DIRS 160401], SN-LBNL-SCI-215-V1, pp. 93 to 94).

The time-varying pneumatic pressure boundary condition used to simulate barometric pumping is a combination of records from the surface at Boreholes USW NRG-6 and USW NRG-7a. The record from USW NRG-7a is used as the basis for the surface signal. Where there are gaps in the data from USW NRG-7a, data from USW NRG-6 are used to fill them. Four discontinuous 60-day periods are concatenated into a 240 day record of barometric pressure. The four 60 -day periods cover the four 30-day periods selected for data inversion and the 30 days immediately preceding each. The 30 days preceding the data sets are included in the simulations to develop a dynamic pressure history in the simulation. Because pressures are constantly changing in the real system, pneumatic pressure is never in equilibrium (i.e., pneumatically static conditions are never achieved). Initial conditions for pneumatic simulations are either pneumatically static conditions or dynamic conditions from a previous simulation. When the barometric signal is applied to the upper boundary of the model, the pressure variations within the model quickly equilibrate to the boundary condition, because propagation of the pressure fronts from the upper boundary is all that is necessary. The mean pressure, however, takes slightly longer to equilibrate, because flow from the upper boundary must reach the entire model. Previous work with the Yucca Mountain models have shown that after 30 days, the effects of the initial conditions are insignificant (i.e., dynamic pneumatic conditions corresponding to the current dynamic boundary conditions are developed) (Ahlers et al. 1998 [DIRS 124842], p. 224). This is also true when the initial conditions are the dynamic conditions at the end of a 60-day period (i.e., when switching from one 60-day boundary condition period to the next). The mean 
pressure at the collar (surface) of each borehole is different because each borehole is at a different elevation. The mean pressure of the pneumatic bounding condition for each boundary node is calculated based on the initial condition. The formatted gas pressure data (files with an extension txt) and top boundary condition (file timvsp.dat) from DTN: LB991091233129.001 (DIRS 125868) are directly used in the relevant modeling studies (Section 6.3). Observed pneumatic pressure data (input files) were taken at irregular time intervals. Therefore, iTOUGH2 V5.0 (LBNL 2002 [DIRS 160106]) automatically interpolates the data to obtain a data set suitable for inversions. These interpolated data are plotted in Figures 6-7 and 6-10.

\subsubsection{Other Considerations}

Dominant fracture flow throughout the TSw is part of the current conceptual model (Section 6.1). To incorporate this conceptual model more easily, liquid-water fluxes reflecting 100 percent fracture flow in the TSw are used as an input in inversions for matrix-to-fracture connections between ptn26 and tsw31 and fracture to fracture connections between tsw31 and tsw32, tsw32 and tsw33, and tsw33 and tsw34 (Wang 2002 [DIRS 160401], SN-LBNL-SCI-003-V2, p. 89). Note that this does not actually result in 100 percent fracture flux in simulated flow fields, although this does give the required dominant fracture flow throughout the TSw.

\subsection{UZ FLOW MODEL PARAMETER CALIBRATION}

\subsubsection{General Calibration Approach}

Inversion is an iterative process in which predictions from a numerical model are compared to data. The numerical model parameters are adjusted (calibrated) to improve the match between the model prediction and the data. Data that are inverted to provide the calibrated properties documented in this model report include saturation in the rock matrix, water potential in the rock matrix, and pneumatic pressure in the fractures. Hydrologic-property estimates from laboratory and field measurements, which provide initial estimates for model parameters, are included as data in the inversion. These data, which are referred to as "prior information" in this report, are just as important to the inversion as data about the state of the system (e.g., saturation). The combination of the two types of information allows the inversion to match the data as close as possible, while simultaneously estimating model parameters that are reasonable according to the prior information. Three different kinds of parameter sets, drift-scale, mountain-scale and fault parameter sets, are determined from these calibration activities.

The software iTOUGH2 V5.0 (LBNL 2002 [DIRS 160106]) is used to carry out the automatic portion of the inversion process. This software not only allows the consideration of both data and prior information, but also allows them to be weighted. The data and prior information are weighted according to the uncertainty of the estimated value. The software attempts to minimize the sum of the squared, weighted residuals (called the objective function). It does this by iteratively adjusting (calibrating) selected model parameters. Finsterle (1998 [DIRS 103783]; 1999 [DIRS 104367]) describes further details of the inversion approach. Also note that averaged matrix saturation values (for numerical gridblocks) (Section 6.2.2) are used in inversions. The averaged data are also plotted in Figures 6-1, 6-3, 6-5, and 6-8. 


\subsubsection{Calibration of Drift-Scale Parameters}

Calibration Procedure - One-dimensional inversion of the matrix-saturation and waterpotential data is carried out for drift-scale parameters. The EOS9 module (Richards' equation) of iTOUGH2 V5.0 (LBNL 2002 [DIRS 160106]) is used for the inversion. The one-dimensional submodels correspond to 16 surface-based boreholes from which saturation and water potential have been measured. Table 6-6 shows the types of data used from each borehole, and Figure 4-1 shows the locations of some selected boreholes. Steady-state water flow is simulated simultaneously in all columns. Layer-averaged effective parameters are estimated, i.e., the same set of parameter values is used for each geologic layer in all columns.

Table 6-6. Data Used for One-Dimensional Calibration of Drift-Scale Properties from Each Borehole

\begin{tabular}{|c|c|c|c|}
\hline Borehole & $\begin{array}{c}\text { Matrix Liquid } \\
\text { Saturation (core) }\end{array}$ & $\begin{array}{c}\text { Matrix Liquid Water } \\
\text { Potential (in situ) }\end{array}$ & Data Tracking Numbers \\
\hline USW NRG-6 & & $\mathrm{x}$ & \multirow{14}{*}{$\begin{array}{l}\text { MO0109HYMXPROP.001 } \\
\text { (DIRS 155989) }\end{array}$} \\
\hline USW SD-7 & $\mathrm{x}$ & & \\
\hline USW SD-9 & $\mathbf{x}$ & & \\
\hline USW SD-12 & & $\mathrm{X}$ & \\
\hline UE-25 UZ\#4 & & $x$ & \\
\hline USW UZ-14 & $\mathrm{x}$ & & \\
\hline UE-25 UZ\#16 & $x$ & & \\
\hline USW UZ-N11 & $\mathrm{x}$ & & \\
\hline USW UZ-N31 & $\mathrm{X}$ & & \\
\hline USW UZ-N33 & $\mathrm{x}$ & & \\
\hline USW UZ-N37 & $\mathrm{X}$ & & \\
\hline USW UZ-N53 & $\mathrm{x}$ & & \\
\hline USW UZ-N57 & $\mathbf{x}$ & & \\
\hline USW UZ-N61 & $\mathbf{x}$ & & \\
\hline USW SD-6 & $x$ & & $\begin{array}{l}\text { GS980808312242.014 } \\
\text { (DIRS 106748) }\end{array}$ \\
\hline USW WT-24 & 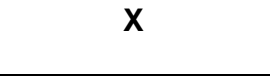 & & $\begin{array}{l}\text { GS980708312242.010 } \\
\text { (DIRS 106752) }\end{array}$ \\
\hline
\end{tabular}

Three calibrated parameter sets are produced, one for each present-day infiltration case (Section 6.2.5). The infiltration scenarios are key inputs to the UZ models because flow and transport are dependent on the amount of water infiltrating into the mountain. The base-case infiltration scenario gives the expected, spatially varying infiltration rates over Yucca Mountain, and parameters calibrated using this scenario are the base-case parameter set. The upper- and lower-bound infiltration scenarios give bounds to the uncertainty of the base-case infiltration scenario. Parameters calibrated using the bounding scenarios are also provided. This gives the parameter sets that consider underestimation and overestimation of the present-day infiltration by the base-case scenario.

The one-dimensional drift-scale property calibration is documented in scientific notebooks by Wang (2002 [DIRS 160401], SN-LBNL-SCI-215-V1, pp. 65 to 70, 100; SN-LBNL-SCI-003-V2, pp. 84 to 97$)$. 
Choice of Parameters for Calibration-Model parameters to be estimated are matrix permeability, $k$, matrix van Genuchten parameter $\alpha$ (van Genuchten 1980 [DIRS 100610], pp. 892 to 893), fracture van Genuchten parameters $\alpha$ and an active-fracture-model parameter, $\gamma$ (Liu et al. 1998 [DIRS 105729]). Other parameters are not changed in the calibration. These parameters are calibrated for model layers shown in Table 6-3 (except the zeolitic portion of $\mathrm{CHn}$ ), though in some cases a common parameter value is estimated for groups of layers. (Details of which layers are grouped for parameter estimation are discussed below.) Inverse modeling involves iterations through many forward simulations and is therefore computationally intensive. For computational efficiency, one-dimensional columnar models are used because the time required for each forward simulation is relatively short (on the order of one minute) compared to two- and three- dimensional simulations. Further adjustment of calibrated properties using three-dimensional analyses is discussed in Section 8.2. Thus, many simulations, thousands in this case, can be accomplished in a reasonably short period. The effect of using onedimensional columnar models is that all flow is forced to be vertical; no lateral flow is considered in these models. From the surface to the repository, lateral flow is not expected to be significant because perched water has not been found here. Below the repository, in the Calico Hills nonwelded hydrogeologic unit (CHn: see Table 6-3) and the Crater Flat undifferentiated unit $(\mathrm{CFu})$, areas of perched water exist where lateral flow may be significant. Properties needed to produce perched water and varying degrees of lateral flow are addressed in UZ Flow Models and Submodels (BSC 2004 [DIRS 169861]). Properties for the zeolitic portion of CHn, the unit where perched water is observed, are not calibrated here. Fracture permeability and van Genuchten $m$ are not calibrated here because they are expected to be relatively insensitive to simulated matrix-saturation and water-potential distributions. A detailed discussion of sensitivities of rock properties to the relevant simulation results is provided by Bandurraga and Bodvarsson (1999 [DIRS 103949], Section 5). Nevertheless, reduction in the number of calibrated properties is necessary because of the limited data points available for inversions. A total of 78 rock parameters are to be estimated. This set of parameters is chosen for calibration because it is a relatively small set that could represent ambient conditions in the UZ.

Residual and satiated saturation are parameters that do not influence the calibration to ambient data as strongly as the van Genuchten parameter $\alpha$. This is because ambient saturation and water-potential data are generally not at the extremes of the relationships where these bounding values play a stronger role. Like matrix porosity, matrix residual saturation is another property that is simple to measure with low error, so it makes more sense to calibrate the parameters that are not well constrained.

The matrix van Genuchten $m$ parameter, which is essentially a pore-size distribution index, is well constrained by the desaturation data (Table 4-3), whereas the same data may give an estimate of the van Genuchten $\alpha$ that is biased toward the drainage condition. In this study, matrix van Genuchten $m$ parameters are not calibrated. This reduces the number of parameters in the calibration.

Other hydrological parameters not calibrated are fracture and matrix porosity, residual saturation, and satiated saturation. Liquid flow simulations, because they are in steady state, are insensitive to porosity variations, so porosity could not be calibrated by inversion of saturation and water-potential data. Further, matrix porosity is a well-constrained property because the techniques used to measure porosity are simple and the measurement error is low. 
Because there are no data for model layers tr 3 and tr2, they are assigned the same properties as model layers bf3 and bf2, respectively (Assumption 1, in Section 5). This assignment is based on the common depositional profile of the Tram and Bullfrog Tuffs. Because the Bullfrog Tuff represents a very small portion of the UZ within the UZ model boundaries (it is present above the water table only immediately next to the Solitario Canyon fault and in the extreme northern portion of the UZ models) (BSC 2004 [DIRS 169855], Section 6), the impact of this approximation is not significant.

Common values of $k_{M}, \alpha_{M}, \alpha_{F}$, are used for the vitric Tac (material types ch2v, ch3v, ch4v, and $\operatorname{ch} 5 \mathrm{v}$ ) and for the zeolitic Tac (material types $\operatorname{ch} 2 \mathrm{z}, \operatorname{ch} 3 \mathrm{z}, \operatorname{ch} 4 \mathrm{z}$, and $\operatorname{ch} 5 \mathrm{z}$ ), respectively. The common value refers to a property value shared by several model layers. As reflected in Table 6-3, these layers do not represent actual geologic or hydrogeologic divisions, but are employed to better characterize which portions of the Tac are vitric or zeolitic, as documented in the Scientific Analysis report Development of Numerical Grids for UZ Flow and Transport Modeling (BSC 2004 [DIRS 169855], Section 6).

The lower nonlithophysal layer of the TSw (Tptpln) is subdivided into two layers based on matrix property development consistent with the report by Flint (1998 [DIRS 100033], pp. 27 to 29). This division does not exist for the fracture properties (see Table 4-4), so common values of fracture properties are used for material types tsw36 and tsw37.

The fracturing characteristics of the rocks of Yucca Mountain are considered to be primarily dependent on the degree of welding and alteration. Data in Table 4-4 show that this is true of fracture frequency. The welded rocks have higher fracture frequencies than nonwelded rocks. Because of the general division between the fracture characteristics of welded and nonwelded rocks, model layers are grouped together, based on welding, to estimate common values of the active fracture parameter. Alteration is believed to possibly influence the active fracture parameter, so it is also used as a criterion for grouping layers. Common values of $\gamma$ are estimated for the TCw; PTn; some layers of the TSw; zeolitic portions of the TSw, $\mathrm{CHn}$, and $\mathrm{CFu}$; and devitrified/welded portions of the $\mathrm{CHn}$ and $\mathrm{CFu}$. Table 6-7 shows the material types included in each of these groups. The value of $\gamma$ is estimated individually for tsw3 1 because matrix-tofracture flow is expected to be high in this layer, as a result of the transition from matrixdominated flow in the PTn to fracture-dominated flow in the TSw. No prior information exists for the active fracture parameter, $\gamma$. Initial estimates for $\gamma$ are taken as 0.25 for all layers, as shown in Table 6-7. 
Table 6-7. Initial Estimates of the Active Fracture Parameter, $\gamma$, for Saturation and Water-Potential Data Inversion

\begin{tabular}{|l|l|}
\hline \multicolumn{1}{|c|}{ Material Type (group) } & \multicolumn{1}{|c|}{$\gamma$} \\
\hline tcw11, tcw12, tcw13 & 0.25 \\
\hline ptn21, ptn22, ptn23, ptn24, ptn25, ptn26 & 0.25 \\
\hline tsw31 & 0.25 \\
\hline tsw32 and tsw33 & 0.25 \\
\hline tsw34, tsw35, tsw36, tsw37, tsw38, tsw39 & 0.25 \\
\hline ch1z, ch2z, ch3z, ch4z, ch5z, ch6, pp4, pp1, bf2, and tswz (zeolitic portion of tsw39) & 0.25 \\
\hline pp3, pp2, bf3 & 0.25 \\
\hline
\end{tabular}

Output-DTNs: LB0208UZDSCPLI.001; LB0208UZDSCPMI.001.

Prior information (Section 6.2.4) is used as initial guesses of inversions, except for the upper infiltration case. For that case, numerical convergence is difficult to obtain, and therefore the calibrated drift-scale property set for the base-case infiltration scenario is used as initial guesses. Fracture permeabilities for pp4 and pp3 are adjusted.

Calibration Results_-The one-dimensional calibrated drift-scale parameter set for the base-case (mean) infiltration scenario is presented in Table 6-8. Matches to the saturation data achieved with this parameter set for USW SD-9 are shown in Figure 6-1. Note that saturation data in the zeolitic portion of $\mathrm{CHn}$ (where perched water was observed) are not used for calibration. Figure 6-1 shows one data point in the uncalibrated CHn zone, which shows close match with model predictions. Additional calibrations to produce perched water and varying degrees of lateral flow are performed in UZ Flow Models and Submodels (BSC 2004 [DIRS 169861]) and briefly described in Section 8.2. Figure 6-2 shows matches to the water-potential data for USW SD-12. The objective function value for this run is $0.46 \mathrm{E}+4$.

The one-dimensional calibrated parameter set for the upper-bound infiltration scenario is presented in Table 6-9. Matches to the saturation data achieved with this parameter set for USW SD-9 are shown for saturation in Figure 6-3. Note that a comparison between data and simulation results for the zeolitic portion of $\mathrm{CHn}$ is not shown because saturation data from that location are not used for calibration. Figure 6-4 shows matches to the water-potential data for USW SD-12. The objective function value for this run is $0.59 \mathrm{E}+4$.

The one-dimensional calibrated parameter set for the lower-bound infiltration scenario is presented in Table 6-10. Matches to the saturation data achieved with this parameter set for USW SD-9 are shown for saturation in Figure 6-5. Note that a comparison between data and simulation results for zeolitic portion of $\mathrm{CHn}$ is not shown because saturation data from that location are not used for calibration. Figure 6-6 shows matches to the water-potential data for USW SD-12. The objective function value for this run is $0.62 \mathrm{E}+4$. 
Table 6-8. Calibrated Parameters from One-Dimensional Inversion of Saturation, and Water-Potential Data for the Base-Case Infiltration Scenario

\begin{tabular}{|c|c|c|c|c|c|c|c|}
\hline Model Layer & $\begin{array}{c}\mathbf{k}_{M} \\
\left(\mathbf{m}^{2}\right)\end{array}$ & $\begin{array}{c}\alpha_{M} \\
(1 / P a)\end{array}$ & $\begin{array}{c}\mathrm{m}_{\mathrm{M}} \\
(-)\end{array}$ & $\begin{array}{c}k_{F} \\
\left(m^{2}\right)\end{array}$ & $\begin{array}{c}\alpha_{F} \\
(1 / P a)\end{array}$ & $\begin{array}{l}m_{F} \\
(-)\end{array}$ & $\begin{array}{c}\gamma \\
(-)\end{array}$ \\
\hline tcw11 & 3.74E-15 & $1.01 \mathrm{E}-5$ & 0.388 & $3.0 \mathrm{E}-11$ & $5.27 \mathrm{E}-3$ & 0.633 & 0.587 \\
\hline tcw12 & 5.52E-20 & $3.11 \mathrm{E}-6$ & 0.280 & 5.3E-12 & $1.57 \mathrm{E}-3$ & 0.633 & 0.587 \\
\hline tcw13 & 5.65E-17 & $3.26 \mathrm{E}-6$ & 0.259 & $4.5 \mathrm{E}-12$ & $1.24 \mathrm{E}-3$ & 0.633 & 0.587 \\
\hline ptn21 & 4.60E-15 & 1.62E-4 & 0.245 & $3.2 \mathrm{E}-12$ & $8.70 \mathrm{E}-4$ & 0.633 & 0.232 \\
\hline ptn22 & 4.43E-12 & $1.46 \mathrm{E}-4$ & 0.219 & $3.0 \mathrm{E}-13$ & $1.57 \mathrm{E}-3$ & 0.633 & 0.232 \\
\hline ptn23 & $9.20 \mathrm{E}-15$ & 2.47E-5 & 0.247 & 3.0E-13 & $5.18 \mathrm{E}-3$ & 0.633 & 0.232 \\
\hline ptn24 & 2.35E-12 & $7.90 \mathrm{E}-4$ & 0.182 & 3.0E-12 & $1.86 \mathrm{E}-3$ & 0.633 & 0.232 \\
\hline ptn25 & $2.15 \mathrm{E}-13$ & 1.04E-4 & 0.300 & 1.7E-13 & $1.33 \mathrm{E}-3$ & 0.633 & 0.232 \\
\hline ptn26 & $1.00 \mathrm{E}-11$ & $9.83 \mathrm{E}-4$ & 0.126 & 2.2E-13 & $1.34 \mathrm{E}-3$ & 0.633 & 0.232 \\
\hline tsw31 & $2.95 \mathrm{E}-17$ & 8.70E-5 & 0.218 & $8.1 \mathrm{E}-13$ & 1.60E-5 & 0.633 & 0.129 \\
\hline tsw32 & $2.23 \mathrm{E}-16$ & 1.14E-5 & 0.290 & $7.1 \mathrm{E}-13$ & $1.00 \mathrm{E}-4$ & 0.633 & 0.600 \\
\hline tsw33 & $6.57 \mathrm{E}-18$ & $6.17 \mathrm{E}-6$ & 0.283 & $7.8 \mathrm{E}-13$ & $1.59 \mathrm{E}-3$ & 0.633 & 0.600 \\
\hline tsw34 & 1.77E-19 & $8.45 \mathrm{E}-6$ & 0.317 & 3.3E-13 & $1.04 \mathrm{E}-4$ & 0.633 & 0.569 \\
\hline tsw35 & 4.48E-18 & 1.08E-5 & 0.216 & $9.1 \mathrm{E}-13$ & 1.02E-4 & 0.633 & 0.569 \\
\hline tsw36 & 2.00E-19 & $8.32 \mathrm{E}-6$ & 0.442 & 1.3E-12 & 7.44E-4 & 0.633 & 0.569 \\
\hline tsw37 & 2.00E-19 & $8.32 \mathrm{E}-6$ & 0.442 & 1.3E-12 & 7.44E-4 & 0.633 & 0.569 \\
\hline tsw38 & 2.00E-18 & $6.23 \mathrm{E}-6$ & 0.286 & $8.1 \mathrm{E}-13$ & $2.12 \mathrm{E}-3$ & 0.633 & 0.569 \\
\hline tswz (zeolitic portion of tsw39) & $3.5 \mathrm{E}-17$ & $4.61 \mathrm{E}-6$ & 0.059 & $8.1 \mathrm{E}-13$ & $1.5 \mathrm{E}-3$ & 0.633 & $0.370^{b}$ \\
\hline tswv (vitric portion of tsw39) & $1.49 \mathrm{E}-13$ & $4.86 \mathrm{E}-5$ & 0.293 & 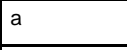 & a & a & $\mathrm{a}$ \\
\hline $\operatorname{ch} 1 z$ & $3.5 \mathrm{E}-17$ & $2.12 \mathrm{E}-7$ & 0.349 & $2.5 \mathrm{E}-14$ & $1.4 \mathrm{E}-3$ & 0.633 & $0.370^{\mathrm{b}}$ \\
\hline $\operatorname{ch} 1 v$ & $6.65 \mathrm{E}-13$ & $8.73 \mathrm{E}-5$ & 0.240 & $a$ & $a$ & $a$ & $\mathrm{a}$ \\
\hline $\operatorname{ch} 2 v$ & 2.97E-11 & $2.59 \mathrm{E}-4$ & 0.158 & $\mathrm{a}$ & $a$ & $\mathrm{a}$ & $\mathrm{a}$ \\
\hline $\operatorname{ch} 3 v$ & 2.97E-11 & $2.59 \mathrm{E}-4$ & 0.158 & a & a & $\mathrm{a}$ & $a$ \\
\hline $\operatorname{ch} 4 v$ & 2.97E-11 & $2.59 \mathrm{E}-4$ & 0.158 & a & $a$ & $a$ & $a$ \\
\hline ch5v & $2.97 \mathrm{E}-11$ & $2.59 \mathrm{E}-4$ & 0.158 & $\mathrm{a}$ & $a$ & $a$ & $\mathrm{a}$ \\
\hline ch6v & $2.35 \mathrm{E}-13$ & 1.57E-5 & 0.147 & $a$ & $a$ & $a$ & $a$ \\
\hline $\operatorname{ch} 2 z$ & $5.2 \mathrm{E}-18$ & $2.25 \mathrm{E}-6$ & 0.257 & $2.5 \mathrm{E}-14$ & $8.9 \mathrm{E}-4$ & 0.633 & $0.370^{b}$ \\
\hline $\operatorname{ch} 3 z$ & 5.2E-18 & $2.25 \mathrm{E}-6$ & 0.257 & $2.5 \mathrm{E}-14$ & 8.9E-4 & 0.633 & $0.370^{b}$ \\
\hline $\operatorname{ch} 4 z$ & 5.2E-18 & $2.25 \mathrm{E}-6$ & 0.257 & $2.5 \mathrm{E}-14$ & $8.9 \mathrm{E}-4$ & 0.633 & $0.370^{b}$ \\
\hline $\operatorname{ch} 5 z$ & $5.2 \mathrm{E}-18$ & $2.25 \mathrm{E}-6$ & 0.257 & $2.5 \mathrm{E}-14$ & 8.9E-4 & 0.633 & $0.370^{b}$ \\
\hline $\operatorname{ch} 6 z$ & 8.2E-19 & 1.56E-7 & 0.499 & $2.5 \mathrm{E}-14$ & $1.4 \mathrm{E}-3$ & 0.633 & $0.370^{b}$ \\
\hline pp4 & 8.77E-17 & 4.49E-7 & 0.474 & $2.5 \mathrm{E}-14$ & 1.83E-3 & 0.633 & 0.370 \\
\hline pp3 & 7.14E-14 & 8.83E-6 & 0.407 & 2.2E-13 & $2.47 \mathrm{E}-3$ & 0.633 & 0.199 \\
\hline $\mathrm{pp} 2$ & 1.68E-15 & 2.39E-6 & 0.309 & $2.2 \mathrm{E}-13$ & 3.17E-3 & 0.633 & 0.199 \\
\hline pp1 & 2.35E-15 & 9.19E-7 & 0.272 & $2.5 \mathrm{E}-14$ & 1.83E-3 & 0.633 & $0.370^{b}$ \\
\hline bf3 & 4.34E-13 & $1.26 \mathrm{E}-5$ & 0.193 & 2.2E-13 & $2.93 \mathrm{E}-3$ & 0.633 & 0.199 \\
\hline bf2 & 8.1E-17 & $1.18 \mathrm{E}-7$ & 0.617 & $2.5 \mathrm{E}-14$ & $8.9 \mathrm{E}-4$ & 0.633 & $0.370^{b}$ \\
\hline
\end{tabular}

NOTES: Correlation of the UZ model grid layers given above with the Major Units [modified from the report by Montazer and Wilson (1984 [DIRS 100161])], the Lithostratigraphic Nomenclature (see Table 6-4) (BSC 2004 [DIRS 170029]), and the Hydrogeologic Units (Flint 1998 [DIRS 100033], Table 1) are given in Table 6-3. These data have been developed as documented in this model report and submitted under Output-DTN: LB0208UZDSCPMI.002. Not all the properties in this table are fixed (i.e., not allowed to change) in calibration (Section 6.3.2). Fixed property values are directly taken from Tables 4-2 and 4-3.

${ }^{a}$ Calibrated properties model conceptual model does not include fractures in these model layers (Section 5).

${ }^{b}$ The $\gamma$ parameter was not calibrated for those layers. The value from pp4 is assigned to these layers. 


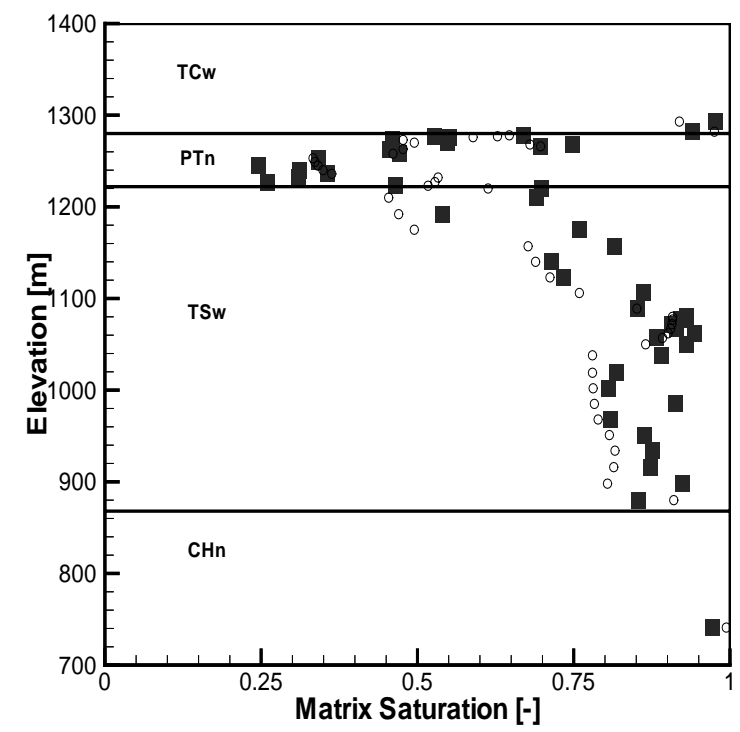

Output-DTN: LB0208UZDSCPMI.001.

NOTE: $\quad$ Filled squares correspond to averaged core data and circles to simulation results.

Figure 6-1. Saturation Matches at USW SD-9 for One-Dimensional, Drift-Scale, Calibrated Parameter Set for the Base-Case Infiltration Scenario

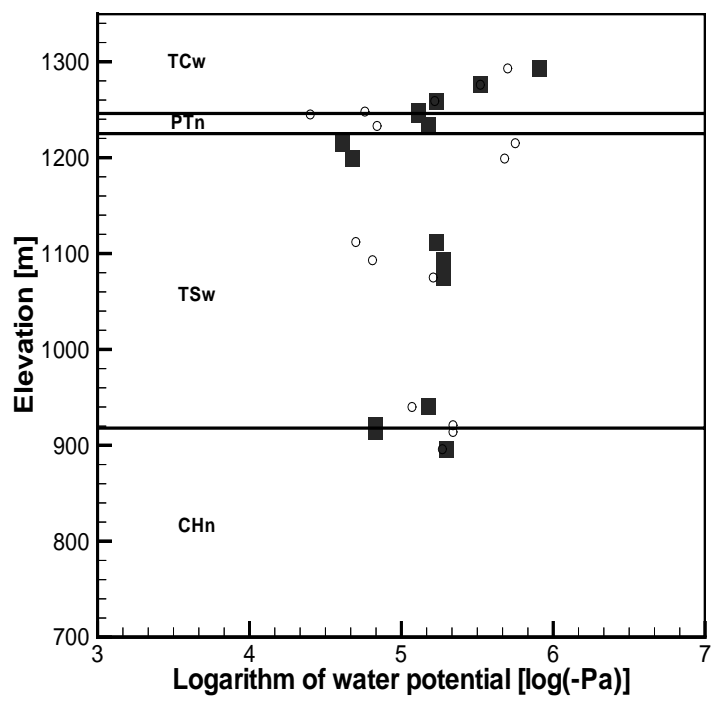

Output-DTN: LB0208UZDSCPMI.001.

NOTE: Filled squares correspond to data and circles to simulation results.

Figure 6-2. Water-Potential Matches at USW SD-12 for One-Dimensional, Drift-Scale, Calibrated Parameter Set for the Base-Case Infiltration Scenario 
Table 6-9. Calibrated Parameters from One-Dimensional Inversion of Saturation, and Water-Potential Data for the Upper-Bound Infiltration Scenario

\begin{tabular}{|c|c|c|c|c|c|c|c|}
\hline Model Layer & $\begin{array}{c}k_{M} \\
\left(m^{2}\right)\end{array}$ & $\begin{array}{c}\alpha_{M} \\
(1 / P a)\end{array}$ & $\begin{array}{c}m_{M} \\
(-)\end{array}$ & $\begin{array}{c}k_{F} \\
\left(m^{2}\right)\end{array}$ & $\begin{array}{c}\alpha_{\mathrm{F}} \\
(1 / \mathrm{Pa})\end{array}$ & $\begin{array}{l}m_{F} \\
(-)\end{array}$ & $\begin{array}{c}\gamma \\
(-)\end{array}$ \\
\hline tcw11 & 3.90E-15 & 1.23E-5 & 0.388 & 3.0E-11 & 5.01E-3 & 0.633 & 0.500 \\
\hline tcw12 & 1.16E-19 & $3.39 \mathrm{E}-6$ & 0.280 & 5.3E-12 & $2.19 \mathrm{E}-3$ & 0.633 & 0.500 \\
\hline tcw13 & 4.41E-16 & $3.25 \mathrm{E}-6$ & 0.259 & 4.5E-12 & 1.86E-3 & 0.633 & 0.500 \\
\hline ptn21 & $2.14 \mathrm{E}-14$ & $1.56 \mathrm{E}-4$ & 0.245 & $3.2 \mathrm{E}-12$ & $2.69 \mathrm{E}-3$ & 0.633 & 0.100 \\
\hline ptn22 & 1.29E-11 & $1.33 \mathrm{E}-4$ & 0.219 & $3.0 \mathrm{E}-13$ & $1.38 \mathrm{E}-3$ & 0.633 & 0.100 \\
\hline ptn23 & 4.07E-14 & $2.39 \mathrm{E}-5$ & 0.247 & 3.0E-13 & 1.23E-3 & 0.633 & 0.100 \\
\hline ptn24 & 4.27E-12 & $5.62 \mathrm{E}-4$ & 0.182 & 3.0E-12 & $2.95 \mathrm{E}-3$ & 0.633 & 0.100 \\
\hline ptn25 & $1.01 \mathrm{E}-12$ & $9.48 \mathrm{E}-5$ & 0.300 & $1.7 \mathrm{E}-13$ & 1.10E-3 & 0.633 & 0.100 \\
\hline ptn26 & 1.00E-11 & $5.23 \mathrm{E}-4$ & 0.126 & $2.2 \mathrm{E}-13$ & $9.55 \mathrm{E}-4$ & 0.633 & 0.100 \\
\hline tsw31 & 1.77E-17 & 4.85E-5 & 0.218 & 8.1E-13 & $1.58 \mathrm{E}-5$ & 0.633 & 0.100 \\
\hline tsw32 & 2.13E-16 & 1.96E-5 & 0.290 & $7.1 \mathrm{E}-13$ & $1.00 \mathrm{E}-4$ & 0.633 & 0.561 \\
\hline tsw33 & 2.39E-17 & $5.22 \mathrm{E}-6$ & 0.283 & 7.8E-13 & $1.58 \mathrm{E}-3$ & 0.633 & 0.561 \\
\hline tsw34 & 2.96E-19 & 1.65E-6 & 0.317 & 3.3E-13 & 1.00E-4 & 0.633 & 0.570 \\
\hline tsw35 & 8.55E-18 & 5.03E-6 & 0.216 & $9.1 \mathrm{E}-13$ & $5.78 \mathrm{E}-4$ & 0.633 & 0.570 \\
\hline tsw36 & 7.41E-19 & $1.08 \mathrm{E}-6$ & 0.442 & 1.3E-12 & 1.10E-3 & 0.633 & 0.570 \\
\hline tsw37 & 7.41E-19 & $1.08 \mathrm{E}-6$ & 0.442 & 1.3E-12 & 1.10E-3 & 0.633 & 0.570 \\
\hline tsw38 & 7.40E-18 & $5.58 \mathrm{E}-6$ & 0.286 & 8.1E-13 & 8.91E-4 & 0.633 & 0.570 \\
\hline tswz (zeolitic portion of tsw39) & $3.5 \mathrm{E}-17$ & 4.61E-6 & 0.059 & $8.1 \mathrm{E}-13$ & $1.5 \mathrm{E}-3$ & 0.633 & $0.500^{\mathrm{b}}$ \\
\hline tswv (vitric portion of tsw39) & $2.24 \mathrm{E}-13$ & 4.86E-5 & 0.293 & $a$ & $a$ & $\mathrm{a}$ & $\mathrm{a}$ \\
\hline $\operatorname{ch} 1 z$ & $3.5 \mathrm{E}-17$ & $2.12 \mathrm{E}-7$ & 0.349 & $2.5 \mathrm{E}-14$ & $1.4 \mathrm{E}-3$ & 0.633 & $0.500^{\mathrm{b}}$ \\
\hline $\operatorname{ch} 1 v$ & 1.39E-12 & 8.82E-5 & 0.240 & a & a & a & a \\
\hline $\operatorname{ch} 2 \mathrm{v}$ & 4.90E-11 & $2.73 \mathrm{E}-4$ & 0.158 & $a$ & $a$ & $a$ & $a$ \\
\hline $\operatorname{ch} 3 \mathrm{v}$ & 4.90E-11 & $2.73 \mathrm{E}-4$ & 0.158 & $a$ & $a$ & $\mathrm{a}$ & $\mathrm{a}$ \\
\hline $\operatorname{ch} 4 \mathrm{v}$ & 4.90E-11 & $2.73 \mathrm{E}-4$ & 0.158 & $a$ & $a$ & $\mathrm{a}$ & $\mathrm{a}$ \\
\hline $\operatorname{ch} 5 \mathrm{v}$ & 4.90E-11 & $2.73 \mathrm{E}-4$ & 0.158 & a & a & a & a \\
\hline $\operatorname{ch} 6 \mathrm{v}$ & $2.72 \mathrm{E}-13$ & 1.67E-5 & \begin{tabular}{|l|}
0.147 \\
\end{tabular} & $a$ & a & a & $\mathrm{a}$ \\
\hline $\operatorname{ch} 2 z$ & 5.2E-18 & 2.25E-6 & 0.257 & $2.5 \mathrm{E}-14$ & $8.9 \mathrm{E}-4$ & 0.633 & $0.500^{\mathrm{b}}$ \\
\hline $\operatorname{ch} 3 z$ & 5.2E-18 & $2.25 \mathrm{E}-6$ & 0.257 & $2.5 \mathrm{E}-14$ & 8.9E-4 & 0.633 & $0.500^{b}$ \\
\hline $\operatorname{ch} 4 z$ & 5.2E-18 & 2.25E-6 & 0.257 & $2.5 \mathrm{E}-14$ & 8.9E-4 & 0.633 & $0.500^{\mathrm{b}}$ \\
\hline $\operatorname{ch} 5 z$ & 5.2E-18 & $2.25 \mathrm{E}-6$ & 0.257 & $2.5 \mathrm{E}-14$ & $8.9 \mathrm{E}-4$ & 0.633 & $0.500^{\mathrm{b}}$ \\
\hline $\operatorname{ch} 6 z$ & 8.2E-19 & \begin{tabular}{|l|}
$1.56 \mathrm{E}-7$ \\
\end{tabular} & 0.499 & $2.5 \mathrm{E}-14$ & $1.4 \mathrm{E}-3$ & 0.633 & $0.500^{\mathrm{b}}$ \\
\hline $\mathrm{pp} 4$ & 1.02E-15 & 4.57E-7 & 0.474 & 2.5E-12 & 8.91E-4 & 0.633 & 0.500 \\
\hline pp3 & 1.26E-13 & $9.50 \mathrm{E}-6$ & 0.407 & $2.2 \mathrm{E}-12$ & $1.66 \mathrm{E}-3$ & 0.633 & 0.500 \\
\hline $\mathrm{pp} 2$ & 1.70E-15 & 2.25E-6 & 0.309 & $2.2 \mathrm{E}-13$ & 1.66E-3 & 0.633 & 0.500 \\
\hline pp1 & 2.57E-15 & 8.77E-7 & 0.272 & $2.5 \mathrm{E}-14$ & 8.91E-4 & 0.633 & $0.500^{\mathrm{b}}$ \\
\hline bf3 & 3.55E-14 & $3.48 \mathrm{E}-5$ & 0.193 & $2.2 \mathrm{E}-13$ & 1.66E-3 & 0.633 & 0.500 \\
\hline bf2 & 8.1E-17 & $1.18 \mathrm{E}-7$ & 0.617 & $2.5 \mathrm{E}-14$ & $8.9 \mathrm{E}-4$ & 0.633 & $0.500^{\mathrm{b}}$ \\
\hline
\end{tabular}

NOTES: These data have been developed as documented in this model report and submitted under OutputDTN: LB0302UZDSCPUI.002. Not all the properties in this table are fixed (i.e., not allowed to change) in calibration (Section 6.3.2). Fixed property values are directly taken from Tables 4-2 and 4-3 (except fracture permeability for $\mathrm{pp} 3$ and $\mathrm{pp} 4$ ).

${ }^{a}$ Calibrated properties model conceptual model does not include fractures in these model layers (Section 5).

${ }^{\mathrm{b}}$ The $\gamma$ was not calibrated for these layers. The value from pp4 is assigned to these layers. 


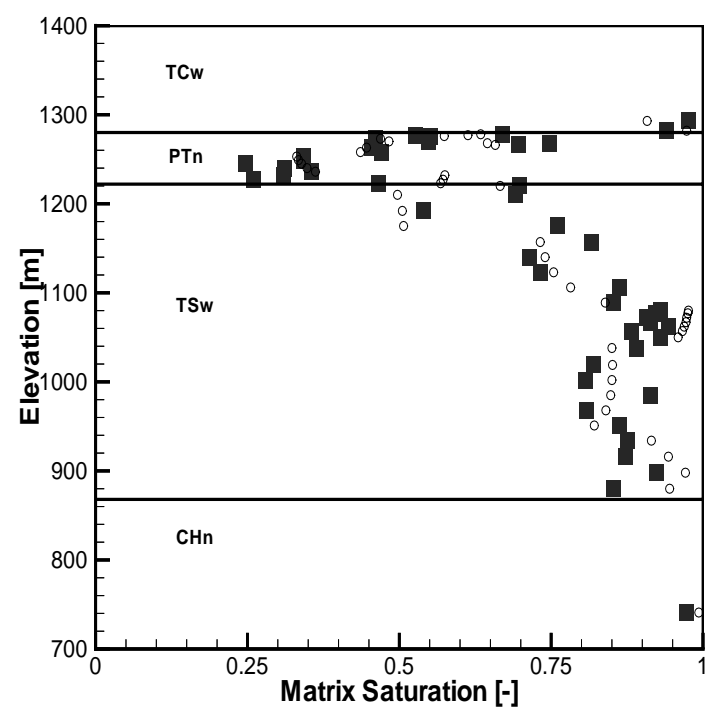

Output-DTN: LB0208UZDSCPUI.001.

NOTE: $\quad$ Filled squares correspond to averaged core data and circles to simulation results.

Figure 6-3. Saturation Matches at USW SD-9 for One-Dimensional, Drift-Scale, Calibrated Parameter Set for the Upper-Bound Infiltration Scenario

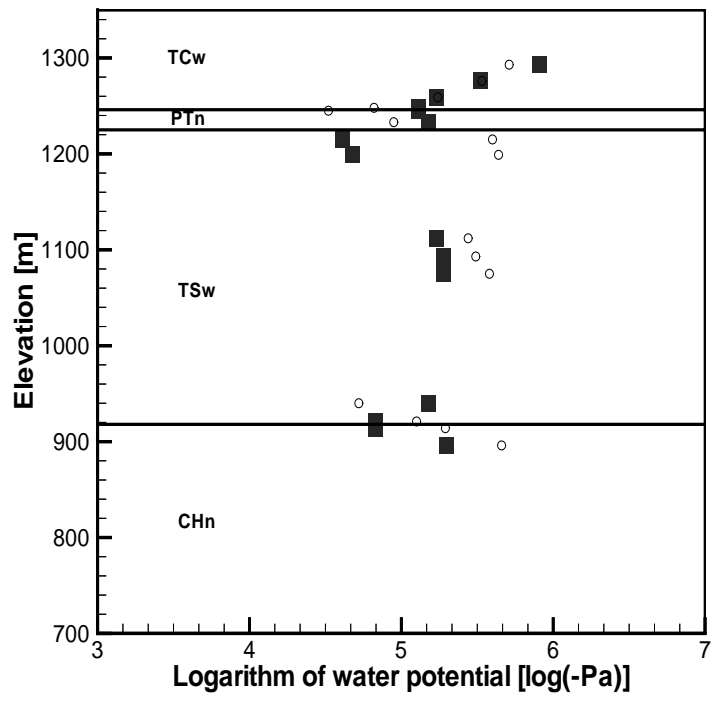

Output-DTN: LB0208UZDSCPUI.001.

NOTE: $\quad$ Filled squares correspond to data and circles to simulation results.

Figure 6-4. Water-Potential Matches at USW SD-12 for a One-Dimensional, Drift-Scale, Calibrated Parameter Set for the Upper-Bound Infiltration Scenario 
Table 6-10. Calibrated Parameters from One-Dimensional Inversion of Saturation and Water-Potential Data for the Lower-Bound Infiltration Scenario

\begin{tabular}{|c|c|c|c|c|c|c|c|}
\hline Model Layer & $\begin{array}{c}k_{M} \\
\left(m^{2}\right)\end{array}$ & $\begin{array}{c}\alpha_{M} \\
(1 / P a)\end{array}$ & $\begin{array}{c}m_{M} \\
(-)\end{array}$ & $\begin{array}{c}k_{F} \\
\left(m^{2}\right)\end{array}$ & $\begin{array}{c}\alpha_{\mathrm{F}} \\
(1 / \mathrm{Pa})\end{array}$ & $\begin{array}{l}m_{F} \\
(-)\end{array}$ & $\begin{array}{c}\gamma \\
(-)\end{array}$ \\
\hline tcw11 & 3.44E-15 & 1.16E-5 & 0.388 & 3.0E-11 & $4.68 \mathrm{E}-3$ & 0.633 & 0.483 \\
\hline tcw12 & $3.00 \mathrm{E}-20$ & $2.67 \mathrm{E}-6$ & 0.280 & 5.3E-12 & $3.20 \mathrm{E}-3$ & 0.633 & 0.483 \\
\hline tcw13 & 3.96E-17 & 1.64E-6 & 0.259 & 4.5E-12 & $2.13 \mathrm{E}-3$ & 0.633 & 0.483 \\
\hline ptn21 & 5.55E-15 & 6.38E-5 & 0.245 & 3.2E-12 & 2.93E-3 & 0.633 & 0.065 \\
\hline ptn22 & $8.40 \mathrm{E}-12$ & $1.67 \mathrm{E}-4$ & 0.219 & 3.0E-13 & $6.76 \mathrm{E}-4$ & 0.633 & 0.065 \\
\hline ptn23 & 1.92E-14 & $4.51 \mathrm{E}-5$ & 0.247 & 3.0E-13 & $3.96 \mathrm{E}-3$ & 0.633 & 0.065 \\
\hline ptn24 & $6.66 \mathrm{E}-13$ & $2.52 \mathrm{E}-3$ & 0.182 & 3.0E-12 & $2.51 \mathrm{E}-3$ & 0.633 & 0.065 \\
\hline ptn25 & 1.96E-14 & 1.24E-4 & 0.300 & 1.7E-13 & 1.53E-3 & 0.633 & 0.065 \\
\hline ptn26 & 1.00E-11 & $1.63 \mathrm{E}-3$ & 0.126 & $2.2 \mathrm{E}-13$ & $1.52 \mathrm{E}-3$ & 0.633 & 0.065 \\
\hline tsw31 & 1.42E-17 & 8.02E-5 & 0.218 & 8.1E-13 & $1.58 \mathrm{E}-5$ & 0.633 & 0.037 \\
\hline tsw32 & 3.96E-16 & 9.46E-6 & 0.290 & 7.1E-13 & $1.31 \mathrm{E}-4$ & 0.633 & 0.528 \\
\hline tsw33 & 1.60E-18 & 4.25E-6 & 0.283 & 7.8E-13 & $1.94 \mathrm{E}-3$ & 0.633 & 0.528 \\
\hline tsw34 & 1.38E-19 & $1.19 \mathrm{E}-6$ & 0.317 & 3.3E-13 & $6.55 \mathrm{E}-4$ & 0.633 & 0.476 \\
\hline tsw35 & 2.33E-18 & 1.97E-6 & 0.216 & 9.1E-13 & 1.35E-3 & 0.633 & 0.476 \\
\hline tsw36 & 5.58E-19 & $4.22 \mathrm{E}-7$ & 0.442 & 1.3E-12 & 1.31E-3 & 0.633 & 0.476 \\
\hline tsw37 & 5.58E-19 & 4.22E-7 & 0.442 & 1.3E-12 & 1.31E-3 & 0.633 & 0.476 \\
\hline tsw38 & 2.93E-18 & 1.43E-6 & 0.286 & 8.1E-13 & $1.75 \mathrm{E}-3$ & 0.633 & 0.476 \\
\hline tswz (zeolitic portion of tsw39) & 3.5E-17 & $4.61 \mathrm{E}-6$ & 0.059 & 8.1E-13 & $1.5 \mathrm{E}-3$ & 0.633 & $0.276^{\mathrm{b}}$ \\
\hline tswv (vitric portion of tsw39) & $3.15 \mathrm{E}-13$ & $1.86 \mathrm{E}-5$ & 0.293 & a & $\mathrm{a}$ & $\mathrm{a}$ & $a$ \\
\hline $\operatorname{ch} 1 z$ & 3.5E-17 & $2.12 \mathrm{E}-7$ & 0.349 & $2.5 \mathrm{E}-14$ & $1.4 \mathrm{E}-3$ & 0.633 & $0.276^{\mathrm{b}}$ \\
\hline $\operatorname{ch} 1 \mathrm{v}$ & 3.15E-14 & $4.50 \mathrm{E}-5$ & 0.240 & $a$ & $\mathrm{a}$ & $a$ & $a$ \\
\hline $\operatorname{ch} 2 v$ & 1.13E-11 & 1.22E-4 & 0.158 & a & a & a & a \\
\hline $\operatorname{ch} 3 v$ & 1.13E-11 & $1.22 \mathrm{E}-4$ & 0.158 & a & a & a & a \\
\hline $\operatorname{ch} 4 \mathrm{v}$ & 1.13E-11 & $1.22 \mathrm{E}-4$ & 0.158 & $a$ & $a$ & $a$ & $a$ \\
\hline ch5v & 1.13E-11 & 1.22E-4 & 0.158 & a & a & $a$ & a \\
\hline $\operatorname{ch} 6 \mathrm{v}$ & $2.54 \mathrm{E}-13$ & 9.05E-6 & 0.147 & a & $a$ & a & a \\
\hline $\operatorname{ch} 2 z$ & $5.2 \mathrm{E}-18$ & $2.25 \mathrm{E}-6$ & 0.257 & $2.5 \mathrm{E}-14$ & $8.9 \mathrm{E}-4$ & 0.633 & $0.276^{\mathrm{b}}$ \\
\hline $\operatorname{ch} 3 z$ & 5.2E-18 & $2.25 \mathrm{E}-6$ & 0.257 & 2.5E-14 & $8.9 \mathrm{E}-4$ & 0.633 & $0.276^{b}$ \\
\hline $\operatorname{ch} 4 \mathrm{z}$ & 5.2E-18 & $2.25 \mathrm{E}-6$ & 0.257 & $2.5 \mathrm{E}-14$ & 8.9E-4 & 0.633 & $0.276^{\mathrm{t}}$ \\
\hline $\operatorname{ch} 5 z$ & 5.2E-18 & $2.25 \mathrm{E}-6$ & 0.257 & 2.5E-14 & $8.9 \mathrm{E}-4$ & 0.633 & $0.276^{b}$ \\
\hline $\operatorname{ch} 6 z$ & $8.2 E-19$ & $1.56 \mathrm{E}-7$ & 0.499 & $2.5 \mathrm{E}-14$ & $1.4 \mathrm{E}-3$ & 0.633 & $0.276^{\mathrm{b}}$ \\
\hline pp4 & 2.98E-16 & 2.88E-7 & 0.474 & 2.5E-14 & $1.88 \mathrm{E}-3$ & 0.633 & 0.276 \\
\hline pp3 & 5.37E-14 & 7.97E-6 & 0.407 & 2.2E-13 & 1.32E-3 & 0.633 & 0.248 \\
\hline $\mathrm{pp} 2$ & 4.24E-16 & $2.41 \mathrm{E}-6$ & 0.309 & 2.2E-13 & 2.80E-3 & 0.633 & 0.248 \\
\hline $\mathrm{pp} 1$ & 7.02E-16 & $1.36 \mathrm{E}-6$ & 0.272 & $2.5 \mathrm{E}-14$ & 6.39E-4 & 0.633 & $0.276^{\mathrm{b}}$ \\
\hline bf3 & 2.97E-14 & 1.32E-5 & 0.193 & 2.2E-13 & $1.91 \mathrm{E}-3$ & 0.633 & 0.248 \\
\hline bf2 & 8.1E-17 & $1.18 \mathrm{E}-7$ & 0.617 & 2.5E-14 & $8.9 \mathrm{E}-4$ & 0.633 & $0.276^{b}$ \\
\hline
\end{tabular}

NOTES: These data have been developed as documented in this model report and submitted under Output-

DTN: LB0208UZDSCPLI.002. Not all the properties in this table are varied in calibration (Section 6.3.2).

Fixed property values are directly taken from Tables 4-2 and 4-4.

${ }^{a}$ Calibrated properties model conceptual model does not include fractures in these model layers (Section 5).

${ }^{b}$ The $\gamma$ parameter was not calibrated for these layers. The value from pp4 is assigned to these layers. 


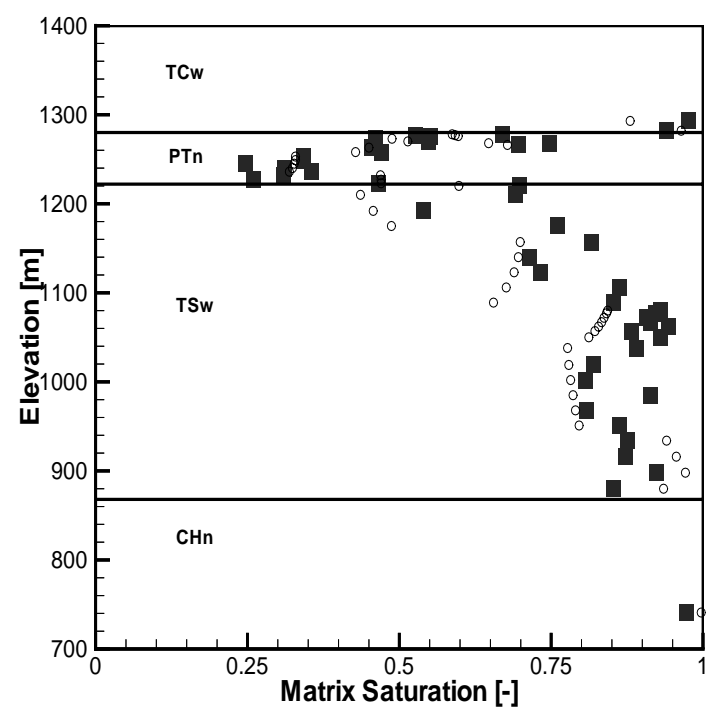

Output-DTN: $\quad$ LB0208UZDSCPLI.001.

NOTE: $\quad$ Filled squares correspond to averaged core data and circles to simulation results.

Figure 6-5. Saturation Matches at USW SD-9 for a One-Dimensional, Drift-Scale, Calibrated Parameter Set for the Lower-Bound Infiltration Scenario

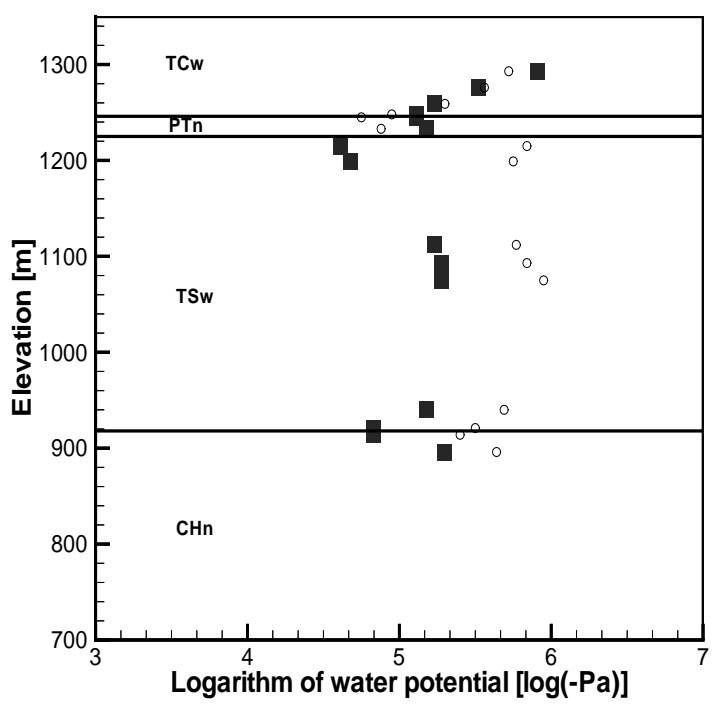

Output-DTN: LB0208UZDSCPLI.001.

NOTE: Filled squares correspond to data and circles to simulation results.

Figure 6-6. Water-Potential Matches at USW SD-12 for a One-Dimensional, Drift-Scale, Calibrated Parameter Set for the Lower-Bound Infiltration Scenario 


\subsubsection{Calibration of Mountain-Scale Parameters}

Scale Dependence of Fracture Permeability - It is well documented in the literature that largescale effective permeabilities are generally larger than smaller-scale ones (Neuman 1994 [DIRS 105731]). An intuitive explanation for this scale-dependent behavior is that a large observation scale, in an average sense, corresponds to a larger opportunity to encounter more permeable zones or paths when observations are made, which considerably increases values of the observed permeability. Because of the scale difference, drift-scale fracture permeabilities, determined from air-injection tests, cannot be applied to mountain-scale modeling. Therefore, development of mountain-scale properties is needed. In addition to matching matrix-saturation and water-potential data, the determination of mountain-scale parameters also involves matching pneumatic pressure data measured in surface boreholes. In the drift-scale parameter sets, fracture permeabilities correspond to those determined from air-injection tests. The pneumatic pressure data result from mountain-scale gas-flow processes, while air-injection tests correspond to scales on an order of several meters or less.

Unlike the connected fracture networks and soils, studies on the scale-dependent behavior of matrix properties in unsaturated fractured rocks are very limited. However, it is reasonable to believe that the scale-dependent behavior of the matrix is different from fracture networks. For example, relatively large fractures can act as capillary barriers for flow between matrix blocks separated by these fractures, even when the matrix is essentially saturated (water potential is close to the air entry value). This might limit the matrix scale-dependent behavior to a relatively small scale associated with the spacing between relatively large fractures. Although it is expected that estimated large-scale matrix permeabilities should be larger than those measured on a core-scale, no evidence exists to indicate that matrix properties should be very different on both the site and drift scales, which are much larger than the scale characterized by the fracture spacing. This point is also supported by the inversion results for the drift-scale properties. For example, the estimated drift-scale matrix permeabilities are generally much closer to prior information than estimated site-scale fracture permeabilities.

Based on the above discussions, only fracture permeabilities for the mountain-scale property sets are recalibrated, whereas other properties remain the same as those in the corresponding driftscale properties. The calibration includes three steps: (1) fracture permeabilities are calibrated by matching the pneumatic pressure data; (2) the matches to matrix-saturation and waterpotential data are checked using parameter sets that include calibrated fracture permeabilities; and (3) if the matches are not maintained, a new calibration using matrix-saturation and waterpotential data would be needed for fracture permeabilities (fracture permeability calibrated in step 1 is used as initial guess for the re-calibration). These steps may need to be repeated until parameter sets match both pneumatic pressure data and matrix-saturation/water-potential data. As can be seen, this calibration is an iterative process.

Calibration Procedure Using Pneumatic Pressure Data-The EOS3 module of iTOUGH2 V5.0 (LBNL 2002 [DIRS 160106]) is used for transient pneumatic simulations. Both the gas phase and the liquid phase are considered in the flow calculations. The pneumatic inversion is carried out in two steps. First, the fracture permeabilities for layers tcw11 through ptn26 are calibrated. Then, the permeabilities for layers tsw31 through 37 are calibrated as a group by multiplying the prior information for all seven layers by the same factor. The calibration 
activities are documented in the scientific notebook by Wang (2002 [DIRS 160401], SN-LBNL-SCI-215-V1, pp. 71 to 80,87 to 88 ).

The calibrated fracture permeabilities resulting from inversion of pneumatic data are expected to be higher than the prior information due to scale dependency of fracture permeabilities as described above. Therefore, the initial guesses for the fracture permeabilities are $\log (\mathrm{k})=-10.5$ for tcw11, tcw12, and tcw 13 , and $\log (\mathrm{k})=-11.5$ for $\mathrm{ptn} 21$ through ptn26. These estimates are higher than the corresponding prior information (Table 4-4). The permeabilities of layers tsw31 through 37 are set to the values previously calibrated using the pneumatic data (DTNs: LB997141233129.001 [DIRS 104055]; LB997141233129.002 [DIRS 119933]; and LB997141233129.003 [DIRS 119940]).

The lack of significant attenuation in the TSw unit is considered an important feature shown by the gas pressure data. The calibrated fracture permeabilities for the model layers in the TSw unit need to be consistent with this feature. Therefore, fracture permeabilities in the TSw need to be determined in such a way that the simulated and observed gas pressure signals at the upper and lower sensor locations in the TSw have similar degrees of attenuation for Borehole USW SD-12. Borehole USW SD-12 is chosen for this analysis because the distance between the two TSw sensors within this borehole is the largest among all the relevant boreholes. The degree of attenuation of the barometric signal through the TSw in USW SD-12, or the relative difference between the signals at the two sensor locations, was determined by using standard functions of Excel 97 SR-1 (see description of QAd.xls in Appendix A) to evaluate

$$
F=\frac{1}{N}\left\{\sum_{i=1}^{N}\left[\left(P_{u}\left(t_{i}\right)-P_{u}\left(t_{1}\right)\right)-\left(P_{b}\left(t_{i}\right)-P_{b}\left(t_{1}\right)\right)\right]^{2}\right\}^{1 / 2}
$$

where $N$ is the total number of calibration time points, $P$ is the gas pressure, and subscripts $u$ and $b$ refer to the sensors in the upper and lower (bottom) portions of the TSw within Borehole USW SD-12. Obviously, if the gas signals from the two sensors are identical, $F$ should be equal to zero. For the USW SD-12 gas-signal data (DTN: LB991091233129.001 [DIRS 125868]), the $F$ value is $2.01 \mathrm{E}-3(\mathrm{kPa})$. In this study, fracture permeabilities need to be determined that will predict $F$ values similar to the value calculated from the data, such that the simulated and observed gas-pressure signals have similar degrees of attenuation.

Since the gas-pressure data from the TSw are relatively limited compared TCW and PTn units and the insignificant attenuation and time lag between the upper-most and lower-most sensors are used for calibration, the fracture permeabilities for different model layers in this unit could not be independently estimated in a reliable manner. Note that the attenuation and time lag are determined by the overall hydraulic properties between the two sensors, rather than by properties in a single model layer. Therefore, the ratios of the permeabilities of layers tsw3 1 through tsw37 are held constant, and the prior information permeability values are multiplied by a single factor, $d$. For a given infiltration map, a number of values, $\log (d)$, between 1 and 2 with an interval of 0.1 are tested to determine the $d$ resulting in an $F$ value closest to the $F$ value corresponding to the data. To calculate an $F$ value for a $d$ factor, modelers used the outputs from the TCw and PTn fracture permeability calibrations to run the forward simulation using iTOUGH2 V5.0 (LBNL 2002 [DIRS 160106]) for generating gas pressures used in Equation 6-10. In a forward 
simulation, all the rock properties are the same as those determined from the corresponding $\mathrm{TCW}$ and PTn fracture permeability calibration, except the fracture permeabilities for model layers tsw31 to tsw37 are determined using the $d$ factor and the prior information.

The determined $\log (d)$ values based on the above procedure (derived from OutputDTN: LB02091DSSCP3I.001) are shown in Table 6-11 for the three infiltration maps. The $\log (d)$ values range from 1.8-2.0, indicating that the fracture permeabilities for the relevant model layers are increased by about two orders of magnitude compared to the prior information. This results from the scale effects, as previously discussed.

Table 6-11. The Calculated $\log (\mathrm{d})$ Factors for the Three Infiltration Maps

\begin{tabular}{|l|l|l|}
\hline \multicolumn{1}{|c|}{ Base-case } & \multicolumn{1}{|c|}{ Upper Bound } & Lower Bound \\
\hline 2.0 & 1.9 & 1.8 \\
\hline
\end{tabular}

Source: $\quad$ Wang 2002 (DIRS 160401), SN-LBNL-SCI-215-V1, p. 75.

Table 6-12 provides mountain-scale fracture permeabilities calibrated with pneumatic pressure data for three infiltration scenarios.

Table 6-12. Calibrated Mountain-Scale Fracture Permeabilities $\left(\mathrm{m}^{2}\right)$

\begin{tabular}{|l|l|l|l|}
\hline \multicolumn{1}{|c|}{ Model Layer } & \multicolumn{1}{|c|}{ Base Case } & \multicolumn{1}{c|}{ Upper Bound } & \multicolumn{1}{c|}{ Lower Bound } \\
\hline tcw11 & $4.24 \mathrm{E}-11$ & $3.16 \mathrm{E}-12$ & $3.16 \mathrm{E}-12$ \\
\hline tcw12 & $9.53 \mathrm{E}-11$ & $1.00 \mathrm{E}-10$ & $9.73 \mathrm{E}-11$ \\
\hline tcw13 & $1.32 \mathrm{E}-11$ & $9.67 \mathrm{E}-13$ & $9.47 \mathrm{E}-13$ \\
\hline ptn21 & $2.11 \mathrm{E}-12$ & $1.00 \mathrm{E}-11$ & $1.00 \mathrm{E}-11$ \\
\hline ptn22 & $9.41 \mathrm{E}-12$ & $3.85 \mathrm{E}-13$ & $1.00 \mathrm{E}-11$ \\
\hline ptn23 & $5.35 \mathrm{E}-13$ & $9.04 \mathrm{E}-14$ & $1.16 \mathrm{E}-13$ \\
\hline ptn24 & $1.00 \mathrm{E}-11$ & $3.16 \mathrm{E}-13$ & $1.00 \mathrm{E}-11$ \\
\hline ptn25 & $1.24 \mathrm{E}-12$ & $1.59 \mathrm{E}-14$ & $4.37 \mathrm{E}-13$ \\
\hline ptn26 & $3.17 \mathrm{E}-13$ & $9.23 \mathrm{E}-14$ & $8.29 \mathrm{E}-14$ \\
\hline tsw31 & $8.13 \mathrm{E}-11$ & $6.46 \mathrm{E}-11$ & $5.13 \mathrm{E}-11$ \\
\hline tsw32 & $7.08 \mathrm{E}-11$ & $5.62 \mathrm{E}-11$ & $4.47 \mathrm{E}-11$ \\
\hline tsw33 & $7.76 \mathrm{E}-11$ & $6.17 \mathrm{E}-11$ & $4.90 \mathrm{E}-11$ \\
\hline tsw34 & $3.31 \mathrm{E}-11$ & $2.63 \mathrm{E}-11$ & $2.09 \mathrm{E}-11$ \\
\hline tsw35 & $9.12 \mathrm{E}-11$ & $7.24 \mathrm{E}-11$ & $5.75 \mathrm{E}-11$ \\
\hline tsw36 & $1.35 \mathrm{E}-10$ & $1.07 \mathrm{E}-10$ & $8.51 \mathrm{E}-11$ \\
\hline tsw37 & $1.35 \mathrm{E}-10$ & $1.07 \mathrm{E}-10$ & $8.51 \mathrm{E}-11$ \\
\hline
\end{tabular}

NOTES: Correlation of the UZ model grid layers given above with the Major Units [modified from the report by Montazer and Wilson (1984 [DIRS 100161])], the Lithostratigraphic Nomenclature (see Table 6-4) (BSC 2004 [DIRS 170029]), and the Hydrogeologic Units (Flint 1998 [DIRS 100033], Table 1) are given in Table 6-3. These data have been developed as documented in this model report and submitted under OutputDTN: LB02091DSSCP3I.002.

a In the numerical grids used in inversions, the name of (fracture) model layer is the same as the corresponding model layer name in the table except that the 4th character is "F". 
Saturation and Water-Potential Check-Matches to the saturation and water-potential data were checked and found to be satisfactory, because for a given infiltration scenario, the objective-function values are almost identical for both the mountain-scale property set and the corresponding drift-scale property set (Wang 2002 [DIRS 160401], SN-LBNL-SCI-215-V1, pp. 75 to 76). Therefore, no further adjustment is needed. This also further confirms the previous assertion that under ambient conditions, simulated matrix water potential and saturation distributions are insensitive to fracture permeability values.

Figure 6-7 shows pneumatic pressure matches at USW SD-12 for a one-dimensional, mountainscale, calibrated parameter set for the base-case infiltration scenario. Similar matches are obtained for other boreholes and for two other infiltration scenarios. In Figure 6-7, both simulated and observed pressure curves for a given geologic layer (Tptrn and Tpbt2) are shifted an identical distance along the vertical axis to better display the matches.

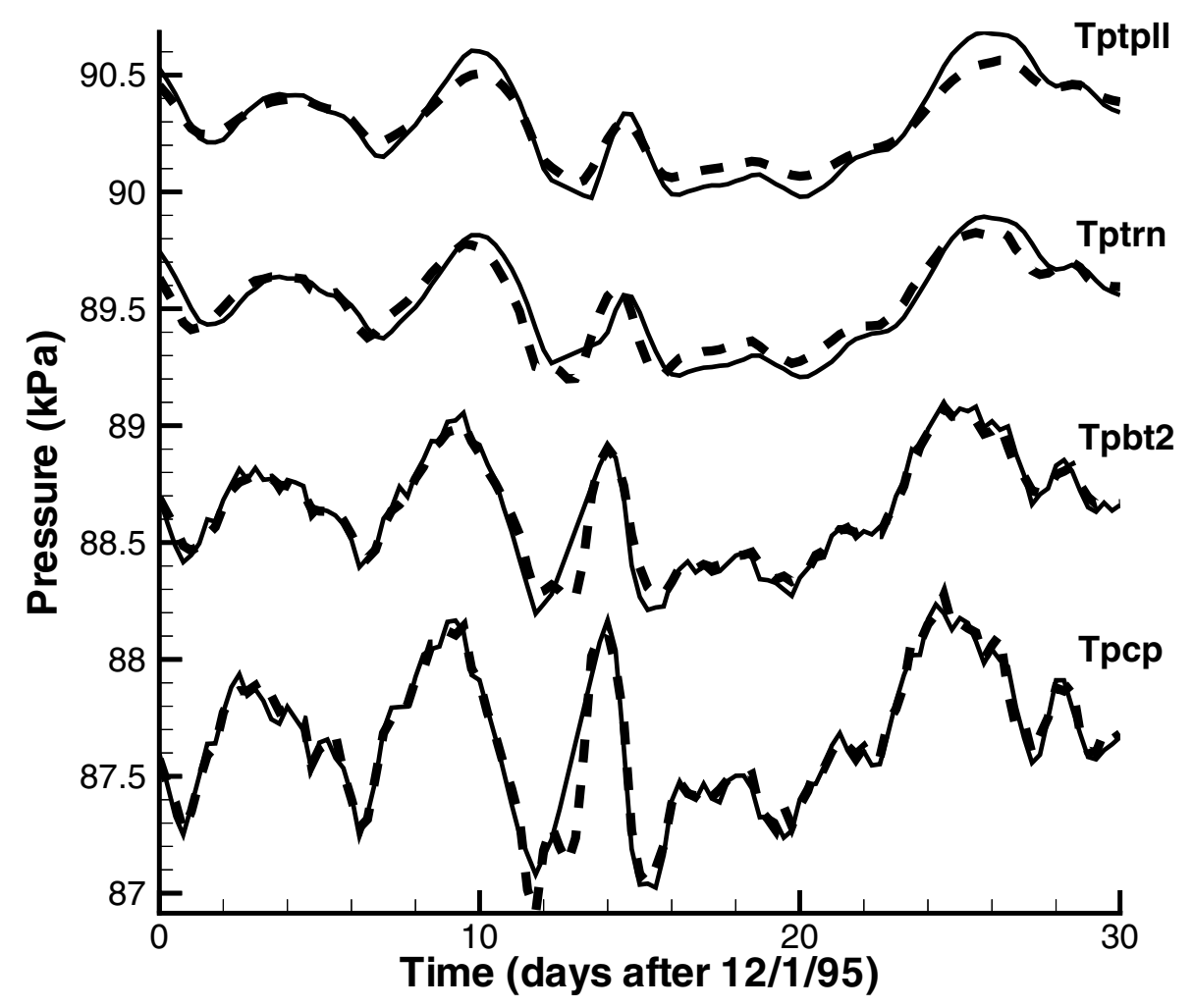

Output-DTN: LB02091DSSCP3I.001.

NOTE: Solid lines correspond to the interpolated raw data and dashed lines to simulated results.

Figure 6-7. Pneumatic Pressure Matches at USW SD-12 for the One-Dimensional, Mountain-Scale, Calibrated Parameter Set for the Base-Case Infiltration Scenario

\subsubsection{Calibration of Fault Parameters}

Two-dimensional flow (vertical and east-west) is considered to adequately describe the flow patterns around Borehole USW UZ-7a, used for fault property calibration. Inverse modeling is computationally intensive. For this reason, it is necessary to use the simplest model that will 
adequately simulate the system being modeled. Because faults are relatively planar in geometry, flow in and around a fault zone (including interaction of the hanging wall, foot zone, and foot wall) can be sufficiently captured by a two-dimensional model. Further adjustment of calibrated properties using three-dimensional analyses is discussed in Section 8.2. An east-west, vertical cross section through USW UZ-7a and the Ghost Dance fault captures this interaction. This cross section is aligned approximately parallel to the dip of the beds and parallel to the dip of the fault (perpendicular to the strike). Any lateral flow in or around the fault zone should follow the dip of the beds and the fault.

The data from Borehole USW UZ-7a represent the most complete data set from within a fault zone. Saturation, water potential, and pneumatic data are available from the surface down into the TSw. Other data sets that are influenced by faults, from Boreholes USW NRG-6, UE-25 UZ\#4, and UE-25 UZ\#5, include only pneumatic pressure data and are only relevant to the TSw. Because of the limited amount of data, it is best to characterize one fault as completely as possible and apply these properties to all other faults. This treatment is necessary because not enough data are available for other faults. The Ghost Dance fault, located near the east boundary of a repository block, is an important hydrogeological feature as a potential flow path for receiving lateral flows along eastwardly tilted layer interfaces.

Use of the Input Data - Data from USW UZ-7a are the most comprehensive with respect to faults. Saturation, water potential, and pneumatic pressure data are available within the Ghost Dance fault zone from the surface to the upper layers of the TSw. Pneumatic-only data (that show fault influence) are available from three other boreholes, but are not used in this analysis (rationale documented in Section 4.1.2.3). Because the data on faults are so limited, they are separated into four layers to reduce the number of parameters used to characterize the fault zones. The layers are the $\mathrm{TCw}, \mathrm{PTn}, \mathrm{TSw}$, and $\mathrm{CHn} / \mathrm{CFu}$. Data for inversion are available for only the first three layers, so only the parameters of these layers are calibrated. Minimization of the objective function is the only criterion used for a successful calibration. The proportion of fracture flow to matrix flow specifically in the fault is not an element of the conceptual model.

Saturation, water potential, and pneumatic pressure data, which are inverted to obtain the calibrated parameter sets, are developed from files with extension prn, UZ7asat.xls, and UZ7acap.xls from DTN: LB991091233129.003 (DIRS 119902) so that they can be compared to the numerical grid in a way similar to that described in Section 6.2.2. However, because geologic layering data from USW UZ-7a are not included in the geologic model used to develop the numerical grid, there is no one-to-one correlation between the grid layer elevations and the geology of USW UZ-7a. This problem is overcome by interpolating the data onto the grid (see description of Excel file UZ-7asat1_02.xls in Appendix A).

The calculation for the average saturations from core and in situ water potentials and their weighting for the inversion is the same as described in Section 6.2.2, except for the necessity of interpolation (based on geology) to assign data to the appropriate model layers. Criteria identical to those used in selecting an appropriate time interval for the pneumatic data as described in Section 6.2.3 are used to select data from USW UZ-7a. Table 6-13 shows the dates, subunits, and elevations for the data that were used in the inversion. The procedure to calculate elevations is the same as that given in Section 6.2.3. Subunits are determined from the elevations of sensors and contacts between the subunits (file contacts00md.dat of DTN: MO0012MWDGFM02.002 
[DIRS 153777]). Subunits Tpc, Tpcpv1, Tpbt2, Tptrv3/2 and Tptrn correspond to sensors TCP1319, TCP 1325, TCP 1331, TCP 1337, and TCP 1343, respectively (DTN: GS960308312232.001 [DIRS 105573]). As with the one-dimensional pneumatic inversion, data are taken from the lowest $\mathrm{TCW}$ instrument station, all instrument stations in the PTn, and in the TSw within the fault zone. Three instrument stations in the footwall (below the fault zone) are not included in the inversion because they represent interactions at the edge of the fault on a subgridblock scale not captured by the UZ models. The calibration activities are documented in scientific notebooks by Wang (2002 [DIRS 160401], SN-LBNL-SCI-215-V1, pp. 81 to 86,100 ; SN-LBNL-SCI-199-V1, pp. 98 to 99,104$)$.

Table 6-13. Pneumatic Pressure Data Used for Inversion

\begin{tabular}{|c|l|l|l|}
\hline Borehole & Subunit & \multicolumn{1}{c}{ Dates } & Elevation (meter) \\
\hline USW UZ-7a & Tpc & $12 / 1-12 / 31 / 95$ & 1243.0 \\
\hline \multirow{5}{*}{} & Tpcpv1 & $12 / 1-12 / 31 / 95$ & 1232.3 \\
\cline { 2 - 4 } & Tpbt2 & $12 / 1-12 / 31 / 95$ & 1221.6 \\
\cline { 2 - 4 } & Tptrv3/2 & $12 / 1-12 / 31 / 95$ & 1213.4 \\
\cline { 2 - 4 } & Tptrn & $12 / 1-12 / 31 / 95$ & 1177.8 \\
\hline
\end{tabular}

DTN: $\quad$ GS960308312232.001 (DIRS 105573).

Calibration Procedure-Data inversion for calibration of the fault parameters is carried out in the same sequence of steps used for the one-dimensional mountain-scale inversion. First, the saturation and water-potential data are inverted. Second, the pneumatic data are inverted. Third, the calibrated parameters are checked against the saturation and water-potential data and further calibrated if needed.

Note that fault properties to be calibrated are fracture properties, whereas matrix properties within fault zones are the same as those in nonfault zones (DTN: LB02081DKMGKID.001 [DIRS 160108]). Fracture permeabilities are fixed during the saturation and water-potential inversion, and are the only parameters calibrated to the pneumatic data. Parameters to be calibrated against matrix-saturation and water-potential data are fracture $\alpha$ and active-fracturemodel parameter $\gamma$.

The calibrated fracture $\alpha$ and active-fracture-model parameter $\gamma$ for the base-case infiltration scenario are used as initial guesses for inversion of matrix-saturation and water-potential data for the other two infiltration scenarios. The resultant objective function values for the other two infiltration scenarios are almost the same as those obtained using the calibrated property set for the base-case infiltration scenario. With this in mind, investigators applied the calibrated fracture $\alpha$ and active-fracture-model parameter $\gamma$ for the base-case infiltration scenario to the other two infiltration scenarios. Note that the same fracture $\mathrm{m}(0.633)$ as that for the nonfault zone (Table 4-4) is used here for the fault zone, because no specific fracture $m$ data are available for the fault zone. As discussed in Section 6.3.2, fracture $m$ is not expected to be sensitive to simulated matrix saturation and water potential distributions.

Using the parameter set from the matrix-saturation and water-potential calibration step, the fracture permeabilities are calibrated by inversion of the pneumatic data for the base-case 
infiltration scenario. Automated inversion successfully improves the objective function and provides a good match to the pneumatic data.

The fault parameters calibrated for the base-case infiltration scenario are checked to determine whether they are satisfactory for the other two infiltration scenarios. The objective function values for the two infiltration scenarios, determined with forward runs of iTOUGH2 V5.0 (LBNL 2002 [DIRS 160106]), are even smaller than that for the base-case infiltration scenario. Therefore, a single calibrated fault parameter set is applied to all three infiltration scenarios. Finally, the calibrated fault parameters are used to check the matches with matrix-saturation and water-potential data for the three infiltration scenarios. For each infiltration scenario, the resultant objective function value is almost identical to that obtained from the matrix saturation and water-potential calibration step. Therefore, the matches are satisfactory.

Calibration Results - The calibrated fault parameter set is presented in Table 6-14. Matches to the data achieved with this parameter set for USW UZ-7a are shown for saturation in Figure 6-8, for water potential in Figure 6-9, and for pneumatic pressure in Figure 6-10. In Figure 6-10, both simulated and observed pressure curves for a given geologic layer (Tptrn, Tptrv3/2, Tpbt2 and Tpcpv1) are shifted along the vertical axis an identical distance to better display the matches. Note that the calibrated fracture permeabilities in the fault zone (Table 6-14) are generally higher than those for nonfault zones (Table 6-12), which is consistent with measurement results of the report by LeCain et al. (2000 [DIRS 144612], Summary).

Table 6-14. Calibrated Fault Parameters from Two-Dimensional Inversions of Saturation, Water Potential, and Pneumatic Data

\begin{tabular}{|l|c|c|c|c|}
\hline \multicolumn{1}{c|}{ Model Layer } & $\begin{array}{c}\boldsymbol{k}_{F} \\
\left(\mathbf{m}^{\mathbf{2}}\right)\end{array}$ & $\begin{array}{c}\alpha_{F} \\
(\mathbf{1 / P a})\end{array}$ & $\begin{array}{c}\boldsymbol{m}_{\boldsymbol{F}} \\
(-)\end{array}$ & $\begin{array}{c}\gamma \\
(-)\end{array}$ \\
\hline Tcwf & $9.77 \mathrm{E}-10$ & $3.89 \mathrm{E}-3$ & 0.633 & 0.40 \\
\hline Ptnf & $1.00 \mathrm{E}-10$ & $2.80 \mathrm{E}-3$ & 0.633 & 0.11 \\
\hline Tswf & $2.51 \mathrm{E}-11$ & $3.16 \mathrm{E}-4$ & 0.633 & 0.30 \\
\hline Chnf & $3.70 \mathrm{E}-13$ & $2.30 \mathrm{E}-3$ & 0.633 & 0.30 \\
\hline
\end{tabular}

NOTES: Parameters for layer chnf are not calibrated. The prior information is taken from DTN: LB0207REVUZPRP.001 (DIRS 159526). These data have been developed as documented in this model report and submitted under Output-DTN: LB02092DSSCFPR.002. 


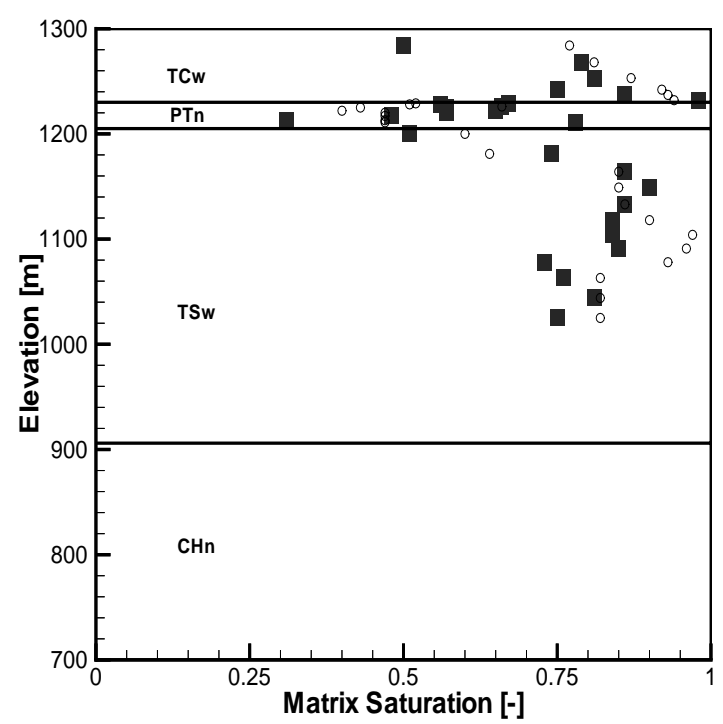

Output-DTN: LB02092DSSCFPR.001.

NOTE: $\quad$ Filled squares correspond to averaged core data and circles to simulation results.

Figure 6-8. Saturation Matches at USW UZ-7a Used in the Two-Dimensional Calibrated Fault Parameter Set for the Base-Case Infiltration Scenario

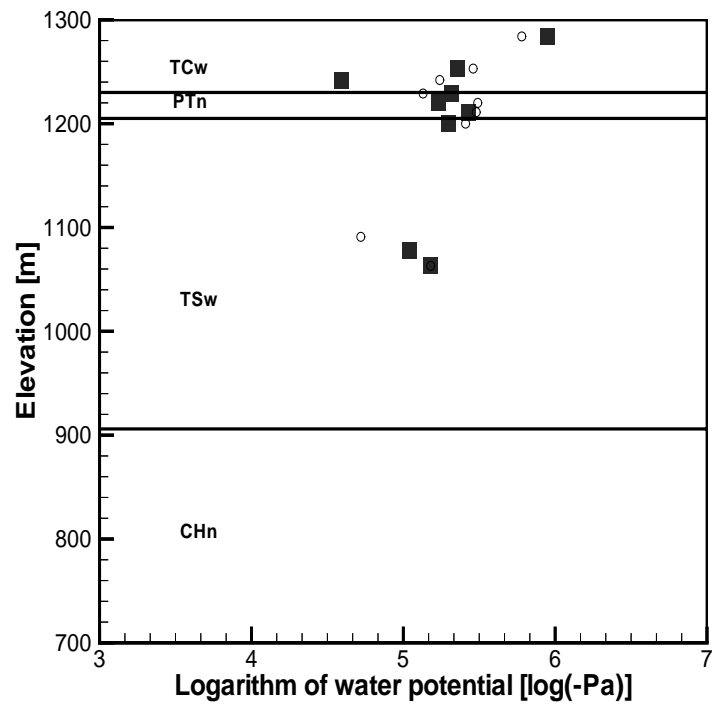

Output-DTN: LB02092DSSCFPR.001.

NOTE: $\quad$ Filled squares correspond to data and circles to simulation results.

Figure 6-9. Water-Potential Matches at USW UZ-7a Used in the Two-Dimensional Calibrated Fault Parameter Set for the Base-Case Infiltration Scenario 


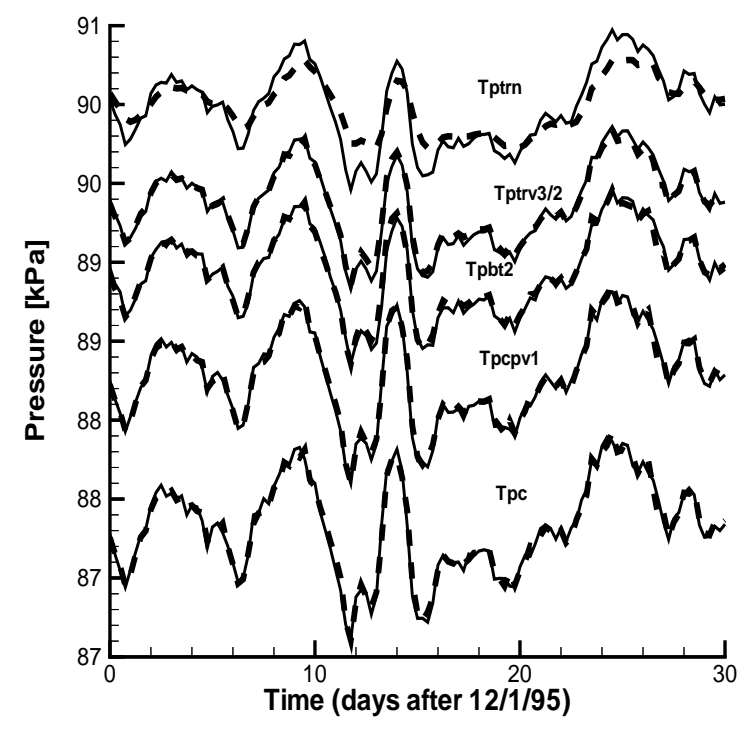

Output-DTN: LB02092DSSCFPR.001.

NOTE: Solid lines correspond to the interpolated raw data and dashed lines to simulation results.

Figure 6-10. Pneumatic Pressure Matches at USW UZ-7a Used in the Two-Dimensional Calibrated Fault Parameter Set for the Base-Case Infiltration Scenario

\subsection{DISCUSSION OF PARAMETER UNCERTAINTY}

This section discusses sources and quantification of uncertainties for the calibrated parameters.

\subsubsection{Sources of Parameter Uncertainty}

A major source of parameter uncertainty is the conceptual model. As previously discussed, the parameter calibration is based on the conceptual model for UZ flow and transport documented in Conceptual Model and Numerical Approaches for Unsaturated Zone Flow and Transport (BSC 2004 [DIRS 170035]). Some aspects of the conceptual model that are important for parameter calibration are presented in Section 6.1. Model simplifications used in this study will also contribute to parameter uncertainty. For example, one-dimensional models are used for calibrating drift-scale and mountain-scale property sets. As a result, lateral flow behavior in the UZ may not be captured by property sets determined from one-dimensional models.

Infiltration-rate uncertainty also contributes to parameter uncertainty, because flow processes in the UZ are largely determined by top boundary conditions. Using the three infiltration scenarios for the parameter calibration documented in this study captures this uncertainty.

In addition, scale effects are a well-known source of parameter uncertainty. This is especially true for determination of the UZ models parameters. For example, matrix parameters are measured in the UZ at core scale on the order of several centimeters, whereas in the UZ flow and transport model, numerical gridblocks are on the order of a few meters to hundreds of meters. Scale-dependence of hydrologic parameters has been widely recognized in the scientific 
community (e.g., Neuman 1994 [DIRS 105731]). This is also clearly indicated by the differences between calibrated and uncalibrated matrix properties, as shown in Table 6-15. Although upscaling is partially considered in developing uncalibrated matrix properties (DTN: LB0207REVUZPRP.002 [DIRS 159672]), the calibrated matrix permeabilities are on average higher than uncalibrated ones for the three infiltration scenarios (Table 6-15). The general increase in permeability with scale is consistent with findings reported in the literature (e.g., Neuman 1994 [DIRS 105731]). Consequently, the calibrated matrix $\alpha$ values are on average also larger than uncalibrated ones. A larger permeability is generally expected to correspond to a larger van Genuchten $\alpha$. For example, fracture $\alpha$ values are significantly larger than matrix values. Scale-dependent behavior for fracture permeability is considered in this study by developing parameter sets at two different scales (mountain scale and drift scale). Calculation of the absolute residuals in Table 6-15 is documented in the scientific notebook by Wang (2002 [DIRS 160401], SN-LBNL-SCI-215-V1, p. 90). The residuals for each layer (uncalibrated $\log x$ minus calibrated $\log x$, where $x=\mathrm{k}_{M}$ or $\alpha_{M}$ ) from Output-DTN: LB02091DSSCP3I.001 (files MGas_Ci.out, LGa_Ci.out, and UGas_Ci.out) were averaged to calculate the values shown in Table 6-15. It should be emphasized that because of the difference between measurement scale and modeling scale, uncalibrated properties are not directly measured, but are in fact estimated values for the scales used in the UZ models. As a result, residuals cannot be used to evaluate the uncertainty as to the true parameter value, although they may be used to bound this uncertainty (as will be discussed below).

Table 6-15. Average Residual for Calibrated Matrix Properties for Three Infiltration Scenarios

\begin{tabular}{|l|l|l|}
\hline & Residual for $\log (\mathbf{k M})$ & Residual for $\log (\alpha \mathbf{M})$ \\
\hline Base-case & -0.37 & -0.25 \\
\hline Upper bound & -0.65 & -0.17 \\
\hline Lower bound & -0.17 & -0.06 \\
\hline
\end{tabular}

Source: Wang (2002 [DIRS 160401], SN-LBNL-SCI-215-V1, p. 90).

NOTE: $\quad$ The residual refers to an uncalibrated matrix property minus the corresponding calibrated property.

Calibrated properties are nonunique because of data limitation. For example, in drift-scale parameter calibration, 78 parameters are calibrated to 300 data points. This is therefore a poorly constrained problem. Further complicating the calibrating process, many of the parameters are cross-correlated; that is, variations in two or more parameters may have the same effect on predicted system response. Because the problem is poorly constrained, there is no well-defined global minimum in the objective function. Rather, there are likely to be many equivalent local minima. With respect to moisture and water-potential data, any of these minima provide an equally good parameter set. To address this issue, this study uses uncalibrated parameters as initial guesses and prior information in most inversions.

Table 6-16 shows the average absolute residual for calibrated matrix properties for three infiltration scenarios. 
Table 6-16. Average Absolute Residual for Calibrated Matrix Properties for Three Infiltration Scenarios

\begin{tabular}{|l|l|l|l|}
\hline & $\begin{array}{c}\text { Absolute Residual } \\
\text { for } \log (\mathrm{kM})\end{array}$ & $\begin{array}{c}\text { Absolute Residual for } \\
\log (\alpha \mathrm{M})\end{array}$ & $\begin{array}{c}\text { Absolute Residual } \\
\text { for } \log (\alpha \mathrm{F})\end{array}$ \\
\hline Base case & 0.75 & 0.44 & 0.41 \\
\hline Upper bound & 0.81 & 0.38 & 0.19 \\
\hline Lower bound & 0.74 & 0.43 & 0.28 \\
\hline
\end{tabular}

Source: Wang 2002 [DIRS 160401], SN-LBNL-SCI-215-V1, p. 90.

NOTE: The absolute residual refers to an absolute difference between uncalibrated matrix property and the corresponding calibrated property.

The absolute value of the residual is always positive, and therefore the average absolute residual is greater than the average residual as shown in Table 6-15. The average standard deviation of $\log \left(\mathrm{k}_{\mathrm{M}}\right)$ for uncalibrated matrix property sets (prior information) (Table 4-3) is 1.61. The standard deviation for $\log \left(\alpha_{M}\right)$ is not available from Table 4-3. Note that the standard errors for $\log \left(\alpha_{M}\right)$ in Table 4-3 are determined from curve fitting (DTN: LB0207REVUZPRP.002 [DIRS 159672]) and cannot be directly related to the corresponding standard deviations. Wang and Narasimhan (1993 [DIRS 106793], pp. 374 to 376) reported that permeability could be approximately related to $\alpha$ by

$$
k \propto \alpha^{2}
$$

This yields

$$
\sigma_{\log (\alpha)}=\frac{1}{2} \sigma_{\log (k)}
$$

where $\sigma$ refers to standard deviation. Based on Equation 6-11, $\log (\alpha)$ can be expressed as $\log (\mathrm{k}) / 2$ plus a constant (for a given model layer), resulting in Equation 6-12. For each model layer, a standard deviation for $\log \left(\alpha_{M}\right)$ can be estimated from the corresponding standard deviation of $\log \left(\mathrm{k}_{\mathrm{M}}\right)$ based on Equations 6-11 and 6-12. Average standard deviation (calculated by hand) for $\log \left(\alpha_{M}\right)$ for the uncalibrated matrix property set (Table 4-3) is 0.81 . The calculation of the residuals given in Table 6-16 and the standard deviations is documented in the scientific notebook by Wang (2002 [DIRS 160401], SN-LBNL-SCI-215-V1, pp. 90 to 92). The absolute residual values (Table 6-16) for the matrix properties are smaller than the corresponding average standard deviations. The residual values for $\log \left(\alpha_{F}\right)$ are also given in Table 6-16. They are close to or smaller than the average standard deviation of $\log \left(\alpha_{\mathrm{F}}\right)(0.30)$ determined from uncalibrated fracture property sets (Table 4-4) using Equation 6-12. All these support the appropriateness of the calibrated property sets documented in this report, which results from the use of uncalibrated rock properties as initial guesses and prior information in most inversions.

\subsubsection{Quantification of Parameter Uncertainty}

Quantifiable uncertainties are difficult to establish for the estimated parameter sets. In principle, these uncertainties could be evaluated either by Monte Carlo simulation or by linear error analysis, both of which are capabilities of iTOUGH2 V5.0 (LBNL 2002 [DIRS 160106]). 
Because of the large numbers of parameters and the high nonlinearity of the unsaturated flow process, the linear error analysis is not reliable (Finsterle 1999 [DIRS 104367]). The linear uncertainty analysis quantifies the parameter uncertainty by linearization (based on its first-order Taylor series expansion). This method is a powerful tool only for problems that have sufficiently small parameter uncertainties (e.g., a small number of parameters and a large number of data points for model calibration) or are linear (Finsterle 1999 [DIRS 104367], Section 2.8.7). However, the problem under consideration is characterized by a large number of parameters (on the same order of data point number for drift-scale parameter calibrations) and high nonlinearity. The criteria for the linear uncertainty analysis to apply are not met for the problem under consideration. The sensitivity matrix evaluated at the solution and the resulting covariance matrix provide insight into the correlation structure of the estimated parameters, revealing strong interdependencies. This information is used to support the qualitative statements regarding estimation uncertainty. It also indicates that probabilistic statements about the confidence region around the best-estimate parameter set cannot be based on a linear uncertainty analysis, which assumes linearity and normality within that region (as previously discussed). Such statements would have no defensible basis. Evaluating the correct shape and extent of the confidence region would require mapping the objective function in the n-dimensional parameter space and determining the hypersurface corresponding to the appropriate confidence level. Such an approach is outlined (for two parameters only) in the report by Finsterle and Pruess (1995 [DIRS 161750]). Alternatively, Monte Carlo type methods (such as the bootstrap method) would be required. (The large number of parameters make uncertainty analysis by Monte Carlo simulation prohibitively time consuming.) Based on these considerations, the uncertainty information from prior information is believed to be more reliable (and practical) for determining uncertainties for the calibrated property sets.

In this study, parameter uncertainties (standard deviations) for the uncalibrated parameter sets (Tables 4-2 and 4-3) are directly used for the calibrated parameter sets, because these uncertainties are determined from measurements. The parameter uncertainty of the uncalibrated property sets are largely a result of small-scale spatial variability. Because the degree of spatial variability decreases with scale (subgrid scale [or high frequency] spatial variability is removed at a large scale), this is likely to provide upper limits of uncertainty on calibrated parameters for the given conceptual model and infiltration rates.

Table 6-17 gives the parameter uncertainties for the calibrated parameters. They are applied to both drift-scale and mountain-scale property sets because both scales are larger than those on which uncalibrated parameters were measured. Uncertainties for $\log \left(\mathrm{k}_{\mathrm{M}}\right)$, and $\log \left(\mathrm{k}_{\mathrm{F}}\right)$ are taken directly from Tables 4-2 and 4-3. When a $\log \left(\mathrm{k}_{\mathrm{F}}\right)$ uncertainty is not available in Table 4-4 for a model layer, the largest value among the uncertainties (standard deviations) in all the layers for which uncertainty values are available is used. Uncertainties for $\log \left(\alpha_{M}\right)$ and $\log \left(\alpha_{F}\right)$ are approximated from uncertainty values of the corresponding permeability, based on Equation 6-12. Uncertainties of the active-fracture-model parameter $\gamma$ are difficult to obtain here and have not been calculated because prior information for $\gamma$ is not available. Further discussions of the uncertainties of $\gamma$ are provided in other model reports describing analyses of hydrological properties data and UZ flow and transport models (BSC 2004 [DIRS 169861], Section 6.8 and BSC 2004 [DIRS 170041]). No information is available for quantifying uncertainties for $m_{F}$ that are not calibrated parameters (Section 6.3.2). 
Table 6-17 also shows estimated uncertainties for calibrated fault properties taken from Table 4-4. Because fault properties are calibrated with limited data points (Section 6.3.4), the parameter uncertainties are expected to be relatively large. For each parameter type, the largest parameter uncertainty within the corresponding hydrogeologic unit for the nonfault property set is used as the corresponding fault parameter uncertainty. Note that the fault property set does not include matrix parameters. Because complete measured data were available only for the Borehole UZ-7a, which crosses the Ghost Dance fault, the calibrated fault properties of the Ghost Dance fault are considered as representative of all other faults in the UZ flow model. These considerations are expected to be supported by the large uncertainties of the fault parameters.

Finally, it should be indicated that the propagation of uncertainty in model calibration is addressed in this study. The uncertainty data for measurements are used as inputs into inversions (Equation 6-1). The uncertainty in boundary conditions is reflected by developing property sets for different infiltration scenarios. The uncertainty in prior information has been used for characterizing uncertainties for calibrated properties.

Table 6-17. Uncertainties of Calibrated Parameters

\begin{tabular}{|c|c|c|c|c|}
\hline \multirow[b]{2}{*}{ Model layer } & \multicolumn{2}{|c|}{ Matrix Property } & \multicolumn{2}{|c|}{ Fracture Property } \\
\hline & $\log \left(k_{M}\right)$ & $\log \left(\alpha_{M}\right)$ & $\log \left(k_{F}\right)$ & $\log \left(\alpha_{F}\right)$ \\
\hline tcw11 & 0.47 & 0.24 & 1.15 & 0.58 \\
\hline tcw12 & 2.74 & 1.37 & 0.78 & 0.39 \\
\hline tcw13 & 2.38 & 1.19 & 1.15 & 0.58 \\
\hline ptn21 & 2.05 & 1.03 & 0.88 & 0.44 \\
\hline ptn22 & 1.41 & 0.71 & 0.20 & 0.10 \\
\hline ptn23 & 0.64 & 0.32 & 0.20 & 0.10 \\
\hline ptn24 & 1.09 & 0.55 & 1.15 & 0.58 \\
\hline ptn25 & 0.39 & 0.20 & 0.10 & 0.05 \\
\hline ptn26 & 1.12 & 0.56 & 1.15 & 0.58 \\
\hline tsw31 & 3.02 & 1.51 & 1.15 & 0.58 \\
\hline tsw32 & 0.94 & 0.47 & 0.66 & 0.33 \\
\hline tsw33 & 1.61 & 0.81 & 0.61 & 0.31 \\
\hline tsw34 & 0.97 & 0.49 & 0.47 & 0.24 \\
\hline tsw35 & 1.65 & 0.83 & 0.75 & 0.38 \\
\hline tsw36 & 3.67 & 1.84 & 0.54 & 0.27 \\
\hline tsw37 & 3.67 & 1.84 & 0.28 & 0.14 \\
\hline tsw38 & 1.57 & 0.79 & 1.15 & 0.58 \\
\hline tswz (zeolitic portion of tsw39) & 2.74 & 1.37 & 1.15 & 0.58 \\
\hline tswv (vitric portion of tsw39) & 1.38 & 0.69 & $a$ & $\mathrm{a}$ \\
\hline $\operatorname{ch} 1 z$ & 2.74 & 1.37 & 1.15 & 0.58 \\
\hline ch1v & 1.11 & 0.56 & $\mathrm{a}$ & $\mathrm{a}$ \\
\hline $\operatorname{ch} 2 v$ & 1.62 & 0.81 & $\mathrm{a}$ & $\mathrm{a}$ \\
\hline $\operatorname{ch} 3 \mathrm{v}$ & 1.62 & 0.81 & $\mathrm{a}$ & a \\
\hline ch4v & 1.62 & 0.81 & $\mathrm{a}$ & $\mathrm{a}$ \\
\hline ch5v & 1.62 & 0.81 & $\mathrm{a}$ & $\mathrm{a}$ \\
\hline ch6v & 1.11 & 0.56 & $a$ & $\mathrm{a}$ \\
\hline $\operatorname{ch} 2 z$ & 0.91 & 0.46 & 1.15 & 0.58 \\
\hline $\operatorname{ch} 3 z$ & 0.91 & 0.46 & 1.15 & 0.58 \\
\hline
\end{tabular}


Table 6-17. Uncertainties of Calibrated Parameters (Continued)

\begin{tabular}{|c|c|c|c|c|}
\hline \multirow[b]{2}{*}{ Model layer } & \multicolumn{2}{|c|}{ Matrix Property } & \multicolumn{2}{|c|}{ Fracture Property } \\
\hline & $\log \left(k_{M}\right)$ & $\log \left(\alpha_{M}\right)$ & $\log \left(k_{F}\right)$ & $\log \left(\alpha_{F}\right)$ \\
\hline $\operatorname{ch} 4 z$ & 0.91 & 0.46 & 1.15 & 0.58 \\
\hline $\operatorname{ch} 5 z$ & 0.91 & 0.46 & 1.15 & 0.58 \\
\hline $\operatorname{ch} 6 z$ & 2.05 & 1.03 & 1.15 & 0.58 \\
\hline pp4 & 2.74 & 1.37 & 1.15 & 0.58 \\
\hline pp3 & 0.75 & 0.38 & 1.15 & 0.58 \\
\hline pp2 & 1.18 & 0.59 & 1.15 & 0.58 \\
\hline pp1 & 1.52 & 0.76 & 1.15 & 0.58 \\
\hline bf3 & 1.64 & 0.82 & 1.15 & 0.58 \\
\hline bf2 & 1.52 & 0.76 & 1.15 & 0.58 \\
\hline Tcwf & b & b & 1.15 & 0.58 \\
\hline Ptnf & $\mathrm{b}$ & $\mathrm{b}$ & 1.15 & 0.58 \\
\hline Tswf & $\mathrm{b}$ & $\mathrm{b}$ & 1.15 & 0.58 \\
\hline Chnf & $\mathrm{b}$ & $\mathrm{b}$ & 1.15 & 0.58 \\
\hline
\end{tabular}

Input DTNs: LB0207REVUZPRP.002 (DIRS 159672); LB0205REVUZPRP.001 (DIRS 159525).

Output-DTN: LB0210AMRU0035.002.

NOTE: These uncertainty values are taken or developed from Tables 4-2 and 4-4.

a Calibrated properties model conceptual model does not include fractures in these model layers (Section 5).

b Fault property set does not include matrix properties. 


\section{VALIDATION}

Validation activities for the calibrated properties model are carried out based on Technical Work Plan for: Performance Assessment Unsaturated Zone (BSC 2004 [DIRS 167969], Attachment I, Section I-1-1-1) and Technical Work Plan (TWP) for: Unsaturated Zone Flow Analysis and Model Report Integration (BSC 2004 [DIRS 169654], Section 2.2).

The relative importance of UZ flow to the potential performance of the repository system has been evaluated based on sensitivity analyses as documented in Risk Information to Support Prioritization of Performance Assessment Models (BSC 2003 [DIRS 168796]). The TSPA sensitivity studies do not show strong sensitivity of the estimate of mean annual dose to the amount of water contacting the waste or the flow carrying radionuclides (BSC 2003 [DIRS 168796], Sections 3.3.1 and 4.2). Consequently, the lowest level of validation (Level I) for the TSPA UZ flow models was considered appropriate (BSC 2003 [DIRS 168796], Section 4.2 ), requiring a demonstration that basic physical principles are appropriately represented.

The TWP provides guidance for Level I validation for this model report. Level I validation shall include, at a minimum, discussion of documented decisions and activities that are implemented during the model development process that build confidence and verify that a reasonable, credible, technical approach using scientific and engineering principles was taken to (a) evaluate and select input parameters and/or data; (b) formulate defensible assumptions and simplifications; (c) ensure consistency with physical principles, such as conservation of mass, energy, and momemntum; (d) represent important future state (aleatoric), parameter, and alternative model uncertainties; (e) ensure simulation conditions have been set up to span the range of intended use and avoid inconsistent outputs; and (f) ensure that model predictions (performance parameters) adequately represent the range of possible outcomes, consistent with important uncertainties (AP-2.27Q/Rev. 1/ICN 3, Attachment 3). Additionally, for postmodel development Level I validation per AP-SIII.10Q, a single method described in paragraph 5.3.2c of AP-SIII.10Q is chosen, consistent with a model of limited importance to the mean annual dose.

\subsection{CONFIDENCE BUILDING DURING MODEL DEVELOPMENT TO ESTABLISH SCIENTIFIC BASIS AND ACCURACY FOR INTENDED USE}

For Level I validation, Section I-1-1-1 of TWP-NBS-HS-000003, Rev 02 (BSC 2004 [DIRS 167969]) specifies the following steps for Confidence Building During Model Development: The development of the model should be documented in accordance with the requirements of Section 5.3.2(b) of AP-SIII.10Q. The development of the Calibrated Properties Model has been conducted according to these criteria, as follows:

1. Discussion and justification of the use of input parameters and/or input data [AP-SIII.10Q 5.3.2(b) (1) and AP-2.27Q Attachment 3 Level I (a)].

The types and quality of the data selected as input builds confidence in the model. The inputs to the calibrated properties model have all been obtained from the TDMS, a controlled source. Discussions about selection of input data and design parameters are given in Section 4.1. Information about the sources of the direct inputs is summarized in Table 4-1. Discussions of data sources, uncertainties, and usage are provided in Sections 
6.2 and 6.34. Model assumptions and their justifications are given in Section 5. Thus, this requirement can be considered satisfied.

2. Discussion and justification of the approach for model calibration [AP-SIII.10Q 5.3.2(b) (2)].

Several factors are important for successful model calibration. Section 6.3 provides detailed discussions and justifications with regards to selection of initial guesses (prior information), the objective function minimization, data weighting, and selection of parameters to be calibrated. Thus, this requirement can also be considered satisfied.

3. Discussion and evaluation of the impact of the aggregate and input uncertainties on the model results, and uncertainty of calibrated properties [AP-SIII.10Q 5.3.2(b) (3)].

The major sources of calibrated parameter uncertainties include the conceptual model of UZ flow, infiltration-rate uncertainty, scale effects, and limitation of input data. The impact of these sources of uncertainties on the calibrated properties are discussed in Section 6.4.1. Quantification and propagation of uncertainties are discussed in detail in Section 6.4.2. Thus, this requirement can also be considered satisfied.

4. Formulation of defensible assumptions and simplifications. [AP-2.27Q Attachment 3 Level I (b)]

Assumptions that are basic to the UZ models of Yucca Mountain are summarized in Section 6 and fully documented in Conceptual Model and Numerical Approaches for Unsaturated Zone Flow and Transport (BSC 2004 [DIRS 170035]). Specific assumptions used in the development of the calibrated properties model are described and fully justified in Section 5. Thus, this requirement can also be considered satisfied.

5. Consistency with physical principles, such as conservation of mass, energy, and momentum. [AP-2.27Q Attachment 3 Level I (c)]

The core concepts and mathematical formulations of the calibrated properties model are based on UZ models as described in Conceptual and Numerical Approaches for Unsaturated Zone Flow and Transport (BSC 2004 [DIRS 170035]). These concepts and formulations are consistent with physical principles. The aspects of the conceptual model and numerical schemes that are most relevant to this study as well as alternative models and numerical approaches are highlighted in Section 6.1.4. The selection of the iTOUGH2 Code for parameter calibration in this study, and the main equations solved by iTOUGH2 for forward and inverse modeling are described in Section 6.1.5. Thus, this requirement can also be considered satisfied.

\subsection{MODEL VALIDATION AFTER MODEL DEVELOPMENT TO SUPPORT THE SCIENTIFIC BASIS OF THE MODEL}

For confidence building after model development, Section I-1-1-1 of TWP-NBS-HS-000003, Rev 02 (BSC 2004 [DIRS 167969]), "Post-Development validation activities") imposes the that one following requirements for model validation: 
1. AP-SIII.10Q, Section 5.3.2(c), Method 1: Corroboration of model results with Experimental data.

Comparison of model results with experimental data is the main method of validation for the Calibrated Properties Model. Section 7.2 below explains the respective validation and modeling activities in detail, and discusses explicitly how the criteria for this validation method, as defined in Section I-1-1-1 of TWP-NBS-HS-000003, Rev 02 (BSC 2004 [DIRS 167969]) have been met.

2. AP-SIII.10Q, Section 5.3.2(c), Method 5: Independent Technical Review.

The model validation section in this report has been reviewed by an Independent Technical Reviewer.

3. AP-SIII.10Q, Section 5.3.2(d), Technical review through publication in a refereed professional journal.

Previous model calibration efforts using essentially the same methodology as used in this model report have undergone technical review have been published in a peer reviewed technical journal and peer-reviewed book:

- "Calibrating Hydrogeologic Parameters for the 3-D Site-Scale Unsaturated Zone Model of Yucca Mountain, Nevada." Journal of Contaminant Hydrology, 38, (1-3), 25-46. (Bandurraga and Bodvarsson 1999 [DIRS 103949]);

- "Parameterization and Upscaling in Modeling Flow and Transport in the Unsaturated Zone of Yucca Mountain." Chapter 11 of Conceptual Models of Flow and Transport in the Fractured Vadose Zone. Washington, D.C.: National Academy Press. (Bodvarsson et al. 2001 [DIRS 160133]).

In this postdevelopment validation activity, the calibrated properties model predictions are compared to observed saturation, water potential, and pneumatic pressure data outside of calibration periods. The model will be accepted as valid for its purpose if all three of the following criteria are met (BSC 2004 [DIRS 167969], Attachment I, Section I-1-1-1 and BSC 2004 [DIRS 169654], Section 2.2): (1) for saturation data, the root-mean-square prediction errors (i.e., the difference between the validation data and the data predicted by the calibrated models) shall not exceed the greater of: 0.1 or three times the root-mean-square calibration errors (i.e., the difference between the data used in calibration and the simulation results from calibrated properties model); (2) for water-potential data, the root-mean-square prediction errors (i.e., the differences between the validation data and the data predicted by the calibrated models) shall not exceed the greater of one order of magnitude of the water-potential data or three times the root-mean-square calibration errors (i.e., the difference between the validation data and the data predicted by the calibrated models); (3) for pneumatic pressure data, the root mean square prediction errors (i.e., the differences between the validation data and the data predicted by the calibrated models) shall not exceed the greater of 10 percent of the magnitude of the measured pneumatic pressure or three times the root-mean-square calibration errors. Note that allowed prediction errors are larger than calibration errors, considering that prediction errors are obtained using data that are not used for calibration. 
The calibrated hydrological properties are obtained by matching the observed data (saturation, in situ water potential, and dynamic pneumatic pressure data) using the iTOUGH2 V5.0 (LBNL 2002 [DIRS 160106]), which minimizes the objective function (a measure of the misfit between the iTOUGH2 V5.0 (LBNL 2002 [DIRS 160106]) model output and the observed data) by automatically adjusting hydrological property values. For validation purposes, we use root-mean-square error (RMSE) between the model output and the data to describe the misfit between the iTOUGH2 V5.0 (LBNL 2002 [DIRS 160106]) model (the numerical model of UZ) and the real system (the UZ at Yucca Mountain). The corresponding RMSE is called the calibration residual if the observed data were used in inversion (calibration activities). The calibration residual mainly reflects the errors in the conceptual model and the numerical schemes with respect to the real system. Measurement errors can also contribute to the calibration error. In all validation activities, mountain-scale calibrated property sets are used. For each infiltration scenario, a mountain-scale property set and the corresponding drift-scale property set give essentially the same matrix-saturation and water-potential distributions (Section 6.3.3). The observed raw pneumatic pressure data from the TDMS were taken at irregular time intervals. Therefore, iTOUGH2 V5.0 (LBNL 2002 [DIRS 160106]) automatically interpolates the data to obtain a data set suitable for comparisons with simulation results. The averaged core saturation data at the gridblock scale (Section 6.2.2) are used in a simulation. These interpolated and averaged data are used in this section for calculating RMSE.

The validation approach used in this study involves predicting the calibrated properties model's responses to present-day environments and comparing these responses to the available observed data not used in inversion (calibration activities). The prediction error (i.e., the corresponding RMSE between the model output and the observed data) is calculated to describe the accuracy of the calibrated model. The validation is performed using three data sets: saturation data, in situ water potential data, and the dynamic pneumatic pressure data. The validation activities are also documented in scientific notebooks (Wang 2002 [DIRS 160401], SN-LBNL-SCI-229-V1, pp. 9 to 21; SN-LBNL-SCI-215-V1, pp. 93 to 98). The Excel files, verification.xls and VGas.xls, are described in Appendix A. Data for model calibration and validation are selected in such a manner that adequate qualified data (especially data from deep boreholes) are used for calibration to obtain reliable calibrated property sets, and data that are not used for calibration and still contain important information about the UZ under ambient conditions are employed for validation to gain confidence of the calibrated properties model.

\subsubsection{Validation with Observed Saturation Data}

Table 6-6 lists boreholes from which matrix saturation data are used for calibration. The saturation data observed in the following boreholes are used in validation: USW SD-12, USW UZ-N32, USW UZ-N38, USW UZ-N54, USW UZ-N55, USW UZ-N58, and USW UZ-N59. The calculation of values for RMSE is presented in Verification.xls in Output DTN: LB0302AMRU0035.001 (See Appendix A).

Validation results are summarized in Table 7-1. In all three infiltration scenarios, the prediction errors are smaller than the corresponding calibration residuals. On average, the prediction error is 84 percent of the calibration residuals and much smaller than the validation criteria. Thus, the calibrated properties model can be accepted as valid in terms of predicting saturation. 
Table 7-1. Validation in Terms of Saturation for Three Infiltration Scenarios

\begin{tabular}{|c|c|c|c|}
\hline Infiltration Scenario & Lower Bound & Base case & Upper Bound \\
\hline Calibration residual (RMSE) $^{a}$ & 0.1514 & 0.1343 & 0.1456 \\
\hline Prediction error (RMSE) ${ }^{a}$ & 0.1314 & 0.1094 & 0.1208 \\
\hline Validation Criteria $^{b}$ & $<0.4542$ & $<0.4029$ & $<0.4368$ \\
\hline Meet Criteria & Yes & Yes & Yes \\
\hline
\end{tabular}

\subsubsection{Validation with Observed In Situ Water Potential Data}

The in situ water potential data observed in the following boreholes were used in calibration: USW NRG-6, UE25 UZ\#4, and USW SD-12 (Table 6-6). The in situ water potential data observed in USW NRG-7a are used in validation. The calculation of values for RMSE is presented in Verification.xls in Output-DTN: LB0302AMRU0035.001 (see Appendix A).

These validation results are summarized in Table 7-2. In all three infiltration scenarios, the prediction errors are slightly larger than the corresponding calibration residual, but much smaller than the validation criteria, which are three times the calibration error. On average, the prediction error is 111 percent of the calibration residual. The validation criteria are met, and thus the calibrated properties model can be accepted as valid in terms of predicting water potential.

Table 7-2. Validation in Terms of Water Potential for Three Infiltration Scenarios

\begin{tabular}{|c|c|c|c|}
\hline Infiltration scenario & Lower bound & Base case & Upper bound \\
\hline Calibration residual (RMSE) $^{\mathrm{a}}$ & 0.7181 & 0.4865 & 0.4402 \\
\hline Prediction error (RMSE) $)^{a}$ & 0.7250 & 0.4984 & 0.5736 \\
\hline Validation Criteria $^{b}$ & $<2.1543$ & $<1.4595$ & $<1.3206$ \\
\hline Meet Criteria & Yes & Yes & Yes \\
\hline
\end{tabular}

\subsubsection{Validation with the Dynamic Pneumatic Pressure Data}

The observed dynamic pneumatic pressure data in boreholes were collected from several time periods. Their usage for calibration and validation is summarized in Table 7-3. The calculation of values for RMSE is presented in VGas.xls in Output-DTN: LB0302AMRU0035.001 (see Appendix A). 
Table 7-3. Usage of the Observed Dynamic Pneumatic Pressure Data

\begin{tabular}{|c|l|l|l|l|l|}
\hline \multirow{2}{*}{ Borehole } & \multicolumn{1}{|c|}{ Data Tracking Number } & \multicolumn{2}{c|}{ Calibration Period } & \multicolumn{2}{c|}{ Prediction Period } \\
\cline { 3 - 6 } & \multicolumn{1}{|c|}{ Start } & End & \multicolumn{1}{c|}{ Start } & \multicolumn{1}{c|}{ End } \\
\hline USW NRG-7a & $\begin{array}{l}\text { GS950208312232.003 } \\
\text { (DIRS 105572) } \\
\text { GS951108312232.008 } \\
\text { (DIRS 106756) } \\
\text { LB991091233129.001 } \\
\text { (DIRS 125868) }\end{array}$ & $03 / 27 / 95$ & $04 / 26 / 95$ & $04 / 26 / 95$ & $05 / 26 / 95$ \\
\hline USW SD-12 & $\begin{array}{l}\text { GS960308312232.001 } \\
\text { (DIRS 105573) } \\
\text { LB991091233129.001 } \\
\text { (DIRS 125868) }\end{array}$ & $12 / 01 / 95$ & $12 / 31 / 95$ & $12 / 31 / 95$ & $01 / 30 / 96$ \\
\hline USW SD-7 & $\begin{array}{l}\text { GS960908312264.004 } \\
\text { (DIRS 106784) } \\
\text { LB991091233129.001 } \\
\text { (DIRS 125868) }\end{array}$ & $04 / 05 / 96$ & $05 / 05 / 96$ & $05 / 05 / 96$ & $06 / 04 / 96$ \\
\hline USW NRG-6 & $\begin{array}{l}\text { GS950208312232.003 } \\
\text { (DIRS 105572) } \\
\text { GS951108312232.008 } \\
\text { (DIRS 106756) } \\
\text { LB991091233129.001 } \\
\text { (DIRS 125868) }\end{array}$ & Not used & Not used & $03 / 27 / 95$ & $04 / 26 / 95$ \\
\hline
\end{tabular}

NOTES: Only 25 days of data available for the sensor at Tpcpln of USW NRG-6, starting at 04/01/95. USW NRG5 has been excluded in validation because data are not available beyond the calibration period.

Validation results are summarized in Table 7-4. The files surfbc3d.prn from DTN: LB02103DPNEUSM.001 (DIRS 160250) is used as top boundary for gas pressure in the validation simulations. In all three infiltration scenarios, the prediction errors are slightly larger than the corresponding calibration residuals, but much smaller than the validation criteria, which are three times the calibration residual. On average, the prediction error is 149 percent of the calibration residual. The validation criteria are met. Thus, the calibrated properties model can be accepted as valid in terms of predicting dynamic pneumatic pressure.

Table 7-4. Validation in Terms of Pneumatic Data for Three Infiltration Scenarios

\begin{tabular}{|c|c|c|c|}
\hline Infiltration Scenario & Lower Bound & Base Case & Upper Bound \\
\hline Calibration residual (RMSE) $^{\mathrm{a}}$ & 0.0832 & 0.0783 & 0.0870 \\
\hline Prediction error (RMSE) ${ }^{\mathrm{a}}$ & 0.1131 & 0.1428 & 0.1124 \\
\hline Validation Criteria ${ }^{\mathrm{b}}$ & $<0.2496$ & $<0.2349$ & $<0.2610$ \\
\hline Meet Criteria & Yes & Yes & Yes \\
\hline
\end{tabular}

\subsection{VALIDATION SUMMARY}

The calibrated properties model was validated by confidence building activities during and after model development. During model development (Section 7.1), confidence was gained through discussion of input parameters and data; detailed discussions of the calibration approached used; and discussion of the sources and quantification of parameter uncertainties. After model 
development, confidence was gained through publication of some of results in peer reviewed journals (Bandurraga and Bodvarsson 1999 [DIRS 103949]; Bodvarsson et al. 2001 [DIRS 160133]) and through comparison of model predictions with measured data not used for model calibration (Section 7.2).

Based on these activities, the calibrated properties model is considered to be sufficiently accurate and adequate for the intended purpose and to the level of confidence required by the model's relative importance to the potential performance of the repository system. 


\section{INTENTIONALLY LEFT BLANK}




\section{CONCLUSIONS}

\subsection{PARAMETER CALIBRATIONS AND UNCERTAINTIES}

This report has documented the methodologies and the data used for developing rock property sets for three infiltration maps. Model calibration is necessary to obtain parameter values appropriate for the scale of the process being modeled. Although some hydrogeologic property data (prior information) are available, these data cannot be directly used to predict flow and transport processes because they were measured on scales smaller than those characterizing property distributions in models used for the prediction. Since model calibrations were done directly on the scales of interest, the upscaling issue was automatically considered. On the other hand, joint use of data and the prior information in inversions can further increase the reliability of the developed parameters compared with those for the prior information.

Rock parameter sets were developed for both the mountain and drift scales because of the scale-dependent behavior of fracture permeability. These parameter sets, except those for faults (which was determined using two-dimensional simulation), were determined using onedimensional simulations. If the parameters are directly used in three-dimensional simulations, they may not predict lateral flow or water perching in the UZ of Yucca Mountain. Therefore, the calibrated parameters developed in this model report were further adjusted in the downstream report using the mountain-scale UZ Flow Models and Submodels (BSC 2004 [DIRS 169861], Section 6.2). A brief summary of these additional parameter calibrations is given in Section 8.2.

As discussed in Section 6.4, uncertainties for these calibrated properties are difficult to accurately determine, because of the inaccuracy of simplified methods for this complex problem or the extremely large computational expense of more rigorous methods. One estimate of uncertainty that may be useful to investigators using these properties is the uncertainty used for the prior information. In most cases, the inversions did not change the properties very much with respect to the prior information.

The Output DTNs (including the input and output files for all runs) from this study are given in Section 9.4.

\subsection{ADDITIONAL THREE-DIMENSIONAL CALIBRATIONS}

This model report provides parameter sets of fractures and matrix rocks estimated through a series of one-dimensional model inversions, in which lateral flow, perched water, and capillary barrier effects cannot be simulated by the one-dimensional model. The model report UZ Flow Model and Submodels (BSC 2004 [DIRS 169861], Sections 6.2 and 6.4) documents further parameter adjustment to match field observation data. The adjusted parameters include fracturematrix properties of the top TSw layer, PTn unit, and perched water zones, and fracture permeabilities in the upper TSw layers.

The three-dimensional flow model calibration is conducted using the three sets of parameters of one-dimensional site-scale calibrated properties and two-dimensional site-scale calibrated fault properties developed in this model report as initial guesses; three present-day infiltration rates 
(mean, upper-bound, and lower-bound), and the geological model and numerical grid for calibration (BSC 2004 [DIRS 169855]).

The three-dimensional model calibration efforts were performed by starting with the three sets of parameters of one-dimensional site-scale calibrated properties developed in this model report in forward three-dimensional simulations. Then, model results were compared with the fieldobserved data of matrix liquid, along with water-potential data, perched-water elevations, and gas pressures. In general, some model parameters from one-dimensional calibrations are found to need adjustment in order to capture three-dimensional flow behavior or match observations at the mountain. The parameter modifications and the underlying justifications behind the modifications are listed below.

1. Modifications of the fracture $\alpha$ of the tsw 31 unit

Using the one-dimensional calibrated fracture-matrix properties for in threedimensional simulations predicted significant lateral flow in the tsw31. This is an artifact of the one-dimensional calibrations, because there is no evidence to that supports occurrence of lateral flow in the TSw units. Therefore, the one-dimensional inverted fracture $\alpha=1.597 \times 10^{-5} \mathrm{~Pa}^{-1}$ of the tsw31 unit was replaced by a larger value of $\alpha=1.000 \times 10^{-4} \mathrm{~Pa}^{-1}$ leading to a good match between observed data (BSC 2004 [DIRS 169861], Section 6.2.5) and three-dimensional models.

2. Modifications of the PTn fracture-matrix properties

The one-dimensional inverted fracture-matrix properties of the PTn were replaced by data sets developed in previous UZ Flow Model and Submodels (BSC 2004 [DIRS 169861], Tables I-1, I-2, and I-3), because the previous data sets provide better match of the model predictions with observed liquid saturation, water potential data, and chloride data.

3. Perched-water calibrations

The perched water conceptual model was realized and carried out by modifying the three-dimensional UZ model grid files. Fracture-matrix properties of the perched layers/zones are calibrated based on the three-dimensional model calibrated values (BSC 2004 [DIRS 169861]). The active-fracture parameter, $\gamma$, is set to zero for all the perched zones (because the saturation is close to 1), causing the fracture-matrix interface-area factor to be equivalent to liquid saturation (Liu et al. 1998 [DIRS 105729]). The modified "fracture" properties are close to those of the matrix, so that fractures in water perching layers are effectively removed.

4. Modification of fracture permeability in the TSw unit

Pneumatic tests data were used along with the present-day, mean infiltration rate scenario for three-dimensional calibrations of fracture permeability for the TSw (BSC 2004 [DIRS 169861], Section 6.4). These adjustments provide large-scale fracture permeability for the UZ system, which are particularly useful for modeling 
studies of thermal loading, gas flow and transport of gaseous phase radionuclides for the site. The adjusted fracture permeabilities of $\mathrm{TSw}$ units are reduced by a factor of up to 15 from the one-dimensional inversion.

\subsection{HOW THE ACCEPTANCE CRITERIA ARE ADDRESSED}

The following information describes how this analysis addresses the acceptance criteria in the Yucca Mountain Review Plan (NRC 2003 [DIRS 163274], Section 2.2.1.3.6.3). Only those acceptance criteria that are applicable to this report (see Section 4.2) are discussed. In most cases, the applicable acceptance criteria are not addressed solely by this report; rather, the acceptance criteria are fully addressed when this report is considered in conjunction with other analysis and model reports that describe flow and transport in the saturated zone.

\section{Acceptance Criteria from Section 2.2.1.3.6, Flow Paths in the Unsaturated Zone}

\section{Acceptance Criterion 1, System Description and Model Integration Are Adequate.}

Subcriterion (1): Total system performance assessment adequately incorporates, or bounds, important design features, physical phenomena, and couplings, and uses consistent and appropriate assumptions throughout the flow paths in the unsaturated zone abstraction process. Couplings include thermal-hydrologic-mechanical-chemical effects as appropriate.

The model described in this report adequately incorporates physical phenomena related to UZ flow including the various mechanisms involved in fracture-matrix interaction, major faults, transient flow, and focused flow (discussed in Section 6.1.4). The model described in this report is used by UZ flow and transport models that support TSPA.

Subcriterion (2): The aspects of geology, hydrology, geochemistry, physical phenomena, and couplings that may affect flow paths in the unsaturated zone are adequately considered. Conditions and assumptions in the abstraction of flow paths in the unsaturated zone are readily identified and consistent with the body of data presented in the description.

An adequate and detailed discussion of water flow paths and the associated processes is presented in Section 6.1.4. This discussion includes consideration of effects of rock properties, infiltration, major faults, flow focusing and fracture-matrix interaction on the UZ flow paths.

Subcriterion (9): Guidance in NUREG-1297 (Altman et al. 1988 [DIRS 103597]) and NUREG-1298 (Altman et al. 1988 [DIRS 103750]), or other acceptable approaches for peer review and data qualification is followed.

This report was developed in accordance with the QARD, which commits to NUREGs 1297 and 1298. Moreover, compliance with the DOE procedures, which are designed to ensure compliance with the QARD, is verified by audits by QA and other oversight activities. Accordingly, the guidance in NUREGs 1297 and 1298 has been followed as appropriate. 


\section{Acceptance Criterion 2, Data are Sufficient for Model Justification.}

Subcriterion (1): Hydrological and thermal-hydrological-mechanical-chemical values used in the license application are adequately justified. Adequate descriptions of how the data were used, interpreted, and appropriately synthesized into the parameters are provided.

Sufficiency and applicability of input data used in this model report for parameter calibration are discussed in Section 6.2 (numerical grids, infiltration rates, matrixsaturation and water-potential data, pneumatic pressure data and rock-hydraulic-property data) and Section 6.3.4 (data of the fault zone). Adequate descriptions of data use and interpretation are provided throughout Section 6.

Subcriterion (2): The data on the geology, hydrology, and geochemistry of the unsaturated zone, are collected using acceptable techniques.

Collection of input data used in this model report was accomplished via acceptable techniques under the QARD. Table 1 in Section 4.1 provides a listing of sources of input data. Each of these source documents describe the techniques employed in collection of the data covered by the document.

Subcriterion (3): Estimates of deep-percolation flux rates constitute an upper bound, or are based on a technically defensible unsaturated zone flow model that reasonably represents the physical system. The flow model is calibrated, using site-specific hydrologic, geologic, and geochemical data. Deep-percolation flux is estimated, using the appropriate spatial and temporal variability of model parameters, and boundary conditions that consider climate-induced change in soil depths and vegetation.

The inputs from this model report into the unsaturated zone flow model are calibrated from site-specific data as noted in Section 4.1 (Data and Parameters), Section 6.2 (Model Inputs), and Section 6.3 (UZ Flow Model Parameter Calibration). The resulting output of this calibrated properties model document rock property sets for three infiltration maps that represent a good match with observed data.

Subcriterion (4): Appropriate thermal-hydrologic tests are designed and conducted, so that critical thermal-hydrologic processes can be observed, and values for relevant parameters estimated.

Hydrologic-property estimates from laboratory and field measurements provide initial estimates for model parameters (Section 6.3.1), from which, more accurate estimates are derived through the data inversion process.

Subcriterion (5): Sensitivity or uncertainty analyses are performed to assess data sufficiency, and verify the possible need for additional data.

The laboratory and field data and prior information (rock matrix data, water potential in the rock matrix, and pneumatic pressure) are weighted according to the uncertainty of their estimated value in the inversion process (Section 6.3.1).

Subcriterion (6): Accepted and well-documented procedures are used to construct and calibrate numerical models. 
Approved QA procedures identified in the TWP (BSC 2004 [DIRS 169654], Section 4) have been used to conduct and document the activities described in this model report. Calibration of the model was accomplished by the data inversion technique. Inverted data include saturation in the rock matrix, water potential in the rock matrix, and pneumatic pressure in the fractures. Hydrologic-property estimates from laboratory and field measurements, which provide initial estimates for model parameters, also are included as data in the inversion. The combination of the two types of information allows the model to reproduce the data as well as possible, while simultaneously estimating reasonable model parameters as discussed in Section 6.3.1.

Subcriterion (7): Reasonably complete process-level conceptual and mathematical models are used in the analyses. In particular: (i) mathematical models are provided that are consistent with conceptual models and site characteristics; and (ii) the robustness of results from different mathematical models is compared.

The validation process described in Section 7 provides verification that the calibrated properties model described in this report is consistent with site characteristics, is reasonably complete, and predicts the results of independent data (i.e., data not used in the calibration process) within reasonable bounds.

\section{Acceptance Criterion 3, Data Uncertainty is Characterized and Propagated Through the Model Abstraction.}

Subcriterion (1): Models use parameter values, assumed ranges, probability distributions, and bounding assumptions that are technically defensible, reasonably account for uncertainties and variabilities, and do not result in an under-representation of the risk estimate.

The model described in this report employs applicable Yucca Mountain borehole information and parameters (Section 4.1), bounding assumptions (Section 6.2.5), ranges and distributions (Sections 6.1- 6.4) that are technically defensible because the validation of the model (described in Section 7) accurately (within bounds) predicts site data. Parametric uncertainties are expected to be in line with the uncertainties in the prior information because, in most cases, the inversions did not change the properties very much with respect to the prior information (Section 8.1). Therefore, the output of this model is not expected to contribute to an under-representation of the risk estimate.

Subcriterion (4): The initial conditions, boundary conditions, and computational domain used in sensitivity analyses and/or similar analyses are consistent with available data. Parameter values are consistent with the initial and boundary conditions and the assumptions of the conceptual models for the Yucca Mountain site.

Infiltration rates are used as the top boundary conditions for model calibration. Three different infiltration boundary conditions were used for inversions, to examine alternative models and the corresponding parameter sets (Section 6.2.5). A time-varying pneumatic pressure boundary condition based on a combination of records from the surface at boreholes was used to simulate barometric pumping (Section 6.2.5).

Subcriterion (5): Coupled processes are adequately represented.

The effects of coupled processes are adequately represented through the inversion and incorporation of different types of field and laboratory data, which, taken together, 
represent the combination of various processes that influence flow in the unsaturated zone (see Section 6.3.1).

Subcriterion (6): Uncertainties in the characteristics of the natural system and engineered materials are considered.

The major sources of uncertainty (conceptual model, infiltration rate, and scale effects) and their propagation to the calibrated parameters are discussed in detail in Sections 6.4 and 8.3.1. Uncertainties in measured data and uncertainty propagation through inversion were also addressed (Sections 6.4 and 8.3.1). 


\section{INPUTS AND REFERENCES}

The following is a list of the references cited in this document. Column 2 represents the unique six digit numerical identifier (the Document Input Reference System [DIRS] number), which is placed in the text following the reference callout (e.g., BSC 2004 [DIRS 167969]). The purpose of these numbers is to assist in locating a specific reference. Within the reference list, multiple sources by the same author (e.g., BSC 2004) are sorted alphabetically by title.

\subsection{DOCUMENTS CITED}

Ahlers, C.F.; Finsterle, S.; and Bodvarsson, G.S. 1998. "Characterization and 124842

Prediction of Subsurface Pneumatic Pressure Variations at Yucca Mountain, Nevada." Proceedings of the TOUGH Workshop '98, Berkeley, California, May 4-6, 1998.

Pruess, K., ed. LBNL-41995. Pages 222-227. Berkeley, California: Lawrence Berkeley National Laboratory. TIC: 247159.

Ahlers, C.F.; Finsterle, S.; and Bodvarsson, G.S. 1999. "Characterization and 109715 Prediction of Subsurface Pneumatic Response at Yucca Mountain, Nevada." Journal of Contaminant Hydrology, 38, (1-3), 47-68. New York, New York: Elsevier. TIC: 244160 .

Altman, W.D.; Donnelly, J.P.; and Kennedy, J.E. 1988. Peer Review for High-Level Nuclear Waste Repositories: Generic Technical Position. NUREG-1297. Washington, D.C.: U.S. Nuclear Regulatory Commission. TIC: 200651.

Altman, W.D.; Donnelly, J.P.; and Kennedy, J.E. 1988. Qualification of Existing Data for High-Level Nuclear Waste Repositories: Generic Technical Position. NUREG1298. Washington, D.C.: U.S. Nuclear Regulatory Commission. TIC: 200652.

Bandurraga, T.M. and Bodvarsson, G.S. 1999. "Calibrating Hydrogeologic Parameters for the 3-D Site-Scale Unsaturated Zone Model of Yucca Mountain, Nevada." Journal of Contaminant Hydrology, 38, (1-3), 25-46. New York, New York: Elsevier. TIC: 244160.

Bird, R.B.; Stewart, W.E.; and Lightfoot, E.N. 1960. Transport Phenomena. New York, New York: John Wiley \& Sons. TIC: 208957.

Bodvarsson, G.S.; Liu, H.H.; Ahlers, C.F.; Wu, Y-S.; and Sonnenthal, S. 2001. 103750 "Parameterization and Upscaling in Modeling Flow and Transport in the Unsaturated Zone of Yucca Mountain." Chapter 11 of Conceptual Models of Flow and Transport in the Fractured Vadose Zone. Washington, D.C.: National Academy Press. TIC: 252777.

BSC (Bechtel SAIC Company) 2001. Calibrated Properties Model. MDL-NBS-HS000003 REV 00 ICN 01. Las Vegas, Nevada: Bechtel SAIC Company. ACC: MOL.20020311.0012. 
BSC 2003. Calibrated Properties Model. MDL-NBS-HS-000003 REV 01 [Errata

166509

001]. Las Vegas, Nevada: Bechtel SAIC Company. ACC: DOC.20030219.0001;

DOC.20031014.0011.

BSC 2003. Errata for Risk Information to Support Prioritization of Performance

168796

Assessment Models. TDR-WIS-PA-000009 REV 01 ICN 01. Las Vegas, Nevada:

Bechtel SAIC Company. ACC: MOL.20021017.0045; DOC.20031014.0003.

BSC 2004. Geologic Framework Model (GFM2000). MDL-NBS-GS-000002 REV

170029

02. Las Vegas, Nevada: Bechtel SAIC Company. ACC: DOC.20040827.0008.

BSC 2004. Thermal Conductivity of the Potential Repository Horizon. MDL-NBS-

GS-000005, Rev. 01. Las Vegas, Nevada: Bechtel SAIC Company.

BSC 2004. Q-List. 000-30R-MGR0-00500-000-000 REV 00. Las Vegas, Nevada:

Bechtel SAIC Company. ACC: ENG.20040721.0007.

BSC 2004. Analysis of Hydrologic Properties Data. ANL-NBS-HS-000042, Rev. 00.170038 Las Vegas, Nevada: Bechtel SAIC Company.

BSC 2004. Development of Numerical Grids for UZ Flow and Transport Modeling. ANL-NBS-HS-000015 REV 02. Las Vegas, Nevada: Bechtel SAIC Company. ACC: DOC.20040901.0001.

BSC 2004. In Situ Field Testing of Processes. ANL-NBS-HS-000005, Rev. 03. Las 170004 Vegas, Nevada: Bechtel SAIC Company.

BSC 2004. Particle Tracking Model and Abstraction of Transport Process. MDLNBS-HS-000020, Rev. 01. Las Vegas, Nevada: Bechtel SAIC Company.

170041

BSC 2004. Technical Work Plan for: Performance Assessment Unsaturated Zone. TWP-NBS-HS-000003 REV 02 [Errata 001]. Las Vegas, Nevada: Bechtel SAIC Company. ACC: MOL.20030102.0108; DOC.20040121.0001.

BSC 2004. Technical Work Plan for: Unsaturated Zone Flow Analysis and Model Report Integration. TWP-MGR-HS-000001 REV 00. Las Vegas, Nevada: Bechtel SAIC Company. ACC: DOC.20040701.0005.

BSC 2004. UZ Flow Models and Submodels. MDL-NBS-HS-000006, Rev. 02. Las Vegas, Nevada: Bechtel SAIC Company.

Canori, G.F. and Leitner, M.M. 2003. Project Requirements Document. TER-MGRMD-000001 REV 02. Las Vegas, Nevada: Bechtel SAIC Company. ACC: DOC.20031222.0006. 
BSC 2004. Conceptual Model and Numerical Approaches for Unsaturated Zone Flow 170035 and Transport. MDL-NBS-HS-000005 REV 01. Las Vegas, Nevada: Bechtel SAIC Company.

BSC 2004. Simulation of Net Infiltration for Present-Day and Potential Future 170007 Climates. MDL-NBS-HS-000023, Rev. 00. Las Vegas, Nevada: Bechtel SAIC Company.

Finsterle, S. 1998. ITOUGH2 V3.2 Verification and Validation Report. LBNL-42002. 103783 Berkeley, California: Lawrence Berkeley National Laboratory. ACC:

MOL.19981008.0014.

Finsterle, S. 1999. ITOUGH2 User's Guide. LBNL-40040. Berkeley, California:

Finsterle, S. and Pruess, K. 1995. "Solving the Estimation-Identification Problem in

Two-Phase Flow Modeling." Water Resources Research, 31, (4), 913-924.

Washington, D.C.: American Geophysical Union. TIC: 252318.

Flint, L.E. 1998. Characterization of Hydrogeologic Units Using Matrix Properties, Yucca Mountain, Nevada. Water-Resources Investigations Report 97-4243. Denver, Colorado: U.S. Geological Survey. ACC: MOL.19980429.0512.

Forsyth, P.A.; Wu, Y-S.; and Pruess, K. 1995. "Robust Numerical Methods for Saturated-Unsaturated Flow with Dry Initial Conditions in Heterogeneous Media." Advances in Water Resources, 18, 25-38. Southhampton, England: Elsevier. TIC: 235658.

Glass, R.J.; Nicholl, M.J.; and Tidwell, V.C. 1996. Challenging and Improving Conceptual Models for Isothermal Flow in Unsaturated, Fractured Rock Through Exploration of Small-Scale Processes. SAND95-1824. Albuquerque, New Mexico: Sandia National Laboratories. ACC: MOL.19970520.0082.

LeCain, G.D.; Anna, L.O.; and Fahy, M.F. 2000. Results from Geothermal Logging, 144612 Air and Core-Water Chemistry Sampling, Air-Injection Testing, and Tracer Testing in the Northern Ghost Dance Fault, Yucca Mountain, Nevada, November 1996 to August 1998. Water-Resources Investigations Report 99-4210. Denver, Colorado: U.S. Geological Survey. TIC: 247708.

Liu, H.H. and Bodvarsson, G.S. 2001. "Constitutive Relations for Unsaturated Flow 160110 in a Fracture Network." Journal of Hydrology, 252, ([1-4]), 116-125. New York, New York: Elsevier. TIC: 253269.

Liu, H.H.; Doughty, C.; and Bodvarsson, G.S. 1998. "An Active Fracture Model for 105729 Unsaturated Flow and Transport in Fractured Rocks." Water Resources Research, 34, (10), 2633-2646. Washington, D.C.: American Geophysical Union. TIC: 243012. 
Montazer, P. and Wilson, W.E. 1984. Conceptual Hydrologic Model of Flow in the 100161 Unsaturated Zone, Yucca Mountain, Nevada. Water-Resources Investigations Report 84-4345. Lakewood, Colorado: U.S. Geological Survey. ACC: NNA.19890327.0051.

Neuman, S.P. 1994. "Generalized Scaling of Permeabilities: Validation and Effect of 105731 Support Scale.” Geophysical Research Letters, 21, (5), 349-352. Washington, D.C.: American Geophysical Union. TIC: 240142.

NRC (U.S. Nuclear Regulatory Commission) 2003. Yucca Mountain Review Plan, Final Report. NUREG-1804, Rev. 2. Washington, D.C.: U.S. Nuclear Regulatory Commission, Office of Nuclear Material Safety and Safeguards. TIC: 254568.

Pruess, K. 1987. TOUGH User's Guide. NUREG/CR-4645. Washington, D.C.: U.S Nuclear Regulatory Commission. TIC: 217275.

Roberson, J.A. and Crowe, C.T. 1990. Engineering Fluid Mechanics. 4th Edition. Boston, Massachusetts: Houghton Mifflin. TIC: 247390.

Rousseau, J.P.; Kwicklis, E.M.; and Gillies, D.C., eds. 1999. Hydrogeology of the Unsaturated Zone, North Ramp Area of the Exploratory Studies Facility, Yucca Mountain, Nevada. Water-Resources Investigations Report 98-4050. Denver, Colorado: U.S. Geological Survey. ACC: MOL.19990419.0335.

Rousseau, J.P.; Loskot, C.L.; Thamir, F.; and Lu, N. 1997. Results of Borehole Monitoring in the Unsaturated Zone Within the Main Drift Area of the Exploratory Studies Facility, Yucca Mountain, Nevada. Milestone SPH22M3. Denver, Colorado: U.S. Geological Survey. ACC: MOL.19970626.0351.

van Genuchten, M.T. 1980. "A Closed-Form Equation for Predicting the Hydraulic 100610 Conductivity of Unsaturated Soils." Soil Science Society of America Journal, 44, (5), 892-898. Madison, Wisconsin: Soil Science Society of America. TIC: 217327.

Wang, J.S. 2002. "Scientific Notebooks Referenced in AMR U0035, Calibrated Properties Model, MDL-NBS-HS-000003 REV 01.” Memorandum from J.S. Wang (BSC) to File, October 25, 2002, with attachments. ACC: MOL.20021107.0287.

Wang, J.S.Y. and Narasimhan, T.N. 1993. "Unsaturated Flow in Fractured Porous Media." Chapter 7 of Flow and Contaminant Transport in Fractured Rock. Bear, J.; 106793 Tsang, C-F.; and de Marsily, G., eds. San Diego, California: Academic Press. TIC: 235461 .

Weast, R.C., ed. 1987. CRC Handbook of Chemistry and Physics: 1987-1988. 68th 114295 Edition. Pages A-1, F-72, F-185 only. Boca Raton, Florida: CRC Press. TIC: 245444. 


\subsection{CODES, STANDARDS, REGULATIONS, AND PROCEDURES}

10 CFR 63. Energy: Disposal of High-Level Radioactive Wastes in a Geologic 156605

Repository at Yucca Mountain, Nevada. Readily available.

AP-2.22Q, Rev. 01, ICN 1. Classification Analyses and Maintenance of the Q-List. Washington, D.C.: U.S. Department of Energy, Office of Civilian Radioactive Waste Management. ACC: DOC.20040714.0002.

AP-2.27Q, Rev. 1, ICN 4. Planning for Science Activities. Washington, D.C.: U.S. Department of Energy, Office of Civilian Radioactive Waste Management. ACC: DOC.20040610.0006.

AP-SIII.10Q, Rev. 2, ICN 7. Models. Washington, D.C.: U.S. Department of Energy, Office of Civilian Radioactive Waste Management. ACC: MOL.200040920.0002.

LP-SI.11Q-BSC, Rev. 0, ICN 0. Software Management. Washington, D.C.: U.S. Department of Energy, Office of Civilian Radioactive Waste Management. ACC: DOC.20040225.0007.

\subsection{SOURCE DATA, LISTED BY DATA TRACKING NUMBER}

GS000108312232.001. Deep Unsaturated Zone Instrumentation Data from Boreholes 162173 USW NRG-7A, UE-25 UZ\#4, UE-25 UZ\#5, USW UZ-7A and USW SD-12 for 10/01/98 through 03/31/99. Submittal date: 01/03/2000.

GS000308311221.005. Net Infiltration Modeling Results for 3 Climate Scenarios for 147613 FY99. Submittal date: 03/01/2000.

GS000608312261.001. Shut-In Pressure Data from Boreholes UE-25 NRG\#2B, UE25 NRG\#5, USW SD-9, and USW UZ-7A from 4/1/95 through 12/31/95. Submittal date: $07 / 05 / 2000$.

GS000708312232.004. Deep UZ Surface-Based Borehole Instrumentation ProgramInterim Data Submittal for Boreholes USW NRG-7A, UE-25 UZ\#4, and UE-25

UZ\#5. Data Were Collected between 4/1/99 and 3/31/00. Submittal date: 09/13/2000.

GS010908312232.001. Deep Unsaturated Zone Surface-Based Borehole Instrumentation Program-Interim Data Submittal for Boreholes USW NRG-7A, UE25 UZ\#4, and UE-25 UZ\#5. Data Were Collected between April 1, 2000 and March 31, 2001. Submittal date: 09/26/2001.

GS021008312232.001. Deep Unsaturated Zone Surface-Based Borehole 155891 Instrumentation Program - Final Data Submittal for Boreholes USW NRG-7A, UE-25 UZ\#4, and UE-25 UZ\#5. Data Were Collected between April 1, 2001 and December 17, 2001. Submittal date: 12/12/2002. 
GS031208312232.003. Deep Unsaturated Zone Surface-Based Borehole

Instrumentation Program Data from Boreholes USW NRG-7A, UE-25 UZ \#4, USW

NRG-6, UE-25 UZ \#5, USW UZ-7A and USW SD-12 for the Time Period 10/01/97 -

03/31/98. Submittal date: 07/29/2004.

GS940208314211.008. Table of Contacts in Boreholes USW UZ-N57, UZ-N58, UZ145581 N59, and UZ-N61. Submittal date: 02/10/1994.

GS950208312232.003. Data, Including Water Potential, Pressure and Temperature, 105572 Collected from Boreholes USW NRG-6 and USW NRG-7A from Instrumentation through March 31, 1995. Submittal date: 02/13/1995.

GS951108312232.008. Data, Including Water Potential, Pressure and Temperature, Collected from Boreholes UE-25 UZ\#4 \& UZ\#5 from Instrumentation through September 30, 1995, and from USW NRG-6 \& NRG-7A from April 1 through September 30, 1995. Submittal date: 11/21/1995.

GS960308312232.001. Deep Unsaturated Zone Surface-Based Borehole 105573 Instrumentation Program Data from Boreholes USW NRG-7A, USW NRG-6, UE-25 UZ\#4, UE-25 UZ\#5, USW UZ-7A, and USW SD-12 for the Time Period 10/01/95 through 3/31/96. Submittal date: 04/04/1996.

GS960808312232.004. Deep Unsaturated Zone Surface-Based Borehole Instrumentation Program Data for Boreholes USW NRG-7A, USW NRG-6, UE-25 UZ\#4, UE-25 UZ\#5, USW UZ-7A and USW SD-12 for the Time Period 4/1/96 through 8/15/96. Submittal date: 08/30/1996.

GS960908312261.004. Shut-in Pressure Test Data from UE-25 NRG\#5 and USW SD-7 from November, 1995 to July, 1996. Submittal date: 09/24/1996.

GS970108312232.002. Deep Unsaturated Zone, Surface-Based Borehole Instrumentation Program - Raw Data Submittal for Boreholes USW NRG-7A, USW NRG-6, UE-25 UZ\#4, UE-25 UZ\#5, USW UZ-7A, and USW SD-12, for the Period 8/16/96 through 12/31/96. Submittal date: 01/22/1997.

GS970808312232.005. Deep Unsaturated Zone Surface-Based Borehole Instrumentation Program Data from Boreholes USW NRG-7A, UE-25 UZ\#4, UE-25 UZ\#5, USW UZ-7A and USW SD-12 for the Time Period 1/1/97 - 6/30/97. Submittal date: 08/28/1997.

GS971108312232.007. Deep Unsaturated Zone Surface-Based Borehole 105980 Instrumentation Program Data from Boreholes USW NRG-7A, UE-25 UZ \#4, UE-25 UZ \#5, USW UZ-7A and USW SD-12 for the Time Period 7/1/97 - 9/30/97.

Submittal date: 11/18/1997. 
GS980708312242.010. Physical Properties of Borehole Core Samples, and Water

106752

Potential Measurements Using the Filter Paper Technique, for Borehole Samples from

USW WT-24. Submittal date: 07/27/1998.

GS980808312242.014. Physical Properties of Borehole Core Samples and Water 106748

Potential Measurements Using the Filter Paper Technique for Borehole Samples from USW SD-6. Submittal date: 08/11/1998.

GS981208312232.002. Deep UZ Surface-Based Borehole Instrumentation Program

156505

Data from Boreholes USW NRG-7A, UE-25 UZ\#4, USW NRG-6, UE-25 UZ\#5, USW UZ-7A and USW SD-12 for the Time Period 4/1/98 through 9/30/98. Submittal date: $12 / 03 / 1998$.

LB0205REVUZPRP.001. Fracture Properties for UZ Model Layers Developed from Field Data. Submittal date: 05/14/2002.

LB0207REVUZPRP.001. Revised UZ Fault Zone Fracture Properties. Submittal date: 159526 07/03/2002.

LB0207REVUZPRP.002. Matrix Properties for UZ Model Layers Developed from

Field and Laboratory Data. Submittal date: 07/15/2002.

LB02081DKMGRID.001. 2002 UZ 1-D and 2-D Calibration Grids. Submittal date: 160108 08/26/2002.

LB02103DPNEUSM.001. 3-D Pneumatic Simulation (FY99). Submittal date:

160250 $10 / 08 / 2002$.

LB0401H2OPOTEN.001. Statistically Consolidated Water Potential Data. Submittal date: $01 / 29 / 2004$.

LB991091233129.001. One-Dimensional, Mountain-Scale Calibration for AMR

125868 U0035, "Calibrated Properties Model”. Submittal date: 10/22/1999.

LB991091233129.003. Two-Dimensional Fault Calibration for AMR U0035,

119902

“Calibrated Properties Model”. Submittal date: 10/22/1999.

LB997141233129.001. Calibrated Base-case Infiltration 1-D Parameter Set for the

104055

UZ Flow and Transport Model, FY99. Submittal date: 07/21/1999.

LB997141233129.002. Calibrated Upper-Bound Infiltration 1-D Parameter Set for the 119933 UZ Flow and Transport Model, FY99. Submittal date: 07/21/1999.

LB997141233129.003. Calibrated Lower-Bound Infiltration 1-D Parameter Set for the UZ Flow and Transport Model, FY99. Submittal date: 07/21/1999.

119940 
MO0012MWDGFM02.002. Geologic Framework Model (GFM2000). Submittal

153777

date: $12 / 18 / 2000$.

MO0109HYMXPROP.001. Matrix Hydrologic Properties Data. Submittal date:

155989

09/17/2001.

MO0407SEPFEPLA.000. LA FEP List. Submittal date: 07/20/2004.

170760

\subsection{OUTPUT DATA, LISTED BY DATA TRACKING NUMBER}

LB0208UZDSCPLI.001. Drift-Scale Calibrated Property Sets: Lower Infiltration Supporting Files. Submittal date: 08/27/2002.

LB0208UZDSCPLI.002. Drift-Scale Calibrated Property Sets: Lower Infiltration Data Summary. Submittal date: 08/26/2002.

LB0208UZDSCPMI.001. Drift-Scale Calibrated Property Sets: Mean Infiltration Supporting Files. Submittal date: 08/27/2002.

LB0208UZDSCPMI.002. Drift-Scale Calibrated Property Sets: Mean Infiltration Data Summary. Submittal date: 08/26/2002.

LB0208UZDSCPUI.001. Drift-Scale Calibrated Property Sets: Upper Infiltration Supporting Files. Submittal date: 08/27/2002.

LB02091DSSCP3I.001. 1-D Site Scale Calibrated Properties: Supporting Files. Submittal date: 09/18/2002.

LB02091DSSCP3I.002. 1 -D Site Scale Calibrated Properties: Data Summary. Submittal date: $09 / 18 / 2002$.

LB02092DSSCFPR.001. 2-D Site Scale Calibrated Fault Properties: Supporting Files. Submittal date: 09/18/2002.

LB02092DSSCFPR.002. 2-D Site Scale Calibrated Fault Properties: Data Summary. Submittal date: $09 / 18 / 2002$.

LB0210AMRU0035.002. Model Validation and Parameter Uncertainty: Data Summary. Submittal date: 10/10/2002.

LB0302AMRU0035.001. Model Validation and Parameter Uncertainty: Supporting Files. Submittal date: 02/07/2003.

LB0302UZDSCPUI.002. Drift-Scale Calibrated Property Sets: Upper Infiltration Data Summary. Submittal date: 02/05/2003. 


\subsection{SOFTWARE CODES}

LBNL (Lawrence Berkeley National Laboratory) 1999. Software Code: infil2grid. V1.6. PC with Windows/95 or 98. Sun or DEC Workstation with Unix OS. 100771.6-00.

LBNL (Lawrence Berkeley National Laboratory) 2002. Software Code: infil2grid. V1.7. DEC-Alpha, PC. 10077-1.7-00.

LBNL (Lawrence Berkeley National Laboratory) 2002. Software Code: iTOUGH2. 160106 V5.0. SUN UltraSparc., DEC ALPHA, LINUX. 10003-5.0-00.

LBNL (Lawrence Berkeley National Laboratory) 2002. Software Code: TBgas3D. 160107 V2.0. SUN UltraSparc. 10882-2.0-00.

LBNL (Lawrence Berkeley National Laboratory) 2002. Software Routine: aversp_1. 146533 V1.0. Sun workstation. 10878-1.0-00.

LBNL (Lawrence Berkeley National Laboratory) 08/16/1999. Software Routine: e9- 146536 3in V1.0. 1.0. Sun workstation. 10126-1.0-00. 


\section{INTENTIONALLY LEFT BLANK}




\section{APPENDIX A}

\section{DESCRIPTION OF EXCEL FILES}




\section{layavsat.xls (Output-DTN: LB0208UZDSCPMI.001)}

This Excel file was used to calculate and format saturation data for iTOUGH2 V5.0 (LBNL 2002 [DIRS 160106]). All the relevant input and output files (including the Excel file itself) were submitted to the Technical Data Management System (TDMS) under DTN: LB0208UZDSCPMI.001).

In worksheets "***sat", *** corresponds to the borehole name. Columns C-G were imported from files "***.out". These files with the extension "out" are output files from runs of aversp 1 V1.0 (LBNL 2002 [DIRS 146533]) and listed in Output-DTN: LB0208UZDSCPMI.001. Columns H, I, and $\mathbf{J}$ contain the standard error, handling error, and the total error. The formulations used for calculating these errors are Equations 6-1, 6-2, and 6-6 (Section 6.2.2). Columns $\mathrm{A}$ and $\mathrm{B}$ contain the corresponding element names and material types that were imported from file m1di8m.dkm (Output-DTN: LB0208UZDSCPMI.001). Columns A, B, F, and J were copied from worksheets "***sat" to columns B, D, E and F, respectively, in worksheet "iTOUGH2 pre-input" below Row 7. Rows 1 to 7 are iTOUGH2 input format. Worksheet "iTOUGH2 input" was determined from "iTOUGH2 pre-input". Information in Column B in "iTOUGH2 input" was copied from Columns B, C, E, and F in "iTOUGH2 pre-input". The worksheet "iTOUGH2 input" is the final output of this Excel file.

in_situ_pcap.xls (Output-DTN: LB0208UZDSCPMI.001)

This excel file was used for data reduction for water potential data and formatting for iTOUGH2 V5.0 (LBNL 2002 [DIRS 160106]) input. It was modified from file in_situ_pcap2.xls from DTN: LB991091233129.001 [DIRS 125868], and submitted to TDMS under DTN: LB0208UZDSCPMI.001.

In worksheet "iTOUGH2 trans," columns A to G are from in_situ_pcap2.xls, and Columns I to O were copied from numerical grid file "m1di5m.dkm.nvf.SP.nt" (OutputDTN: LB0208UZDSCPMI.001). The appropriate element names and the corresponding information (Columns I to $\mathrm{O}$ ) were determined by comparing borehole information given in "Boreholes.mck" (DTN: LB02081DKMGRID.001 [DIRS 160108]), numerical grids "m1di5m.dkm.nvf.SP.nt" and elevations given in Column C.

In worksheet "iTOUGH2 pre-input", Columns B, D, and F (below row 9) were copied from Columns I, E and J in "iTOUGH2 trans," respectively. Column E is the data in Column D times 10E5 (i.e., converting from bars to $\mathrm{Pa}$ ). The uncertainty of the data is calculated in Column $\mathrm{G}$ as the logarithmic equivalent of \pm 1.0 bars:

$$
\begin{array}{ll}
S E_{\log (\psi)}=\frac{\log (|\psi|+1 \text { bar })-\log (|\psi|-1 \text { bar })}{2} & \psi>1 \text { bar } \\
S E_{\log (\psi)}=\log (|\psi|+1 \text { bar })-\log (|\psi|) & \psi \leq 1 \text { bar }
\end{array}
$$

Worksheet "iTOUGH2 input" was determined from "iTOUGH2 pre-input". Information in Column B in "iTOUGH2 input" was copied from Columns B, C, E, and G in "iTOUGH2 preinput". The worksheet "iTOUGH2 input" is the final output of this Excel file. 


\section{UZ-7asat1_02.xls (Output-DTN: LB02092DSSCFPR.001)}

Gridblock-averaged saturation data for UZ-7a are determined using Excel file: UZ-7asat1_02.xls that is modified from UZ-7asat.xls in DTN: LB991091233129.003 (DIRS 119902). The averaged saturation data were used for calibrating fault properties. The Excel file was submitted to TDMS under DTN: LB02092DSSCFPR.001.

Worksheet "data" contains saturation measurements contained in UZ-7asat.xls in DTN: LB991091233129.003 (DIRS 119902). Because grid mesh is only approximately consistent with the geology of the UZ-7a borehole, some correction is needed for calculating gridblockaveraged saturations:

The top elevation for UZ-7a is $4230 \mathrm{ft}=4230 * 0.3048(\mathrm{~m})=1289.3 \mathrm{~m}$ (from contacts00md.dat of DTN: MO0012MWDGFM02.002 [DIRS 153777]). The top elevation from the grid is $1291.8 \mathrm{~m}$ (from EWUZ7a.mck of DTN: LB02081DKMGRID.001 [DIRS 160108]). Note that in worksheet "fault_grid" of UZ-7asat1_02.xls, elevation information comes from EWUZ7a.mck. The small elevation difference is ignored. In other words, the top of grid is considered to correspond to depth $=0$ in worksheet "data".

The thickness of a geological layer in "data" may be not exactly the same as that in the grid. To map the data to grid elevations, some corrections are needed. In one of the worksheets "ftcw", "fptn", "ftsw", "nftptpul", "nftptpmn," and "nftptpll”, Column A contains three numbers. From top to bottom, they are top and bottom depths of the corresponding geologic unit and the difference between them (the thickness of the unit), respectively. They are determined from worksheet "data". Note that the depth of contacts between subgeological layers in worksheet "data" is calculated as average depth of two closest sample locations within the corresponding sublayers. Columns B and C were copied from "fault grid". Column D contains depth values that were calculated as depths minus the top depth of the unit. The bottom number in this column is the thickness of the unit in the grid. Columns $\mathrm{K}, \mathrm{L}$, and $\mathrm{N}$ were copied from worksheet "data". Column M contains corrected depths that were calculated by

[(depth in Column L - depth at Cell A2) x thickness in grid]/ (thickness calculated from "data")

Column E contains numbers of samples within the gridblock (determined by the top and bottom depth values of the element (Column D) and the sample depth values in Column M). Columns F to $\mathrm{G}$ are mean saturation, standard deviation, standard error, measurement error, and total error, respectively. The formulations used for calculating these errors are Equations (6-1), (6-2) and (6-6) (Section 6.2.2). The mean saturation and total error were used in iTOUGH2 V5.0 (LBNL 2002 [DIRS 160106]) input for the corresponding element (Column B).

\section{QAd.xls (Output-DTN: LB02091DSSCP3I.001)}

This excel file was used to determine $\mathrm{F}$ values (Equation (6-8)). It was submitted to TDMS under DTN: LB02091DSSCP3I.001).

Input files for Qad.xls are one of the files MGasi.tec, LGasi.tec, and UGasi.tec (output DTN: LB02091DSSCP3I.001). Delete lines 1-3041 and then delete lines 122-244 from one of these files with the extension tec. (To calculate $\mathrm{F}$ value for the observed data, delete lines 
1-1919 and then 122-244 from one of these files.) Then, copy the file to Columns A and B in QAd.xls. Copy B1 to C1-121, and Copy B122 to C122 - 242. In Column D, D1-121 correspond to $(\mathrm{Bi}-\mathrm{Ci})(\mathrm{i}=1,121)$. In Column $\mathrm{E}, \mathrm{E} 1-121$ correspond to $(\mathrm{Bj}-\mathrm{Cj})(\mathrm{j}=122-242)$. In Column $\mathrm{F}$, F1-121 correspond to (Di-Ei) ${ }^{2}$ for $i=1$ to 121 . Cell G1 contains summation of Fi for $i=1$ to 121. Cell $\mathrm{H} 1$ contains $(\mathrm{G} 1)^{0.5} / 121$, or the F value in Equation (6-8).

Verification.xls (Output-DTN: LB0302AMRU0035.001)

This file was used for processing data for model validation in terms of matrix saturation and water potential data (Section 7). All data files mentioned below were submitted to TDMS under DTN: LB0210AMRU0035.001.

Copy "Residual Analysis" sections from: LVerify_Ci.out, MVerify_Ci.out, and UVerify_Ci.out into Verification.xls as Worksheets "LVerify_Ci", "MVerify_Ci", and "UVerify_Ci", respectively. In the worksheet known as "Overall", list the boreholes that were used in calibration and the boreholes that were saved for verification purpose separately. In each individual worksheet (LVerify_Ci, MVerify_Ci, and UVerify_Ci), calculate the square of the residual (Measured-computed, column I) for each data point in column P (e.g., enter (I14)^2 in P14). Then calculate the root-mean-square error for each group, saturation in the boreholes used in calibration (P1), Saturation in the boreholes not used in calibration (P2), Water potential in the boreholes used in calibration (Q1), and water potential in the boreholes not used in calibration (Q2), using standard functions SQRT and AVERAGE. In Cell P1, enter "= SQRT( AVERAGE(P14:P142, P191:P288, P302:P327, P330:P339, P364:P366, P373:P375))”. In Cell P2, enter "= SQRT(AVERAGE(P143:P190, P289:P301, P328:P329, P340:P363, P367:P372))" In Cell Q1, enter "= SQRT(AVERAGE(P381:P411))" In Cell Q2, enter "=SQRT(AVERAGE(P376:P380))" Summarize the above results into two tables, saturation (D1-G5) and water potential (D17-G21) on worksheet 'Overall', respectively. In particular,

\begin{tabular}{|c|c|}
\hline Cell E2, enter "=+LVerify_Ci!P2" & --Calibration \\
\hline Cell E3, enter "=+LVerify_Ci!P3" & --Prediction \\
\hline Cell E4, enter " $=3 * \mathrm{E} 2 "$ & --Criteria \\
\hline Cell F2, enter "=+MVerify_Ci!P2" & --Calibration \\
\hline Cell F3, enter "=+MVerify_Ci!P3" & --Prediction \\
\hline Cell F4, enter " $=3 * \mathrm{~F} 2 "$ & --Criteria \\
\hline Cell G2, enter "=+UVerify_Ci!P2" & --Calibration \\
\hline Cell G3, enter "=+UVerify_Ci!P3" & --Prediction \\
\hline Cell G4, enter " $=3 * \mathrm{G} 2 "$ & --Criteria \\
\hline Cell E18, enter "=+LVerify_Ci!Q2" & --Calibratic \\
\hline Cell E19, enter "=+LVerify_Ci!Q3" & --Prediction \\
\hline Cell E20, enter " $=3 * E 18^{*}$ & --Criteria \\
\hline Cell F18, enter "=+MVerify_Ci!Q2" & --Calibrati \\
\hline Cell F19, enter "=+MVerify_Ci!Q3" & --Prediction \\
\hline Cell F20, enter " $=3 * \mathrm{~F} 18 "$ & --Criteria \\
\hline 18, enter "=+UVerify_Ci!Q2" & --Calibratic \\
\hline 9, enter "=+UVerify_Ci!Q3" & --Prediction \\
\hline 0 , enter " $=3 * \mathrm{G} 18 "$ & --Criteria \\
\hline
\end{tabular}


VGas.xls (Output-DTN: LB0302AMRU0035.001)

This file was used for processing data for model validation in terms of gas pressure data (Section 7). All data files mentioned below were submitted to TDMS under DTN: LB0210AMRU0035.001.

Copy vLGasi.tec, vMGasi.tec, vUGasi.tec, Nli.tec, Nmi.tec, and Nui.tec into vGas.xls as worksheets "vLGasi," "vMGasi," "vUGasi," "Nli," "Nmi," and "Nui," respectively. Calculate the square errors (e.g., $=+(\mathrm{C} 4-\mathrm{C} 165)^{\wedge} 2$ in I4) on the column I on worksheets "vLGasi," "vMGasi," and "vUGasi." The related cell addresses are listed in Table A1-1.

Table A1-1. Excel Cell Addresses of Borehole Data

\begin{tabular}{|l|l|}
\hline \multicolumn{1}{|c|}{ Borehole } & \multicolumn{1}{c|}{ Cells } \\
\hline USW NRG-7a & I4-I163; I326-I485; I648-I807; 1970-I1129 \\
\hline USW SD-12 & I3056-I3215; I3378-I3537; I3700-I3859; I4022-I4181 \\
\hline USW SD-7 & I4344-I4503; I4666-I4825; I4988-I5147; I5310-I5469 \\
\hline
\end{tabular}

For each section above, the first half contains the data used in calibration and the second half contains the data not used in calibration. Therefore, calculate the average values for each part of each section separately and put them in the following cells (in the order of the above sections):

Calibration

K4

K326

K648

K970

K3056

K3378

K3700

K4022

K4344

K4666

K4998

K5310

\section{Prediction}

L4

L326

L648

L970

L3056

L3378

L3700

L4022

L4344

L4666

L4998

L5310

The calculation uses standard function AVERAGE, e.g., in Cell K4, enter "=AVERAGE(I4:I83)" and in Cell L4, enter "=AVERAGE(I84:I163)."

Calculate the overall root mean square errors in Cells K2 and L2 using standard functions SQRT and AVERAGE for calibration and prediction, respectively. In Cell K2, enter "=SQRT(AVERAGE(K4:K65536))." In Cell L2, enter "=SQRT(AVERAGE(L4:L65536))." In Cell M2, calculate the number of data points by using standard function COUNT (i.e., enter "=COUNT(I4:I5469)/2"). Note that, in MS Excel, only those cells having data participate in the calculation using either AVERAGE or COUNT. Dividing by 2 in Cell M2 is required because half data are used for either calibration or prediction. 
For worksheets NLi, NMi, and NUi (NRG6), all data were not used in calibration and the second set of calculated data (SIM1) is the final result. Therefore, the square errors of prediction are calculated in cells:

I4-I105, I210-I130, I454-I574, and I698-I818 (e.g., enter “=+(C4-C942)^2” in Cell I4).

Calculate the root mean square error in Cell J2 (i.e., enter "=SQRT(AVERAGE(I4:I818)") ) and the number of data points in Cell K2 (i.e., enter "=COUNT(I4:I818)"), respectively.

Summarize the calibration and prediction errors on Cells A6-E9 of the worksheet 'Summary' in vGas.xls. The calibration errors are from cell K2 in worksheets "vLGasi", "vMGasi", and "vUGasi." The prediction errors are calculated as the averages of the prediction errors of the 30 days after calibration in the same boreholes and the USW NRG-6 (no data used in calibration). Because the numbers of data points are different in the two data sets, the average values are calculated using the numbers of data points in each data set as weighting factors. The detailed calculations are listed in Table A1-2.

Table A1-2. Excel Formulae and Cell Addresses

\begin{tabular}{|c|c|}
\hline Cells & Formula \\
\hline B7 & $=+\mathrm{vLGasi} ! \mathrm{K} \$ 2$ \\
\hline B8 & $=+\mathrm{vMGasi} ! \mathrm{K} \$ 2$ \\
\hline B9 & $=+\mathrm{vMGasi}$ !K\$2 \\
\hline $\mathrm{C7}$ & $\begin{array}{l}=+(\text { vLGasi!L2*VLGasi!M2+NLi!J2*NLi!K2)/(vLGasi!M2+NLi! } \\
\text { K2) }\end{array}$ \\
\hline C8 & $\begin{array}{l}=+(\text { vMGasi!L2*VMGasi!M2+NMi!J2*NMi!K2)/(NMi!K2+vMG } \\
\text { asi!M2) }\end{array}$ \\
\hline C9 & 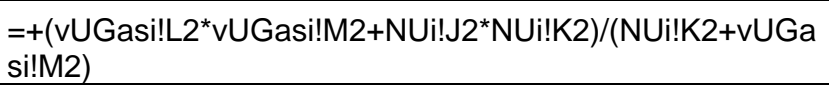 \\
\hline D7 & $=+B 7 * 3$ \\
\hline D8 & $=+B 8 * 3$ \\
\hline D9 & $=+B 9 * 3$ \\
\hline
\end{tabular}

Record time period is relevant to the calibration and prediction (validation) on worksheet "Summary" (H3-K6) based on the input files: vLGasi, vMGasi, vUGasi, NLi, NMi, and NUi. Note that Borehole USW NRG-5 has been excluded in the validation because no measured data were available beyond the calibration period. For Borehole USW NRG-6, only 25 days of measured data were available for the sensor located at layer Tpcpln, starting from April 1, 1995. 


\section{INTENTIONALLY LEFT BLANK}




\section{APPENDIX B}

\section{RECENT WATER-POTENTIAL DATA}


Water potential data from Boreholes USW NRG-6 and USW NRG-7a (November 1994 to March 1998), Borehole UE-25 UZ\#4 (June 1995 to March 1998), and Borehole UE-25 SD-12 (November 1995 to March 1998) were used to determine the equilibrium (steady-state) water potential value, which are used as a direct inputs in this model report (Sections 6.2.2 and 6.3) for calibration (inverse modeling).

More recent water potential data are available from USW NRG-7a (April 1998 to March 2001), UE-25 UZ\#4 (April 1998 to December 2001), and UE-25 SD-12 (April 1998 to December 1998) (DTNs: GS981208312232.002 [DIRS 156505]; GS000108312232.001 [DIRS 162173]; GS000708312232.004 [DIRS 162174]; GS010908312232.001 [DIRS 162175]; and GS021008312232.001 [DIRS 162176]). Monthly averages of all available water potential data are plotted in Figures B-1 to B-4, starting from October 1994 (when the boreholes were instrumented) as month 1 until December 2001. Each plot corresponds to a given measurement station which is instrumented with two sensors. The difference between the data from the two sensors at the same position (for example, TCP 1693 and TCP 1694 in Borehole UE-25 SD-12, see Figure C-4) indicates the measurement error. The measured water potential reached a quasisteady-state within the first 20 months after the instrumentations (Figures B-1 to B-4) and the more recently measured water potentials are stable.

Newer data from two sensors in UE-25 SD-12 (TCP 1675 and TCP 1676 at $76.8 \mathrm{~m}$ deep and TCP 1682 at $65.2 \mathrm{~m}$ deep) show a slightly wetter condition than the adopted equilibrium (steadystate) value as shown in Figure B-4, but the difference between the adopted equilibrium water potential value and the more recent data is within the measurement error.

In general, the difference between the adopted equilibrium (steady-state) value and the more recent data is within the range of the 95 percent confidence interval (plus or minus $0.2 \mathrm{Mpa}$, (Rousseau et al. 1999 [DIRS 102097], p. 144)) except for data from sensor TCP 1688 and TCP 1694 in Borehole UE-25 SD-12, which are possibly caused by measurement errors. The drastic increase in the latest water potential data from TCP 1688 is possibly caused by a sensor failure. The difference between data from TCP 1693 and TCP 1694 (Figure B-4) indicates a large uncertainty in the measured water potential at this particular location.

The comparisons given in Figures B-1 to B-4 indicate that the equilibrium (steady-state) water potential values used for calibration in this model report (based on data collected prior to March 1998) are consistent with the more recent data. This appendix addresses closure of the Key Technical Issue agreement TSPAI 3.26. 

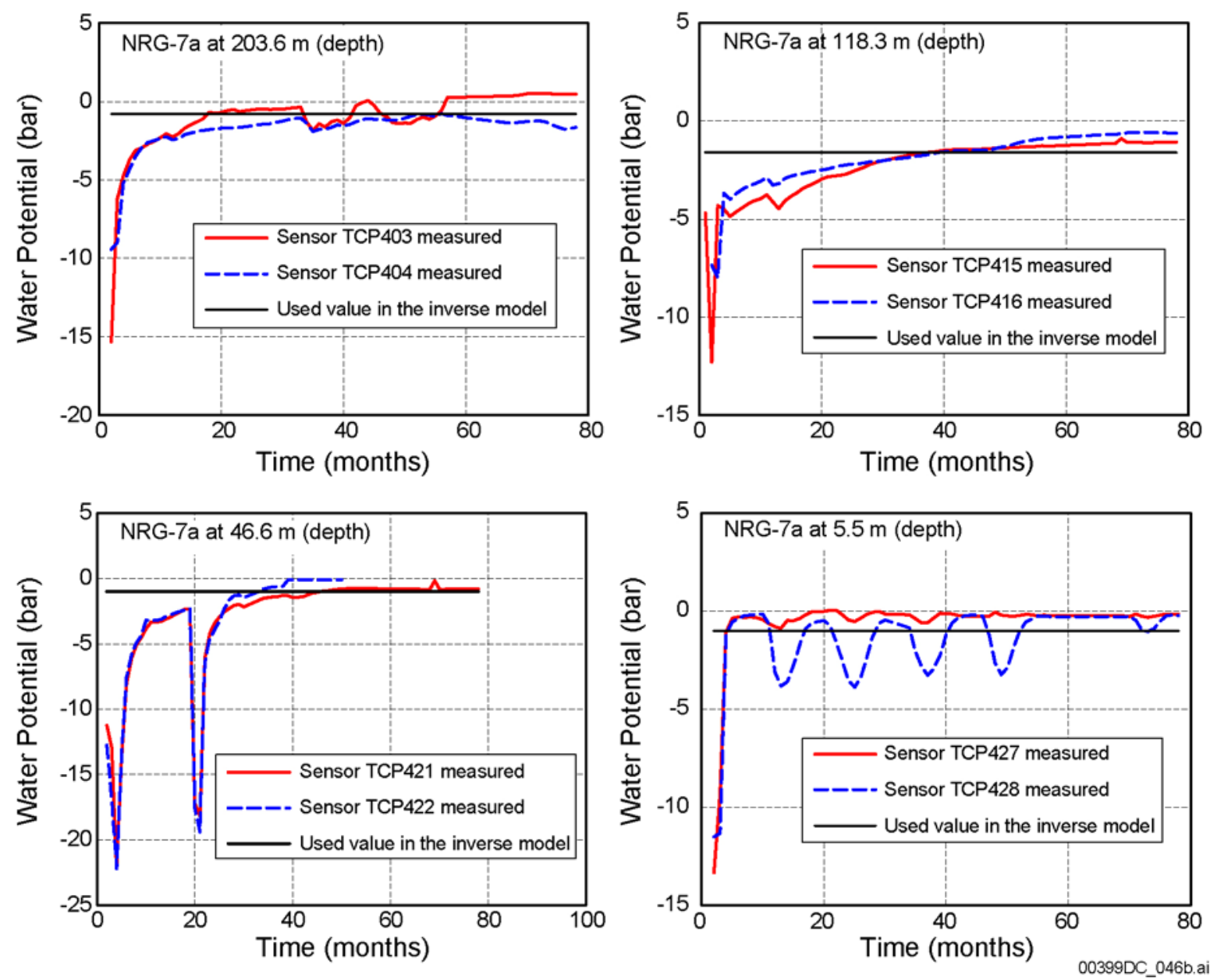

Source: DTN: LB0401H2OPOTEN.001 (DIRS 170678).

NOTE: The equilibrium water potential values used for calibration (inverse modeling) are determined using the data collected before the end of March 1998 (month 42).

Figure B-1. Measured Water Potential (from Available Instrument Stations of Borehole USW NRG-7a) Breakthrough (Starting from October 1994, as Month 1) and the Determined Steady-State Value Used in the Inverse Model for Hydraulic Property Calibration (DIRS 170678) 

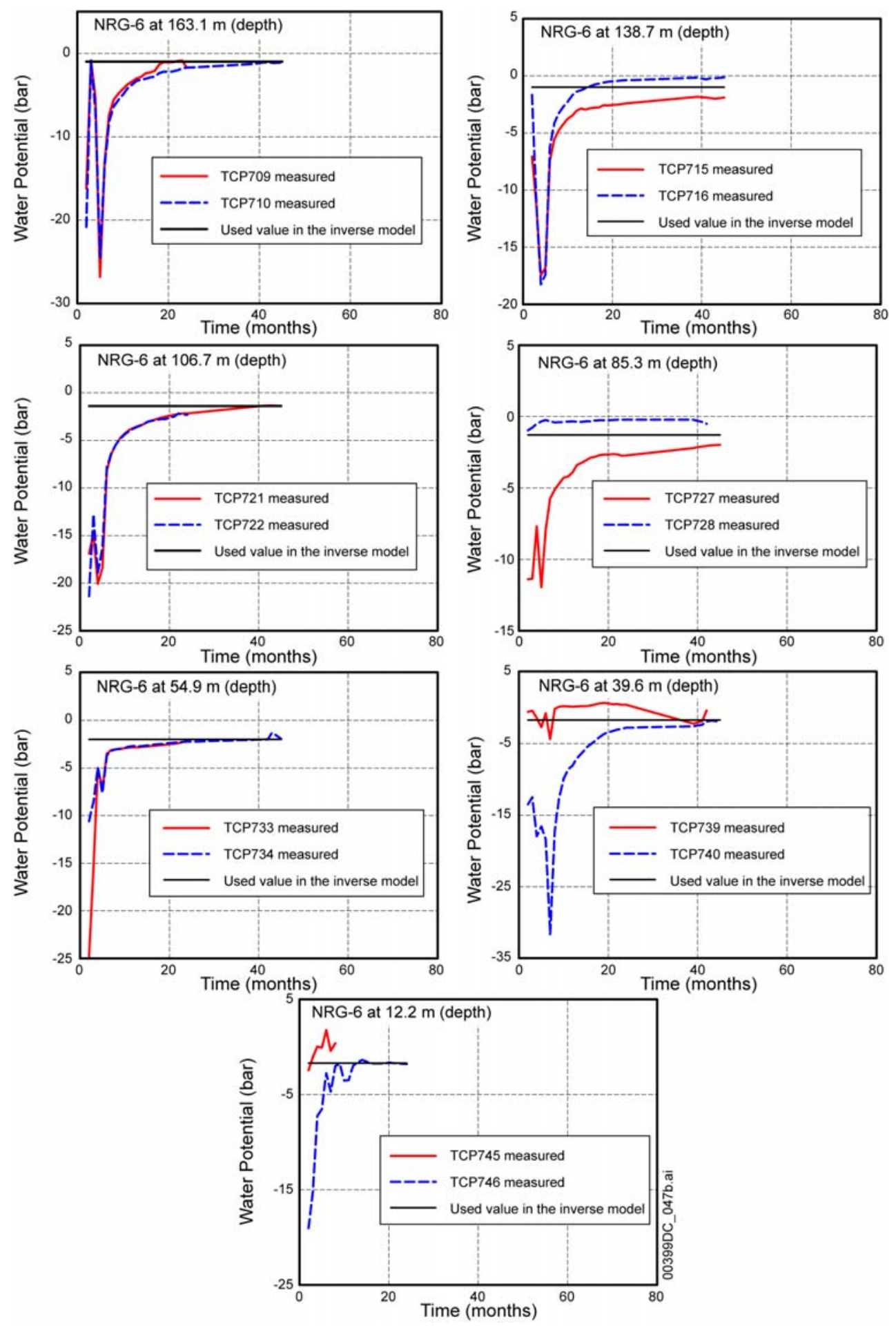

Source: DTN: LB0401H2OPOTEN.001 (DIRS 170678).

NOTE: The equilibrium water potential values used for calibration (inverse modeling) are determined using the data collected before the end of March 1998 (month 42).

Figure B-2. Measured Water Potential (from Available Instrument Stations of Borehole USW NRG-6) Breakthrough (Starting from October 1994, as Month 1) and the Determined Steady-State Value Used in the Inverse Model for Hydraulic Property Calibration (DIRS 170678) 

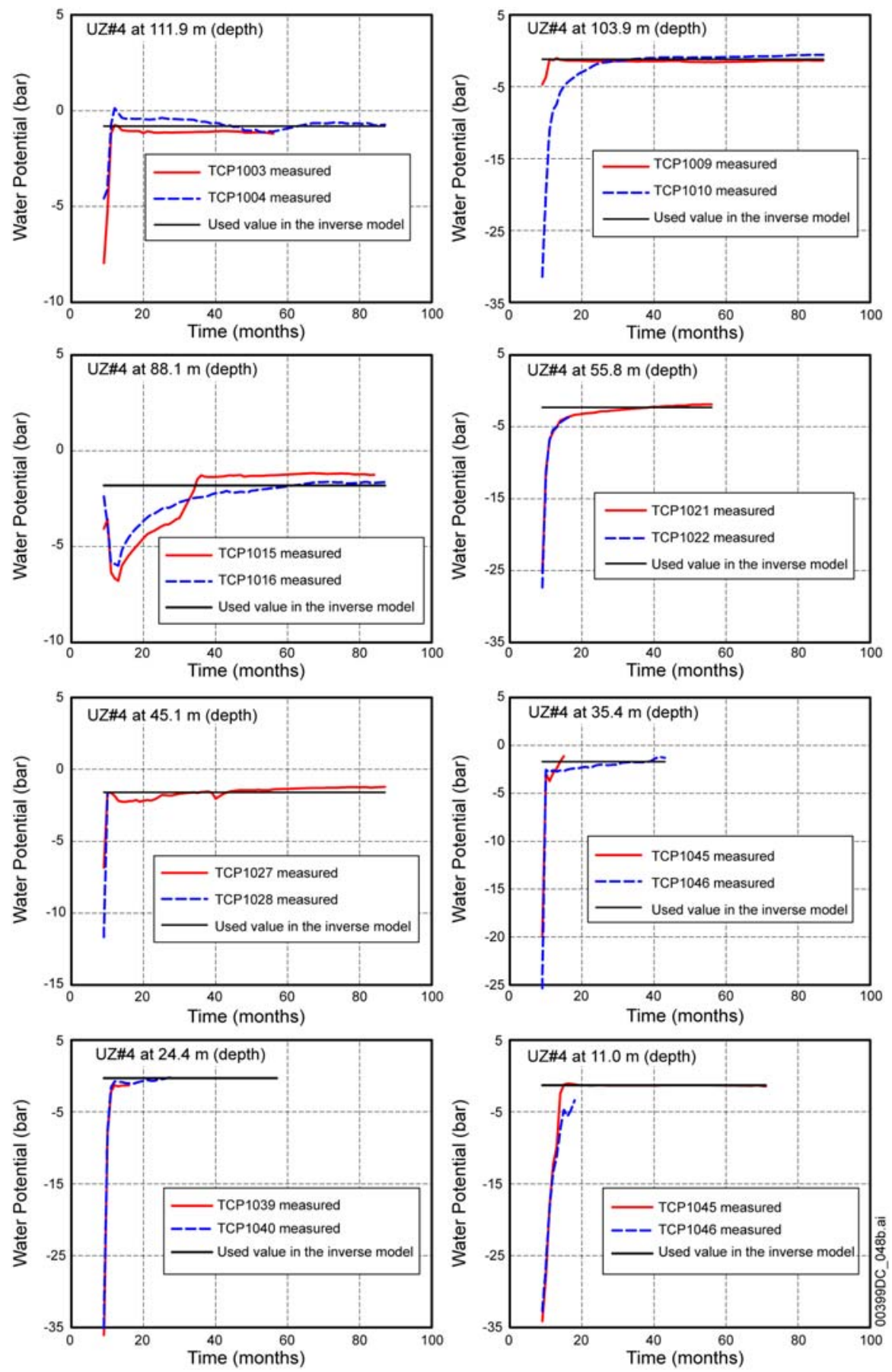

Source: DTN: LB0401H2OPOTEN.001 (DIRS 170678).

NOTE: The equilibrium water potential values used for calibration (inverse modeling) are determined using the data collected before the end of March 1998 (month 42).

Figure B-3. Measured Water Potential (from Available Instrument Stations of Borehole UE-25 UZ\#4) Breakthrough (Starting from October 1994, as Month 1) and the Determined Steady-State Value Used in the Inverse Model for Hydraulic Property Calibration (DIRS 170678) 

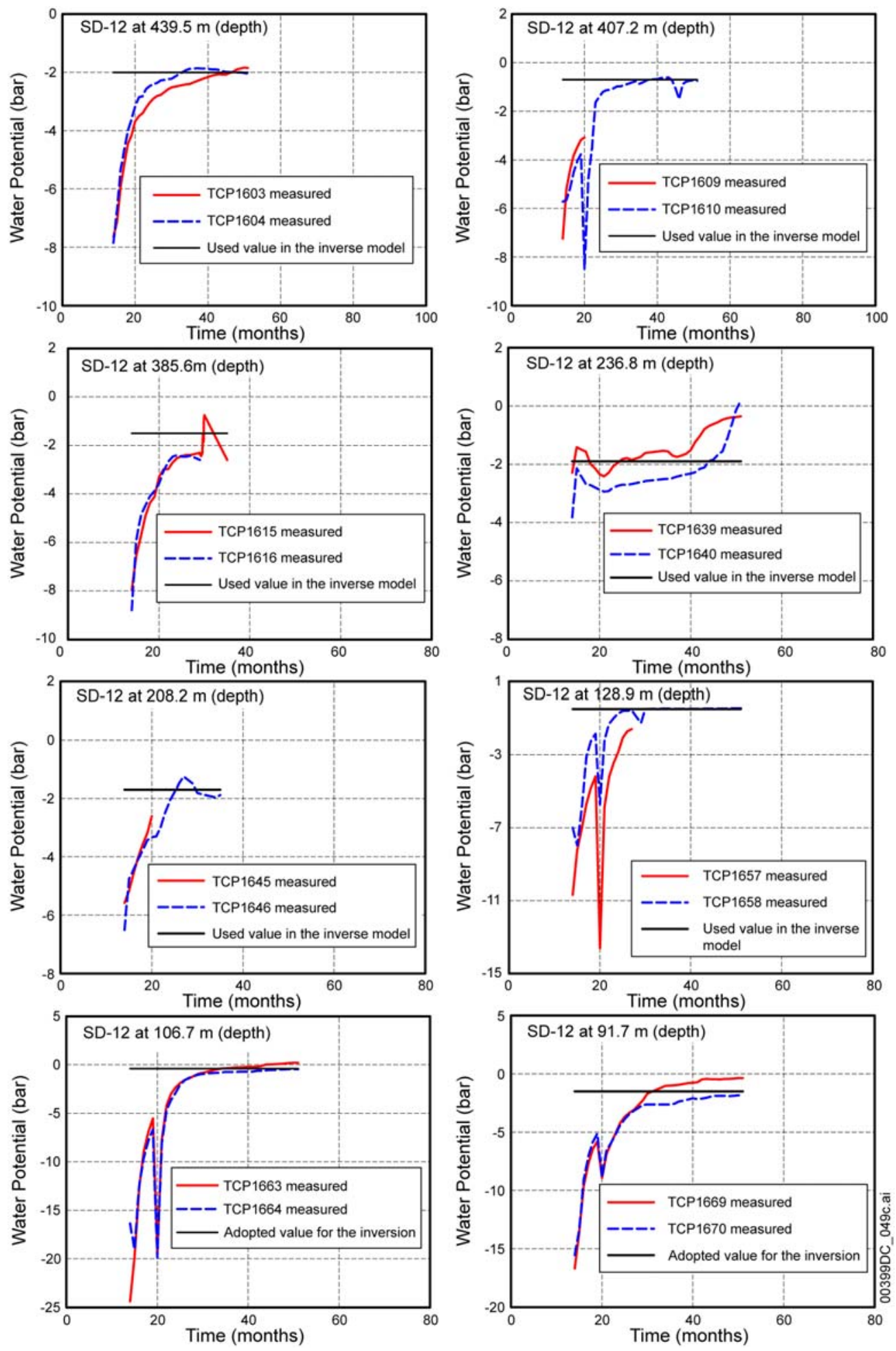

Source: DTN: LB0401H2OPOTEN.001 (DIRS 170678).

NOTE: The equilibrium water potential values used for calibration (inverse modeling) are determined using the data collected before the end of March 1998 (month 42).

Figure B-4. Measured Water Potential (from Available Instrument Stations of Borehole UE-25 SD-12) Breakthrough (Starting from October 1994, as Month 1) and the Determined Steady-State Value Used in the Inverse Model for Hydraulic Property Calibration (DIRS 170678) 

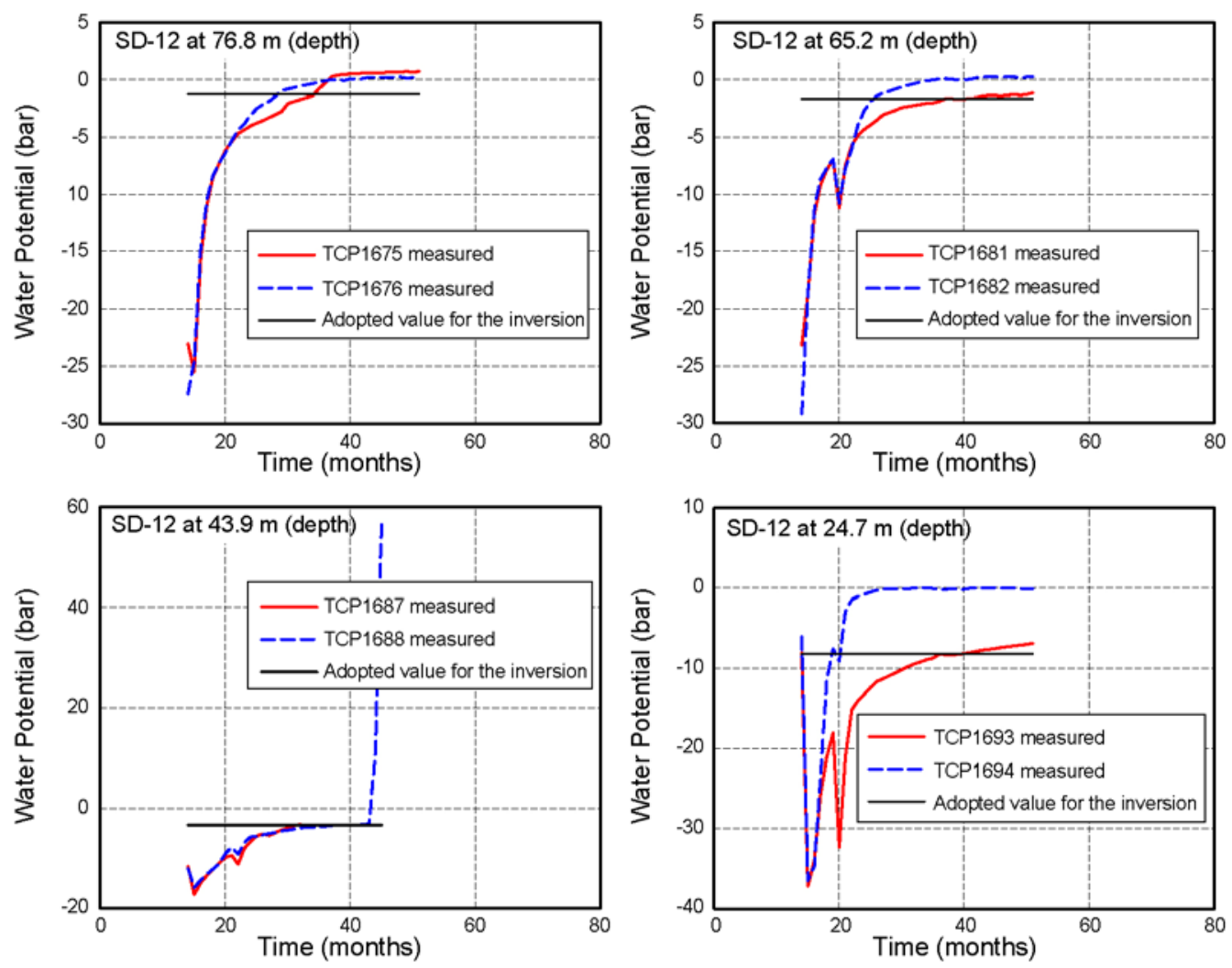

00399DC_049b_cont.ai

Source: DTN: LB0401H2OPOTEN.001 (DIRS 170678).

NOTE: The equilibrium water potential values used for calibration (inverse modeling) are determined using the data collected before the end of March 1998 (month 42).

Figure B-4. $\quad$ Measured Water Potential (from Available Instrument Stations of Borehole UE 25 SD-12) Breakthrough (Starting from October 1994, as Month 1) and the Determined Steady-State Value Used in the Inverse Model for Hydraulic Property Calibration (DIRS 170678) (Continued) 